MAGALI ANDREIA ROSSI

\title{
AVALIAÇÃO DE DESEMPENHO DO PROTOCOLO MIPv6 UTILIZANDO A REDE DE TELECOMUNICAÇÃO AERONÁUTICA (ATN)
}

Dissertação apresentada à Escola

Politécnica da Universidade de São Paulo para obtenção do título de Mestre em Engenharia. 
MAGALI ANDREIA ROSSI

\section{AVALIAÇÃO DE DESEMPENHO DO PROTOCOLO MIPv6 UTILIZANDO A REDE DE TELECOMUNICAÇÃO AERONÁUTICA (ATN)}

Dissertação apresentada à Escola Politécnica da Universidade de São Paulo para obtenção do título de Mestre em Engenharia.

Área de Concentração:

Sistemas Eletrônicos

Orientador:

Prof. Dr. Francisco Javier Ramirez Fernandez 
Este exemplar foi revisado e alterado em relação à versão original, sob responsabilidade única do autor e com a anuência de seu orientador.

São Paulo, de janeiro de 2009.

Assinatura do autor

Assinatura do orientador

\section{FICHA CATALOGRÁFICA}

Rossi, Magali Andreia

Avaliação de desempenho do Protocolo MIPv6 utilizando a Rede de Telecomunicação Aeronáutica (ATN)/ M.A. Rossi.

-- ed. rev. -- São Paulo, 2009.

$130 \mathrm{p}$.

Dissertação (Mestrado) - Escola Politécnica da Universidade de São Paulo. Departamento de Engenharia de Sistemas Eletrônicos.

1.Protocolos de Comunicação 2.Espaço Aéreo 3.Redes de Computadores I.Universidade de São Paulo. Escola Politécnica. Departamento de Engenharia de Sistemas Eletrônicos. II.t. 
Dedico este trabalho aos meus pais Virgilio e Eva, pois tenho a sorte de tê-los como pais. Aos meus irmãos Márcia e Claudio e meu amado sobrinho Thiago, por toda força e carinho. 


\section{Certeza}

"De tudo, ficaram três coisas:

A certeza de que estamos sempre começando...

A certeza de que precisamos continuar...

A certeza de que seremos interrompidos antes de terminar...

Portanto devemos:

Fazer da interrupção, um caminho novo...

Da queda, um passo de dança...

Do medo, uma escada...

Do sonho, uma ponte...

Da procura, um encontro..."

(Fernando Pessoa) 


\section{AGRADECIMENTOS}

Primeiramente a Deus, por me permitir ter forças em muitos momentos difíceis até a conclusão deste trabalho.

Aos meus pais Virgilio e Eva, meu irmão Cláudio e minha irmã Márcia, que são as pessoas mais importantes na minha vida. Por todo o apoio, o que me fez ter e perseverança durante todo tempo.

De uma forma especial agradeço ao meu orientador Prof. Dr. Francisco Javier Ramirez Fernandes, por ter acreditado em mim, pela atenção, amizade e aprendizado que me foi concedido em todo estes anos de convivência. Sem esquecer, é claro, por toda compreensão e preocupação nos momentos difíceis que passei durante a conclusão deste trabalho.

A todos os membros do GAS - Grupo de Análise e Segurança, que desde o primeiro dia gentilmente me acolheram e contribuíram de forma fundamental para meu trabalho. Aos amigos Ricardo Alexandre Veiga Gimenes, Lúcio Vismari, Carlos Costa e Fernando Gil por sempre me ajudarem com suas experiências e atendendo as minhas dúvidas por mais simples que fossem. Aos professores Prof. Dr. João Batista Camargo Jr. e Prof. Dr. Paulo Sérgio Cugnasca, por me permitirem participar de um grupo que através da seriedade e competência de seus trabalhos muito me ajudaram.

Agradecimento especial ao Prof. Dr. Jorge Rady de Almeida Junior pelas oportunidades e atenção sempre dispensada, e ao amigo Ítalo Romani de Oliveira por sempre me incentivar e através de nossas longas conversas e muitos cafés me ajudou a esclarecer pontos importantes para meu trabalho.

A inestimável colaboração dos amigos da INFRAERO, Torre do Aeroporto Internacional de Guarulhos, Engํำ Vicente Carlos Poli (in memorian), Genivaldo Telles de Menezes, 
Bemildo Ferreira e Alexandre Paula, que sempre de forma muito gentil me atenderam e ajudaram a esclarecer dúvidas. Esta colaboração foi essencial para meus estudos.

Igualmente grata a Olivier Mehani do NICTA - Australia's ICT Research Centre of Excellence, pelo apoio em atender minhas dúvidas no suporte ao ambiente Mobiwan.

Aos amigos de Mestrado, pelas inúmeras horas de estudos árduos e momentos de alegria proporcionados pelas nossas amizades.

Não poderia esquecer minhas grandes amigas Patrícia Lima Rocha e Ana Carolina N. da R. Gracioso. Depois de tantas recusas aos vários convites que me fizeram, por tantos cancelamentos que fiz de última hora e por quantas vezes ficaram me ouvindo e me aconselhando, e mesmo assim, ainda continuam minhas amigas!!! Simplesmente, obrigada pela verdadeira amizade!

Ao Prof. Dr. Carlos Eduardo Câmara e ao Prof. Msc. Márcio Henrique Zucchini, agradeço pela amizade qual perdura por todos estes anos e por terem me apoiado no ingresso à pós-graduação. 


\section{RESUMO}

Atualmente a utilização do padrão IPS (Internet Protocol Suite) na ATN compreende os conceitos de mobilidade IP, de convergência na comunicação ar-terra e também as sub-redes ATN em terra. A ICAO (International Civil Aviation Organization) cita a ATN/IPS que é baseada em conexões suportadas pelos protocolos TCP e UDP na camada de transporte e IPv6 na camada de rede. A ATN/IPS deve ser capaz de suportar o ATSC (Air Traffic Service Communication), o AAC (Aeronautical Administrative Communications), bem como o AOC (Aeronautical Operational Communications). Tendo em vista tal panorama, este trabalho de pesquisa aborda um estudo sobre o comportamento do protocolo MIPv6 para a mobilidade IP, analisando a capacidade de roteamento das aeronaves com o objetivo de complementar o serviço de navegação de forma mais precisa, introduzindo-se o conceito de mobilidade à capacidade de flexibilidade e escalabilidade para as aeronaves e os sistemas em terra. Como forma de atingir tal objetivo, primeiramente é realizada uma análise no canal VHF a fim de aferir as possíveis interferências que possam ocorrer em comunicações entre a aeronave e o Controle de Tráfego Aéreo. Após, implementa-se o ambiente onde são simulados os testes de comportamento do protocolo MIPv6. 


\begin{abstract}
Currently the use of standard IPS (Internet Protocol Suite) in the ATN it comprehends the concepts of IP mobility, convergence in the air-to-ground communication and also ATN sub-nets in land. The ICAO (International Civil Aviation Organization) mentions the ATN/IPS, which is based on connections supported by TCP and UDP protocols in the transport layer and by IPv6 in the net layer. The ATN/IPS must be able to support the ATSC (Air Traffic Service Communication), the AAC (Aeronautical Administrative Communications), as well as the AOC (Aeronautical Operational Communications). In view of such a scenario, a study on the behavior of the MIPv6 protocol for mobility IP is approached, analyzing the capacity of router of the aircraft so as to complement the navigation service more accurately, introducing the concept of mobility to the flexibility capacity and scalability for the aircraft and the systems in land. In order to attain this goal, first an analysis in the VHF channel is carried out in order to gauge the possible interferences that may occur in communications between the aircraft and the Air Traffic Control. After that, the environment is implemented where the behavior tests of the MIPv6 protocol are simulated.
\end{abstract}




\section{SUMÁRIO}

\section{LISTA DE FIGURAS}

\section{LISTA DE QUADROS}

\section{LISTA DE TABELAS}

\section{LISTA DE ABREVIATURAS E SIGLAS}

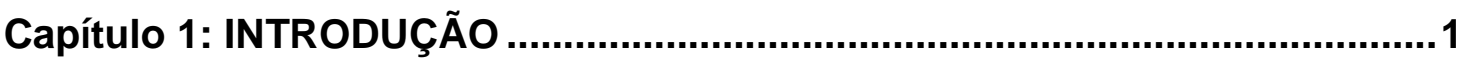

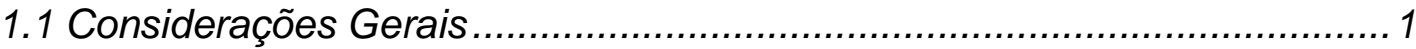

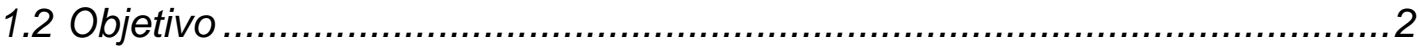

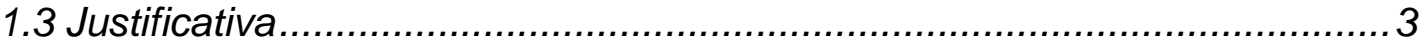

1.4 Organização do Texto ........................................................................

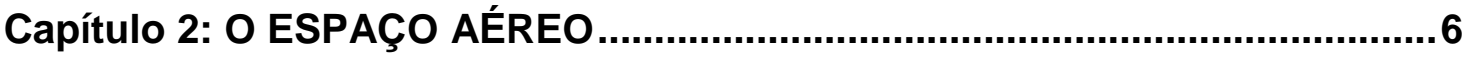

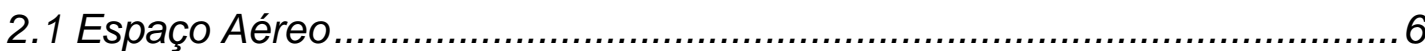

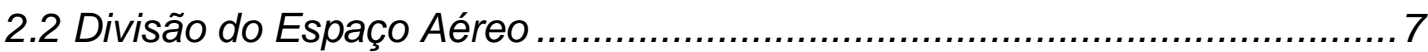

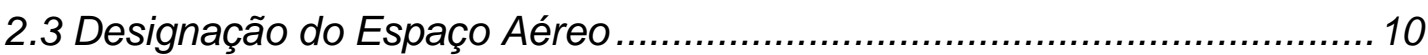

2.4 Classes de Espaços Aéreos ATS........................................................11

2.5 Espaço Aéreo sob Jurisdição do Brasil ................................................. 15

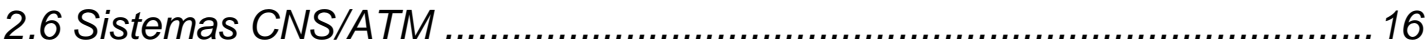

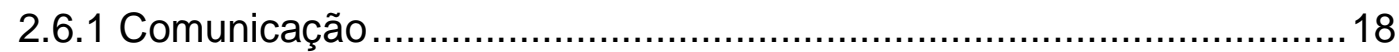

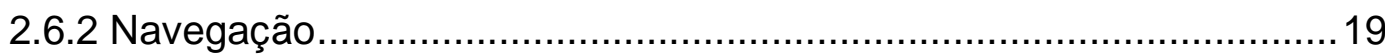




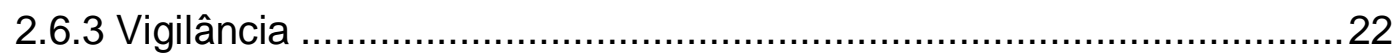

2.6.4 Gerenciamento de Tráfego Aéreo ...............................................24

Capítulo 3: REDE DE TELECOMUNICAÇÃO AERONÁUTICA (ATN)..............27

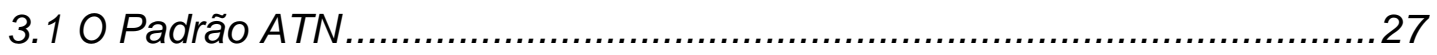

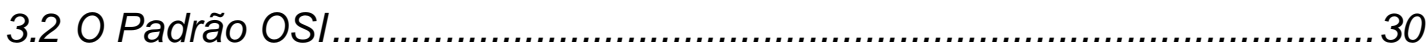

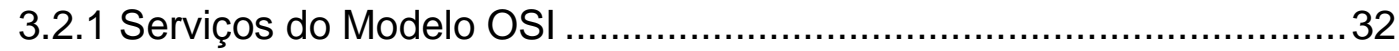

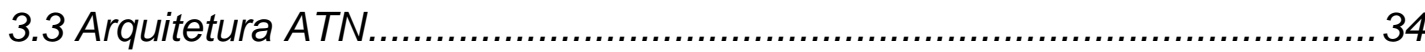

3.3.1 Protocolos ATN ....................................................................... 37

3.3.2 Mobilidade ATN ......................................................................... 46

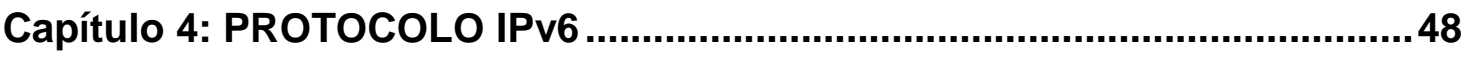

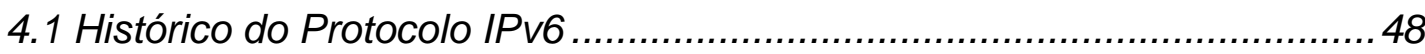

4.1.1 Arquitetura do Protocolo IPv6 ....................................................... 52

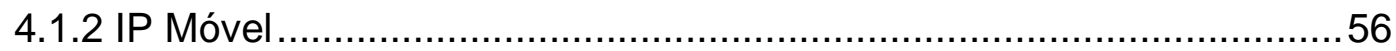

4.1.3 Protocolos MIPv6 e HMIPv6 .........................................................57

Capítulo 5: ESTUDO DE CASO PROSPOSTO E AMBIENTE..........................62

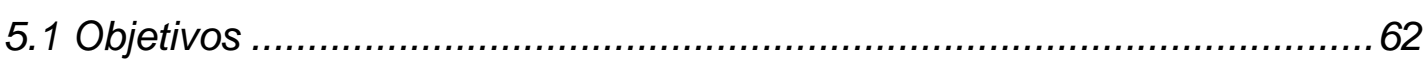

5.2 Estudo de Caso Proposto no Contexto do Protocolo MIPv6 .....................62 62

5.3 Ambiente de Simulação...............................................................64 64

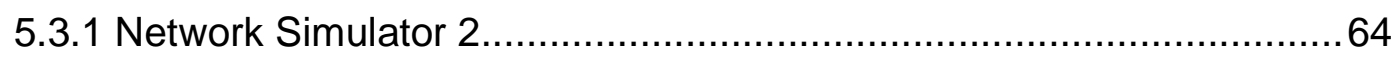

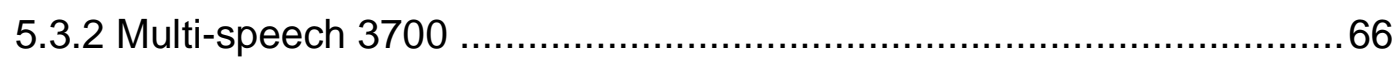

Capítulo 6: INTERFERÊNCIAS GERADAS NO CANAL VHF .........................68

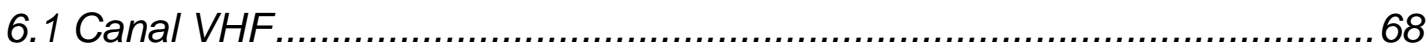

6.1.1 Caracterização do Ambiente ............................................................69

6.1.2 Métodos Utilizados para Este Estudo ......................................... 71

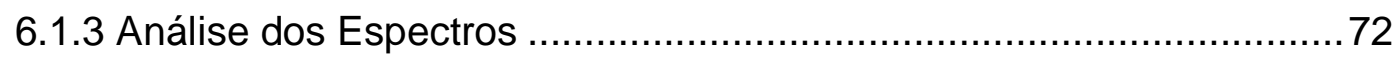


Capítulo 7: ANÁLISE DE RESULTADOS ..................................................... 76

7.1 Ambiente de Simulação.................................................................... 76

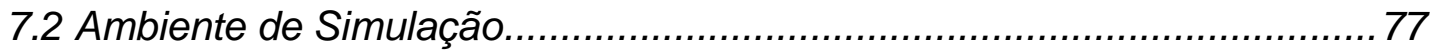

7.2.1 Topologia de Rede Utilizada ......................................................... 80

7.3 Análise dos Resultados por Tipo de Alteração na Rede ..........................81

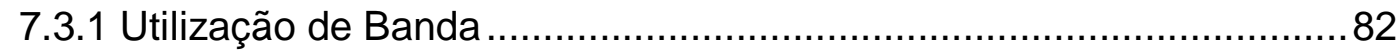

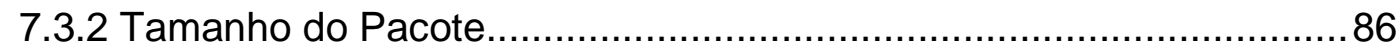

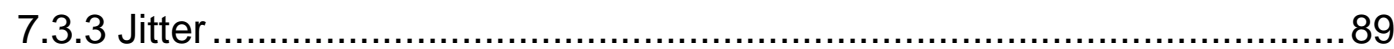

Capítulo 8: CONCLUSÃO E FUTUROS TRABALHOS ....................................92

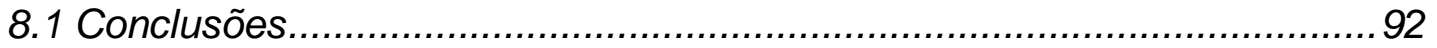

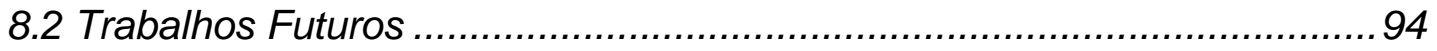

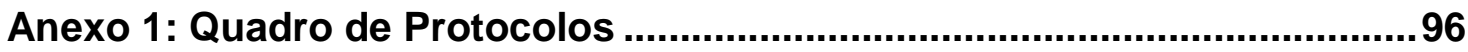

Anexo 2: Código de Preparação do Ambiente ............................................101

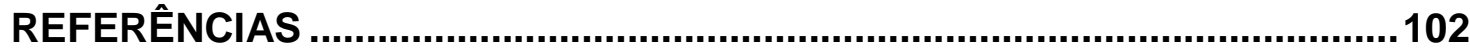

Apêndice A: Código MIPv6 ...................................................................107 


\section{LISTA DE FIGURAS}

Figura 1 - Regiões de Navegação Aérea Determinadas pela ICAO (Fonte:

Ontiveros, 2003)

Figura 2 - Carta Aeronáutica Meteorológica -FL250 / (Fonte: Ontiveros, 2003) ... 9

Figura 3 - Espaços Aéreos ATS 11

Figura 4 - FIRs do Espaço Aéreo da América do Sul (fonte: ROLIM, 2006)........ 16

Figura 5 - Visão Utilizando os Sistemas CNS/ATM (Fonte: Siqueira, 2005)........ 18

Figura 6 - Utilização do ADS-B na Vigilância (Fonte: HARISON, 2006) ............... 23

Figura 7 - Organização de um ATM (Fonte: Oliveira, 2005) ................................. 25

Figura 8 - Visão anterior à implantação ATN (Fonte: HELIOS apud Siqueira, 2004)

Figura 9 - Visão após implantação da ATN (Fonte: HELIOS apud Siqueira, 2004)

Figura 10 - Conceito OSI (Fonte: adaptado de GALLO e HANCOCK, 2003) ...... 30

Figura 11 - Visão das Camadas do Modelo OSI (Fonte: adaptado de GALLO e HANCOCK, 2003)

Figura 12 - Ponto de Acessos de Serviços (Fonte: adaptado de GALLO e HANCOCK, 2003)

Figura 13 - Interconexão Utilizando Padrão OSI 34

Figura 16 - Overhead em Camadas de Pilhas de Protocolos (Fonte: Farrel, 2005) 38

Figura 17 - Arquitetura de Roteamento ISO (Fonte: adaptado de ICAO, 2001).. 41 
Figura 18 - Comparação de Aplicações nos modelos ATN/OSI e ATN/IPS (Fonte: adaptado de ICAO, 2006)

Figura 19 - Camada de Aplicação Utilizando o Conceito ATN/IPS (Fonte: adaptado de ICAO, 2006)

Figura 20 - Arquitetura Utilizando o Conceito ATN/IPS (Fonte: adaptado de ICAO, 2006)

Figura 21 - Comparação entre os modelos OSI, ATN/OSI e ATN/IPS (Fonte: adaptado de ICAO, 2008a) 46

Figura 22 - Hosts reconhecidos em DNS (Fonte: www.isc.org, 2008) 49

Figura 23 - Hosts no Brasil (Fonte: www.cetic.br, 2008) 50

Figura 24 - Cabeçalho IPv6 (Fonte: adaptado IETF, 1998) ..................................... 53

Figura 25 - Cabeçalho IPv4 (Fonte: adaptado IETF, 1981) ………….................... 54

Figura 26 - Formato de Datagrama IPv6 (Fonte: COMER, 1998) .......................... 56

Figura 27 - Entidades utilizadas para roteamento (Fonte: adaptado de PERKINS e JOHNSON, 1996) 58

Figura 28 - Exemplo da implementação do MIPv6 em rede (Fonte: adaptado de PERKINS e JOHNSON, 1996)

Figura 29 - Exemplo da implementação do HMIPv6 em rede. (Fonte: Adaptado de YAIZ e OZTURK, 2006).

Figura 30 - Cenário estudado. 63

Figura 31 - Diagrama de Movimentação das Aeronaves ........................................... 70

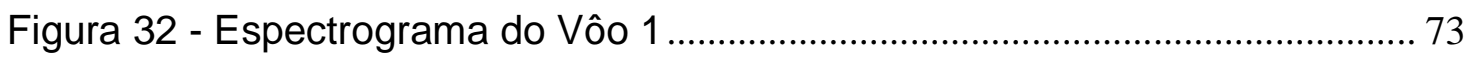

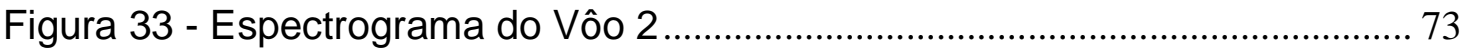

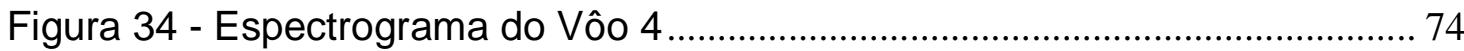


Figura 35 - Espectrograma do Vôo 5

Figura 36 - Localização dos Routers (Fonte: Adaptado de Google Earth, 2008) 78

Figura 37 - Ligação Lógica entre os Routers (Fonte: Adaptado de Google Earth, 2008)

Figura 38 - Topologia da Rede 80 


\section{LISTA DE QUADROS}

Quadro 1 - Quadro de Classificação dos Espaços ATS Utilizados no Brasil ......14

Quadro 2 - Quadro Comparativo entre os Sistemas GPS e GLONASS .............21

Quadro 3 - Brasil x América do Sul (Fonte: www.cetic.br, 2008) .......................50

Quadro 4 - Brasil x Américas (Fonte: www.cetic.br, 2008) .............................51

Quadro 5 - Brasil x Mundo (Fonte: www.cetic.br, 2008) ................................. 51 


\section{LISTA DE TABELAS}

Tabela 1 - Parâmetro para Análise da Banda 10MB........................................84

Tabela 2 - Resultado: Pacote 1000k e Largura de Banda 10MB ........................84

Tabela 3 - Parâmetro para Análise de Banda 2MB.......................................... 85

Tabela 4 - Resultado: Pacote 1000k e Largura de Banda 2MB .......................... 85

Tabela 5 - Parâmetros para Análise de Pacotes 1200k ......................................87

Tabela 6 - Resultado: Pacote 1200k e Largura de Banda de 10MB ...................87

Tabela 7 - Resultado: Pacote 150k e Largura de Banda de 10MB ..................... 88

Tabela 8 - Resultado: Pacote 150k e Largura de Banda de 10MB .....................88

Tabela 9 - Parâmetro para Análise de Jitter 3,8s e Pacote de 500k................... 89

Tabela 10 - Resultado: Pacote 500k e Jitter 3,8s ..........................................90

Tabela 11 - Parâmetro para Análise de Jitter 3,8s e Pacote de 1000k ...............90

Tabela 12 - Resultado: Pacote 1000k e Jitter 3,8s ...........................................91 


\section{LISTA DE ABREVIATURAS E SIGLAS}

AAC

ABNT-NBR

ACC

$\mathrm{ACIRI}$

ACP

ADS

ADS-A

ADS-B

ADS-C

ADS-S

$\mathrm{AE}$

AFCEA

AMSS

AMCP

ANC

AOC

AP

APP

APU

ARC

ARPA

ATC

ATCS

ATFM

ATIS
Aeronautical Administrative Communication

Associação Brasileira de Normas Técnicas - Norma Brasileira de Regulamentação

Centro de Controle de Área

International Computer Science Institute

Aeronautical Communications Panel

Automatic Dependent Surveillance

ADS - Addressing

ADS - Broadcast

ADS - Contact

ADS - Squiter

Application Entity

Armed Forces Communications and Electronics Association

Aeronautical Mobile Satellite Service

Aeronautical Mobile Communications Panel

Air Navigation Commission

Aeronautical Operational Communication

Aplication Process

Aproach Control

Auxiliary Power Unit

Carta de Área

Advanced Research Projects Agency

Air Traffic Control

Air Traffic Service Communication

Air Traffic Flow Management

Automatic Terminal Information Service 
ATM

ATN

ATNP

ATS

ATZ

BIS

BS

CDMA

CDMA/CD

CINDACTA

CLNP

CLTP

CN

CNS

CNS/ATM

COSER

CoA

COTS

CPDLC

CTA

CTR

DARPA

DECEA

DoD

ELSEG

ERC

ES

ES-IS
Air Traffic Management

Aeronautical Telecommunication Networking

Aeronautical Telecommunication Networking Panel

Air Traffic Service

Zona de Tráfego de Aeródromo

Boundary Intermediate System

Base Station

Code Division Multiple Access

Carrier Sense Multiple Access with Collision Detection

Centro Integrado de Defesa Aérea e Controle de Tráfego Aéreo

Connectionless Network Protocol

Connectionless Transport Protocol

Correspondent Node

Communication Navigation and Surveillance

Communication Navigation and Surveillance / Air Traffic Management

Collaborative Simulation for Education and Research

Care-of Address

Commercial of the Shelf

Controller-Pilot Data Link Communications

Área de Controle

Zona de Controle

Defense Advanced Research Projects Agency

Departamento de Controle do Espaço Aéreo

American Department of Defense

Elektronic Service $\mathrm{GmbH}$

Carta de Rota

End System

End System to Intermediate System Routing Protocol 
FAA Federal Aviation Administration

FAN Future Air Navigation

FANS Future Air Navigation System

FDMA Frequency Division Multiple Access

FHMIPv6 Fast Handovers for Mobile IPv6

FIFO First in First Out

FIR Flight Information Region

$\mathrm{FL}$

Flight Level

GLONASS Global Orbiting Navigation System

GNSS Global Navigation Satellite System

GPS Global Positioning System

HF High Frequency

HMIPv6 Hierarchical Móbile lpv6

HoA Home of Address

IAL Carta de Aproximação por Instrumentos

IAS Indecated Airspeed

ICAO International Civil Aviation Organization

IDRP Intra-domain Router Protocol

IETF The Internet Engineering Task Force

IETF/3GPP The Internet Engineering Task Force / 3rd Generation Partnership Project

IFR Flight Instrument

IP Internet Protocol

IPS Internet Protocol Suite

IPv4 Internet Protocol version 4

IPv6 Internet Protocol Version 6

ISC Internet Systems Consortium

IS Intermediate System

IS-IS Intermediate System to Intermediate System Routing Protocol 
ISO

$\mathrm{K}$

$\mathrm{km}$

kt

MAG

MAP

$\mathrm{MHz}$

MIPv6

MN

NAM

NEMO

NETLMN

Domain

NICTA

NM

NPDU

NS

NS2

OOOI

OSI

PCoA

PDC

PMIP

PZ-90

QoS

RACAM

RBAC

RBHA

RFC
International Organization for Standardization

Kopter

Kilômetro

knot

Mobile Access Gateway

Mobility Anchor Point

Milhões de Hertz por Segundo

Mobile Internet Protocol version 6

Mobile Node

Network Animator

Networks in Motion

Network-based Localized Mobility Management Domain

Australia's ICT Research Centre of Excellence

Nautical Mile

Network Protocol Data Units

Networking Simulation

Networking Simulation 2

Out, Off, On, In

Open System Interconnection

Phisical Care-of Address

Pre-departure Clear

Proxy Mobile IPv6

Sistema Russo Geodésico

Quality of Service

Rede Administrativa de Comutação Automática de Mensagens

Regulamento Brasileiro de Aviação Civil

Regulamento Brasileiro de Homologação Aeronáutica

Request for Comments 


$\begin{array}{ll}\text { RNAV } & \text { Area Navigation } \\ \text { RNP } & \text { Required Navigation Performance } \\ \text { RTCA } & \text { Radio Technical Commission for Aeronautics } \\ \text { RVSP } & \text { Minimum Reduction of Vertical Separation } \\ \text { S } & \text { Supersonic } \\ \text { SAM } & \text { Simulation Augmented by Measurement and Analysis for } \\ \text { SAP } & \text { Networks } \\ \text { SARP } & \text { Service Acess Points } \\ \text { SBD } & \text { Atandards and Recommended Practices } \\ \text { SBP } & \text { Áreas Proibidas } \\ \text { SBR } & \text { Áreas Restritas } \\ \text { SICASP } & \text { Secondary Surveillance Radar Improvements and Collision } \\ \text { SID } & \text { Avoidance Collision System Painel } \\ \text { SSR } & \text { Carta de Saída por Instrumentos } \\ \text { TCP/IP } & \text { Secondary Surveillance Radar } \\ \text { TCP/UDP } & \text { Transmission Control Protocol/Internet Protocol } \\ \text { TMA } & \text { Transmission Control Protocol/ User Datagram Protocol } \\ \text { TP4 } & \text { Terminal Movement Area } \\ \text { TTL } & \text { Class 4 Transport Protocol } \\ \text { U } & \text { Time to Life } \\ \text { UDP } & \text { Upper } \\ \text { UL } & \text { User Datagram Protocol } \\ \text { UNL } & \text { Upper Layer } \\ \text { UTA } & \text { Ilimitado } \\ \text { UTC (SU) } & \text { Áreas Superiores de Controle } \\ \text { UTC (USNO) } & \text { Coordinated Universal Time (Soviet Union) } \\ \text { VAC } & \text { Carta de Aproximação Visual } \\ & \end{array}$




$\begin{array}{ll}\text { VCoA } & \text { Virtual Care-of-Address } \\ \text { VFR } & \text { Visual Flight Rules } \\ \text { VHF } & \text { Very High Frequency } \\ \text { VINT } & \text { Virtual InterNetwork Testbed } \\ \text { WAC } & \text { Carta Aeronáutica Mundial } \\ \text { WGS-84 } & \text { World Geodetic System-84 }\end{array}$




\section{Capítulo}

1

INTRODUÇÃO

\subsection{Considerações Gerais}

O segmento aeronáutico tem se beneficiado das inovações tecnológicas das últimas décadas, mas nele ainda restam consideráveis avanços a serem feitos através das recentes tecnologias de comunicação digital. A utilização de redes de computadores para o gerenciamento do espaço aéreo foi a primeira grande evolução. Porém, com a contínua mudança tecnológica, teve-se a necessidade de uma forma de gerenciamento integrado.

A ICAO (International Civil Aviation Organization), vendo esta necessidade de evolução, iniciou o trabalho através da criação do comitê FAN (Future Air Navigation) que seria o responsável pela criação de um novo conceito de sistemas para gerenciamento de tráfego aéreo, definido como CNS/ATM (Communication Navigation and Surveillance / Air Traffic Management). Este novo conceito, em fase avançada de implementação em vários países, fez com que sistemas de controles aeronáuticos passassem por uma revolução tecnológica.

Também influenciadas por estas inovações, as companhias aéreas tiveram que se 
adaptar e atender este novo conceito que passa a ter influência direta na operacionalização de suas aeronaves. Um parâmetro de grande influência para que estes sistemas aeronáuticos tenham eficiência em seu funcionamento é a infraestrutura da rede de comunicações que estará sendo utilizada.

\subsection{Objetivo}

A pesquisa apresentada neste trabalho refere-se ao ambiente aéreo tendo como aplicação o controle no roteamento de aeronaves e transmissão de dados em ambiente móvel. Atualmente, o crescimento excessivo do tráfego aéreo vem provocando discussões em todos os níveis e órgãos ligados à aviação. Outro questionamento muito comum são os serviços de conexão para dispositivos móveis de comunicação oferecidos por diversas companhias, os quais geram a incerteza quanto à sua interferência nos sistemas de controle das aeronaves. Desta forma, o principal objetivo desta pesquisa é a avaliação de desempenho do protocolo MIPv6 (Mobile Internet Protocol version 6) como parte do controle de roteamento de aeronaves e transmissão de dados em ambiente móvel.

Como forma de avaliar e validar a estrutura proposta foi construído um ambiente de simulação que constitui a base para avaliação do objetivo proposto, no qual o principal objetivo é a avaliação do protocolo na entrega dos dados neste ambiente. O ambiente construído por simulação deve ser capaz de demonstrar relevâncias de estudo sobre:

- Estabilidade no ambiente para a utilização da transferência dos pacotes;

- Características de roteamento;

- Demonstração de tempo gasto na transmissão de dados, uma vez estipulado o tempo máximo aceitável, e comportamento do protocolo com diferentes valores de jitter.

Para obtenção dos resultados numéricos da simulação do estudo foi utilizado o 
Software NS2 - Networking Simulation 2. Os resultados finais da pesquisa são apresentados através de tabelas comparativas onde os serviços são avaliados.

A pesquisa é baseada nos padrões adotados pela Aeronáutica em nível internacional atualmente sob a responsabilidade da ICAO, órgão que regulamenta as aplicações e infra-estrutura para comunicações aeronáuticas. Em território nacional, segue os padrões e comunicados adotados pelo Departamento de Controle do Espaço Aéreo (DECEA), que tem a missão de planejar, implantar, integrar, normatizar, coordenar e fiscalizar as atividades de controle do espaço aéreo brasileiro, e telecomunicações aeronáuticas (ROLIM et al, 2006).

\subsection{Justificativa}

Cada vez mais a telecomunicação se adapta às novas tecnologias, buscando um maior controle e eficiência operacional. A criação de um comitê para estudo e desenvolvimento de uma nova tecnologia que atendesse os requisitos de QoS (Quality of Service), integridade e confiabilidade, demonstra a preocupação das autoridades responsáveis.

Informações como a localização de aeronaves são importante para os Órgãos de Controle de Tráfego Aéreo, bem como as informações em tempo real que trazem de forma mais clara as possibilidades de tomadas de decisões em situações mais variadas. É determinado que os Órgãos de Controle de Tráfego Aéreo planejem e controlem o fluxo de tráfego sob sua responsabilidade, onde podem executar autorizações que promovam as separações entre aeronaves e a resolução de conflitos de tráfego aéreo, gerados pela falta de comunicação bilateral contínua onde acabam por perder o controle do fluxo de aeronaves (MINISTÉRIO DA AERONÁUTICA, 1999a).

Outro fator de grande relevância é a comunicação existente entre os ATCs (Air Traffic Control) e as aeronaves, que acaba por desempenhar um papel imprescindível para o 
Gerenciamento de Tráfego Aéreo. É determinado ao Órgão de Controle de Tráfego Aéreo (MINISTÉRIO DA AERONÁUTICA, 1999b):

- Ao receber uma chamada, que esta seja atendida rapidamente e em tom alto e claro;

- Utilizar somente fraseologia padrão;

- Utilizar o alfabeto fonético em caso de dúvidas no entendimento de confirmações.

No entanto, muitas vezes, a utilização do idioma inglês, o qual é autorizado como meio de comunicação em casos de não ser utilizada a língua do próprio país, pode acarretar o não entendimento por parte do controlador ou piloto. A inteligibilidade é um fator importante para as comunicações aeronáuticas.

Desta forma, outro fator de grande relevância é o próprio meio de comunicação utilizado, que é o Canal VHF. Em muitas vezes o nível de inteligibilidade oferecido aos seus usuários é baixo, o que pode vir afetar a segurança operacional. Existem outros fatores que também provocam interferências por ruídos no Canal VHF, como equipamentos utilizados nas operações de apoio ao solo. Dentre tais equipamentos podem-se citar os caminhões de abastecimento, loaders (plataformas de cargas), unidades de partida, push back (rebocadores de aeronaves), esteiras motorizadas e os tratores, sendo que as interferências podem ocorrer com tais equipamentos parados ou em movimento (ROSSI, ALMEIDA e MENEZES, 2006).

Para Perrons (1997), os equipamentos aeronáuticos não podem falhar, o que levaria a catástrofes, tais como grande perda de vidas humanas, já citando a importância da arquitetura utilizada e a integração entre os sistemas a serem desenvolvidos.

\subsection{Organização do Texto}

Primeiramente, é feita uma descrição conceitual dos assuntos relacionados ao tema da pesquisa desenvolvida. A descrição é feita por tópicos, de forma ascendente, que 
possibilitará o entendimento do estudo de caso escolhido.

No capítulo 1 são apresentados o objetivo, a justificativa e a estrutura do trabalho.

No capítulo 2 é abordado o Espaço Aéreo, explicando a sua regulamentação através dos órgãos oficiais, sua divisão e sua administração. O sistema CNS/ATM é explicado por ser o princípio para a aplicação da pesquisa. São apresentados os conceitos referentes à sua utilização, abordagem de suas técnicas e as dificuldades para a sua implantação.

No capítulo 3 é feita a apresentação da rede ATN utilizada para as comunicações aeronáuticas. Também é feita a abordagem sobre os protocolos de comunicações, onde são apresentadas as características e seus mecanismos de transmissão.

No capítulo 4 é feita à apresentação do protocolo IPv6 e também se apresenta o protocolo MIPv6, o qual é utilizado neste trabalho durante as simulações. A apresentação do protocolo HMIPv6 é esplanada por ser tratado nos trabalhos futuros.

No capítulo 5 é apresentado o estudo de caso, bem como os programas de simulação que são utilizados.

No capítulo 6 são apresentados os resultados adquiridos na análise do Canal VHF.

O capítulo 7 apresenta os resultados da análise proposta neste trabalho.

Finalizando, o capítulo 8 apresenta as conclusões deste trabalho e os trabalhos futuros. 


\section{Capítulo}

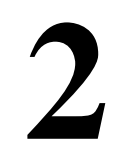

O ESPAÇO AÉREO

\subsection{Espaço Aéreo}

O Espaço Aéreo é definido como uma porção da atmosfera que é controlada por um determinado país. Segundo Ontiveros (2003), a ICAO considerou a grande variedade das condições geográfica e climática como influência na determinação de instalação do vários serviços aéreos, que podem variar consideravelmente por todas as partes do mundo. Da mesma forma houve a necessidade de padronizar as atividades operacionais e técnicas, as quais facilitariam a implantação dos serviços e instalações em terra para desenvolvimento das operações de vôo, o que também facilitaria a divisão do espaço aéreo mundial em Regiões de Navegação Aérea.

Assim, cada país pode oferecer seus serviços de vôo, como informações meteorológicas, informações de vôo, alertas, entre outros. A Figura 1 ilustra a divisão do espaço aéreo definido pela ICAO. 


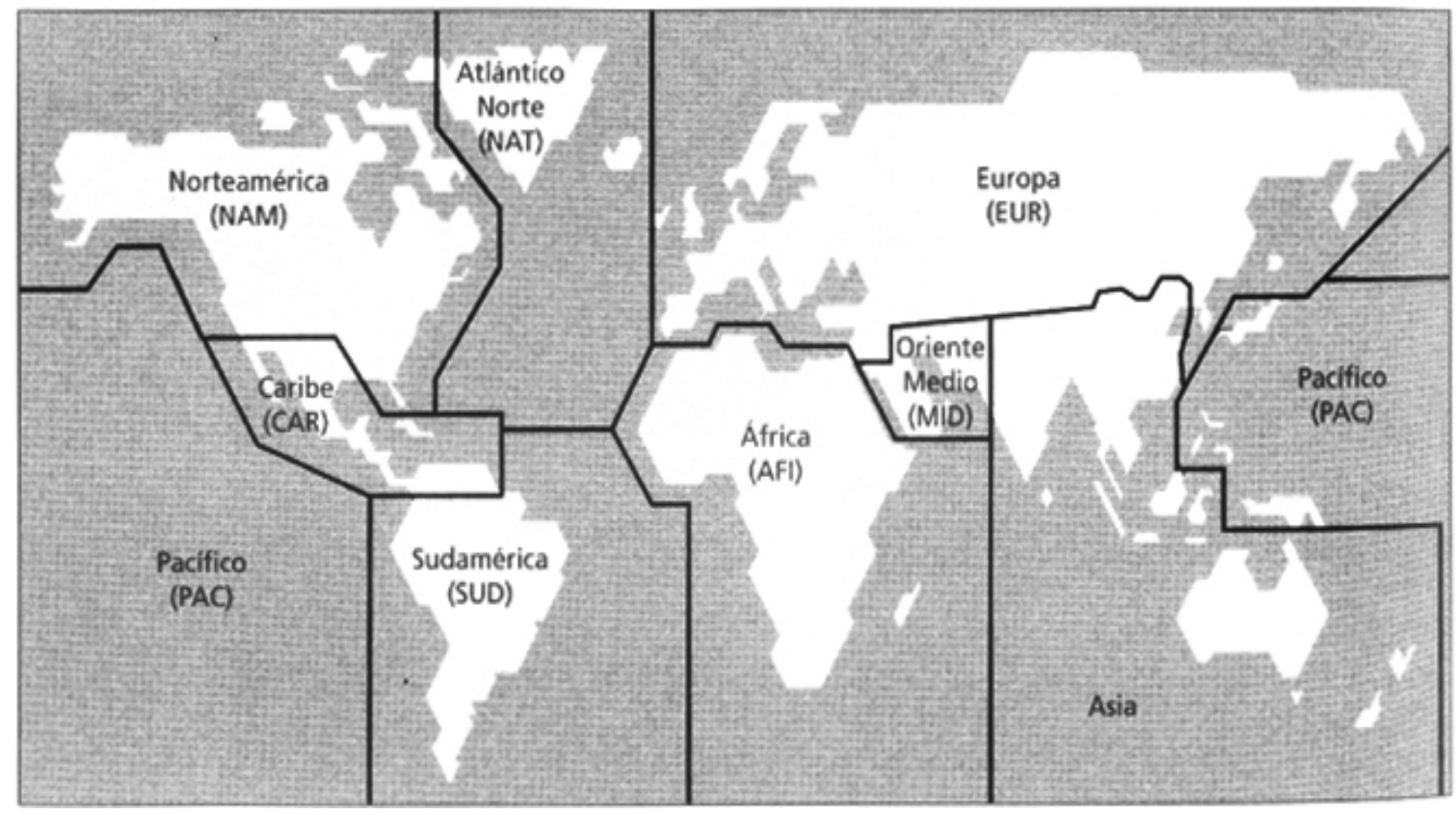

Figura 1 - Regiões de Navegação Aérea Determinadas pela ICAO (Fonte: Ontiveros, 2003)

\subsection{Divisão do Espaço Aéreo}

A estrutura criada pela ICAO, na divisão do espaço aéreo de todos os continentes em regiões de navegação aérea, possibilitou que cada país criasse sua própria estrutura de espaço aéreo, dividida em FIRs (Flight Information Regions). As FIRs são definidas verticalmente por todo espaço aéreo inferior e superior, e de forma horizontal através dos limites impostos por suas cartas de rotas aéreas.

- Espaço aéreo Inferior: abrange desde a superfície do terreno ou da água até 24500 pés ${ }^{1}$, suficiente para os vôos com aeronaves na década de 1940 (Ontiveros, 2003 e MINISTÉRIO DA AERONÁUTICA, 1999).

Limites verticais: Superior - $\mathrm{FL}^{2} 245$ inclusive.

Limites laterais: Indicados nas cartas de rota (ERC).

\footnotetext{
${ }^{1}$ Pés: unidade de medida de comprimento usada intensamente em aviação, sendo 1 pé $=30,48 \mathrm{~cm}$.

${ }^{2}$ FL - Flight Level. É uma altura nominal padrão de vôo, em centenas de pés. Utilizado para determinar se o vôo será par ou ímpar, levando em consideração os dois primeiros números do FL.
} 
- Espaço aéreo superior: possui os mesmos limites laterais que a FIR, porém não possui limites verticais definidos, abrangendo o nível de vôo em 46000 pés (ONTIVEROS, 2003). No entanto, o nível máximo utilizado pelas aeronaves atuais é o FL450, exceto poucas outras que podem voar a FL600, como os aviões militares (MINISTÉRIO DA AERONÁUTICA, 1999).

Limites verticais:

Superior - ilimitado (UNL)

Inferior - FL245 exclusive

Limites laterais: indicados nas cartas de rota (ERC)

- Carta aeronáutica: é uma representação gráfica e espacial da Terra ou parte dela, possuindo diferentes finalidades. É utilizada para facilitar as tarefas da tripulação aérea durante o vôo. Seu objetivo é contribuir para a segurança do vôo em suas diversas fases, como decolagem, em rota, aproximação e pouso (MINISTÉRIO DA AERONÁUTICA, 2000).

Tipos de cartas:

- Carta Aeronáutica Mundial (WAC) - utilizada no auxílio às necessidades do vôo visual.

- Carta de Aproximação por Instrumentos (IAL) - utilizada por todos os aeródromos para aviação geral, desde que estejam homologados para operação IFR (Flight Instruments).

- Carta de Saída por Instrumentos (SID) - permite às aeronaves efetuarem subidas por instrumentos, com relação aos obstáculos, desde a decolagem até a interceptação da rota ATS (Air Traffic Service). Disponível para os aeródromos homologados para operação IFR.

- Carta de Aproximação Visual (VAC) - proporciona ao piloto uma visão gráfica dos procedimentos de circulação visual. No entanto são permitidas apenas em aeródromos cujo tráfego visual possa ser justificado. 
- Carta de Área (ARC) - permite informações que facilitam as transições entre o vôo em rota e a aproximação para um aeródromo, bem como os vôos através de áreas com estruturas complexas de rotas ATS (Air traffic Services).

- Carta de Rotas (ERC) - objetiva facilitar a navegação por meio de auxíliorádio, de acordo com os procedimentos ATS. Compõe-se por várias cartas contendo as rotas ATS no espaço aéreo inferior e superior.

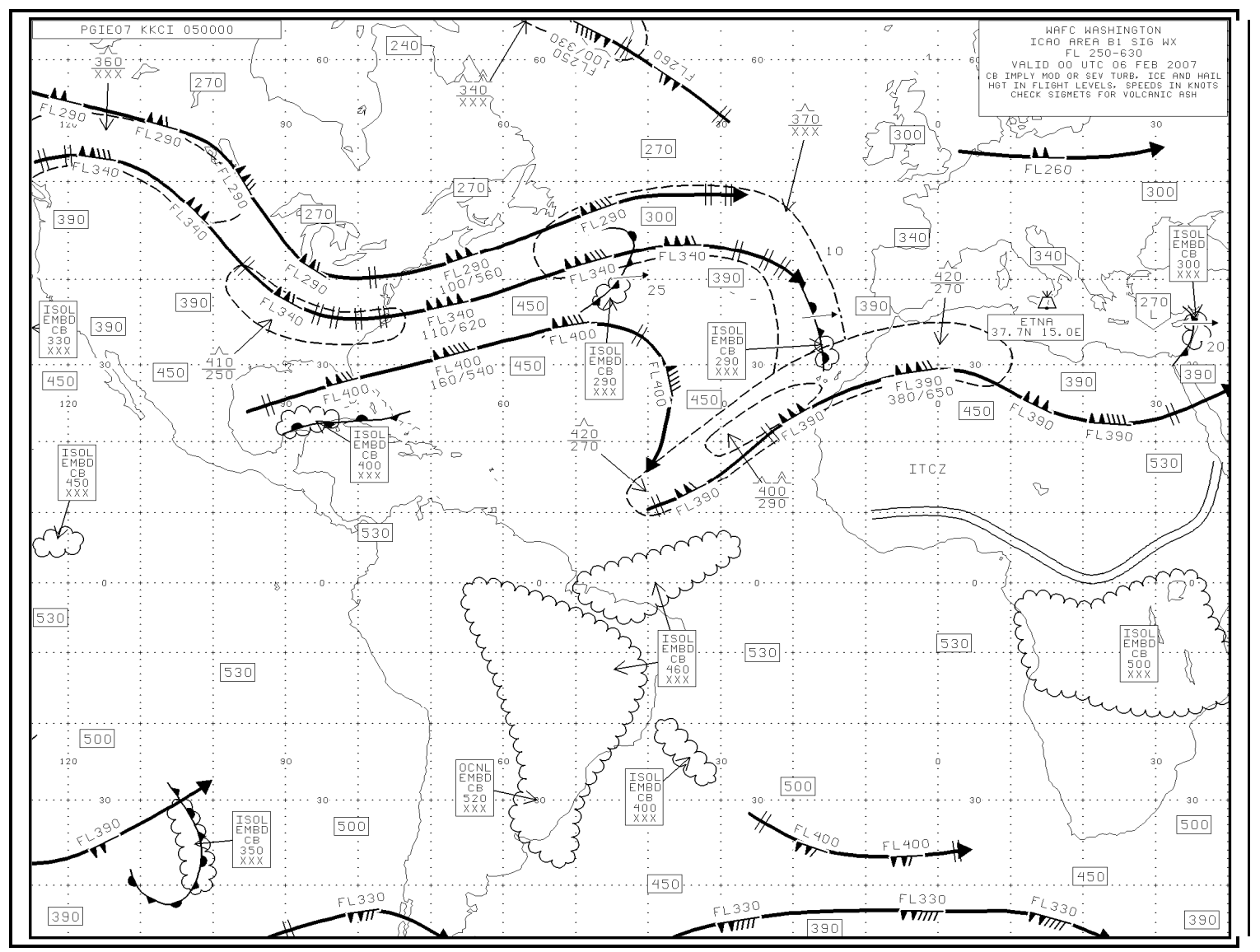

Figura 2 - Carta Aeronáutica Meteorológica -FL250 / (Fonte: Ontiveros, 2003)

Na Figura 2 é ilustrada uma carta aeronáutica meteorológica SIGWX, que é uma carta de prognóstico de tempo significativo dos níveis da superfície ao FL250, do FL100 ao FL450 e do FL250 ao FL630. 


\subsection{Designação do Espaço Aéreo}

O espaço aéreo, obedecendo à divisão das FIRs de cada país, possui também uma divisão que é chamada de espaço aéreo controlado e espaço aéreo condicionado.

No espaço aéreo controlado, o ATC (Air Traffic Control) deve fornecer instruções às aeronaves, informando sobre outras aeronaves existentes em rota e sobre o espaço sobrevoado. Este espaço compõe-se por (MINISTÉRIO DA AERONÁUTICA, 1999):

- Áreas Superiores de Controle (UTA) - compreendem as aerovias superiores e outras partes do espaço aéreo superior;

- Áreas de Controle (CTA) - compreendem aerovias inferiores e outras partes do espaço aéreo inferior;

- Áreas de Controle Terminal (TMA) - configuração variável indicada nas cartas e manuais;

- Zonas de Controle (CTR) - configuração variável indicada nas cartas e manuais;

- Zonas de Tráfego de Aeródromo (ATZ), em aeródromos controlados - configuração variável indicada nas cartas e manuais.

O espaço aéreo condicionado caracteriza-se pelo espaço aéreo onde há necessidade de configuração variável para o vôo (MINISTÉRIO DA AERONÁUTICA, 1999). Este espaço é dividido em:

- Áreas Proibidas (SBP), espaço aéreo onde o vôo é proibido, visando máxima segurança para navegação.

- Áreas Perigosas (SBD), espaço aéreo onde o vôo necessita de autorização por pertencer à área com pouca segurança para navegação.

- Áreas Restritas (SBR), espaço aéreo onde o vôo pode ser feito com autorização e condição pré-estabelecida para navegação.

A Figura 3 ilustra a determinação do Ministério da Aeronáutica na divisão e relação entre as divisões dos Espaços Aéreos ATS (MINISTÉRIO DA AERONÁUTICA, 2000). 
Na figura, a ATZ (Zona de Tráfego de Aeródromo) é de jurisdição da TWR (Torre de Controle de Aeródromo), a CTR (zona de controle) e a TMA (área terminal) - jurisdição do APP (Centro de Controle de Aproximação).

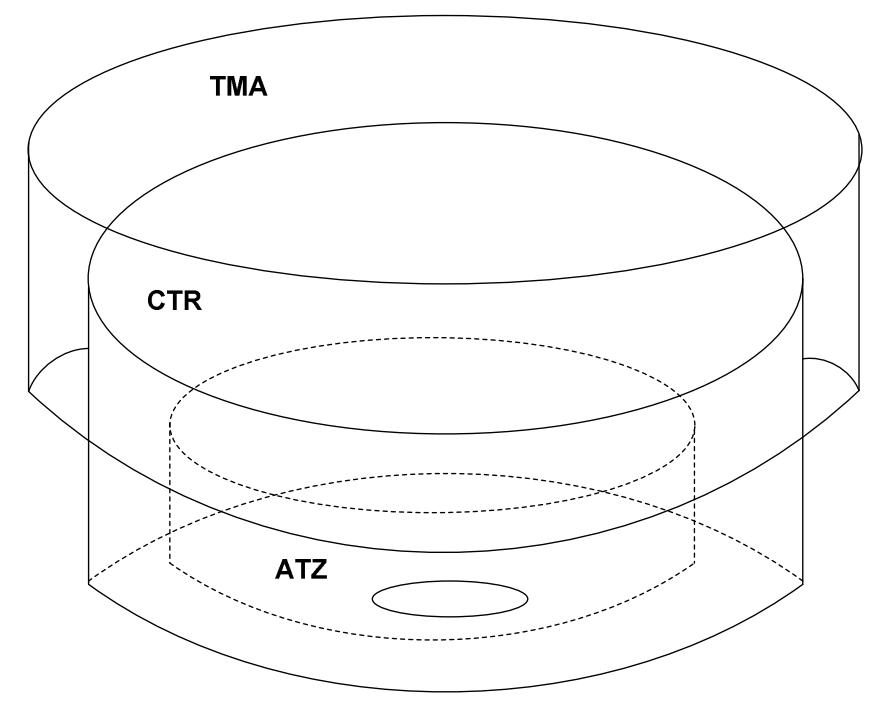

Figura 3 - Espaços Aéreos ATS

\subsection{Classes de Espaços Aéreos ATS}

Os Espaços Aéreos ATS são formados pelos Espaços Aéreos Controlados em conjunto com as FIRs (Flight Information Region), possuindo uma classificação alfabética de A até $\mathrm{G}$.

A classificação utilizada possui como forma de identificar as rotas ATS, estabelecer os serviços ATS prestados em cada espaço e as regras de operações que devem ser seguidas.

Esta classificação é determinada como (MINISTÉRIO DA AERONÁUTICA, 1999): 
- Classe A

Permite somente os vôos IFR, que estão sujeitos aos serviços de controle de tráfego aéreo e que possuem separação entre si.

- Classe B

Permite vôos IFR e VFR, que estão sujeitos aos serviços de controle de tráfego aéreo e que possuem separação entre si.

- Classe C

Permite vôos IFR e VFR, que estão sujeitos aos serviços de controle de tráfego aéreo. Os vôos IFR possuem separação entre si, e também são separados dos vôos VFR. Entretanto, os vôos VFR possuem separação somente em relação aos vôos IFR, recebendo apenas informação referente ao tráfego de outros vôos VFR e aviso para ser evitado tráfego quando requerido.

- Classe D

Permite vôos IFR e VFR, que estão sujeitos aos serviços de controle de tráfego aéreo. Os vôos IFR são separados entre si, recebendo informação de tráfego em relação aos vôos VFR e aviso para ser evitado tráfego quando requerido, enquanto os vôos VFR recebem apenas informação de tráfego em relação a todos os outros vôos e aviso para ser evitado tráfego quando requerido.

- Classe E

Permite vôos IFR e VFR. Somente os vôos IFR estão sujeitos ao serviço de controle de tráfego aéreo e são separados entre si. Neste caso todos os vôos, IFR e VFR, recebem informações de tráfego sempre que necessário. As aeronaves de vôos VFR podem voar neste espaço aéreo sem autorização prévia e sem notificação.

- Classe F

Permite vôos IFR e VFR, que podem receber serviços de informação de vôo. No entanto, apenas os vôos IFR recebem serviço de assessoramento de tráfego aéreo.

- Classe G

Permite vôos IFR e VFR, que recebem somente serviços de informação de vôo.

A classificação para as rotas domésticas (MINISTÉRIO DA AERONÁUTICA, 2000) é representada pelas letras W e Z. Para as rotas RNAV (Area Navigation), para as quais 
existem requisitos especiais de desempenho de navegação, são utilizadas as letras $L$ e Z. No entanto, todas as classes podem ser acompanhadas pelas letras $U, S$ e K, que são definidas como:

- U (UPPER): informa que a rota pertence ao espaço aéreo superior.

- S (SUPERSONIC): informa que a rota é para ser utilizada somente em vôos supersônicos.

- K (KOPTER): informa que a rota é para ser utilizada somente em vôos de helicópteros.

No Quadro 1, é apresentada a classificação utilizado no espaço aéreo brasileiro e quais os tipos de vôos que são permitidos (MINISTÉRIO DA AERONÁUTICA, 2000). 
Quadro 1 - Quadro de Classificação dos Espaços ATS Utilizados no Brasil

\begin{tabular}{|c|c|c|c|c|}
\hline CLASSE & $\begin{array}{c}\text { TIPO DE } \\
\text { VÔO }\end{array}$ & LIMITE DE VELOCIDADE & $\begin{array}{c}\text { RÁDIO } \\
\text { COMUNICAÇÃO }\end{array}$ & $\begin{array}{c}\text { SUJEITO A } \\
\text { AUTORIZAÇÃO } \\
\text { ATC }\end{array}$ \\
\hline A & IFR & Não Aplicável & Bilateral Contínua & Sim \\
\hline \multirow[t]{2}{*}{$B$} & IFR & Não Aplicável & \multirow[t]{2}{*}{ Bilateral Contínua } & \multirow[t]{2}{*}{ Sim } \\
\hline & VFR & $380 \mathrm{KT}$ IAS & & \\
\hline \multirow[t]{2}{*}{ C } & IFR & Não Aplicável & \multirow[b]{2}{*}{ Bilateral Contínua } & \multirow[b]{2}{*}{ Sim } \\
\hline & VFR & $\begin{array}{l}\text { Abaixo FL 100: } 250 \mathrm{KT} \text { IAS } \\
\text { Acima FL 100: } 380 \mathrm{KT} \text { IAS }\end{array}$ & & \\
\hline \multirow[t]{2}{*}{$\mathrm{D}$} & IFR & $\begin{array}{l}\text { Abaixo FL 100: } 250 \text { KT IAS } \\
\text { Igual ou Acima FL 100: Não }\end{array}$ & \multirow[t]{2}{*}{ Bilateral Contínua } & \multirow[t]{2}{*}{ Sim } \\
\hline & VFR & $\begin{array}{l}\text { Aplicável } \\
250 \text { KT IAS } \\
\text { 100: } 380 \text { KT IAS }\end{array}$ & & \\
\hline \multirow[t]{2}{*}{$E$} & IFR & $\begin{array}{l}\text { Abaixo FL 100: } 250 \text { KT IAS } \\
\text { Acima FL 100: Não Aplicável }\end{array}$ & Bilateral Contínua & $\operatorname{Sim}$ \\
\hline & VFR & $\begin{array}{l}\text { Abaixo FL 100: } 250 \text { KT IAS } \\
\text { Acima FL 100: } 380 \text { KT IAS }\end{array}$ & Não & Não \\
\hline \multirow[t]{2}{*}{$F / G$} & IFR & $\begin{array}{l}\text { Abaixo FL 100: } 250 \text { KT IAS } \\
\text { Acima FL 100: Não Aplicável }\end{array}$ & Bilateral Contínua & \multirow[t]{2}{*}{ Não } \\
\hline & VFR & $\begin{array}{l}\text { Abaixo FL 100: } 250 \text { KT IAS } \\
\text { Acima FL 100: } 380 \text { KT IAS }\end{array}$ & Não & \\
\hline
\end{tabular}




\title{
2.5 Espaço Aéreo sob Jurisdição do Brasil
}

Esta estrutura visa auxiliar os ATS em terra e ar, seguindo as normas da ICAO, através do Ministério da Aeronáutica, determinando que:

\begin{abstract}
"Os serviços de tráfego aéreo serão prestados em todo o espaço aéreo que se superpõe ao território nacional, incluindo águas territoriais e jurisdicionais, bem como o espaço aéreo que se superpõe ao alto mar que tiver sido objeto de acordos internacionais. (MINISTÉRIO DA AERONÁUTICA, 1999)"
\end{abstract}

No Brasil, o espaço aéreo sob sua jurisdição é dividido em 5 FIRs (Flight Information Region): Atlântico, Amazônica, Brasília, Recife e Curitiba.

A Figura 4 ilustra a divisão do Espaço Aéreo Brasileiro, bem como os demais países da América do Sul (ROLIM, 2006). 


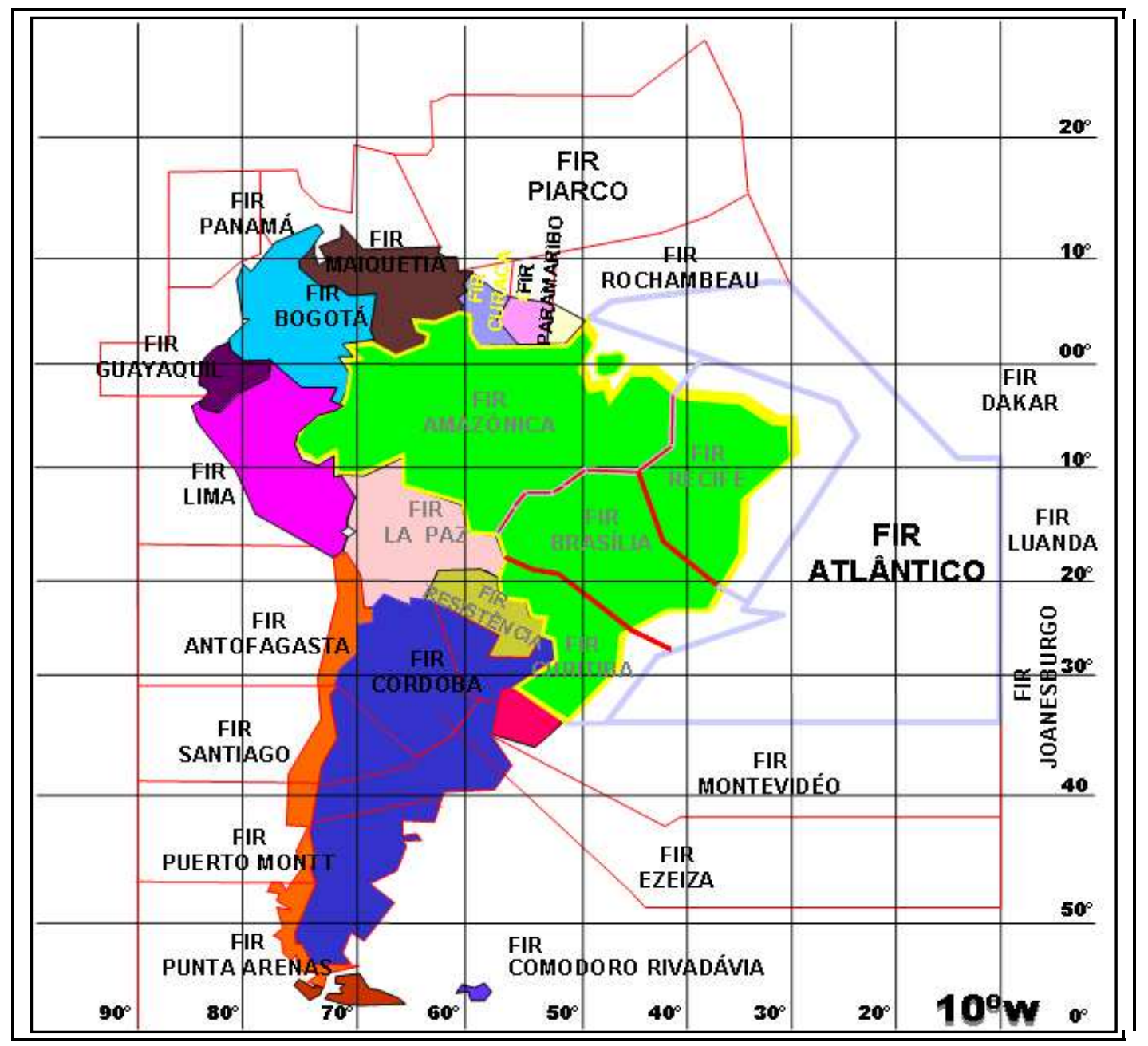

Figura 4 - FIRs do Espaço Aéreo da América do Sul (fonte: ROLIM, 2006)

\subsection{Sistemas CNS/ATM}

No início do século XX a ICAO, reconheceu a necessidade de melhorias nos sistemas utilizados pela aviação, visando suportar a demanda de crescimento em todo do mundo.

Em 1983, através do Comitê FANS (Future Air Navigation Systems), iniciou os estudos para a elaboração de um sistema de apoio à navegação aérea, denominado Sistema CNS/ATM, objetivando, entre outros, o desenvolvimento de sistemas aeronáuticos de 
comunicação que permitissem integrar diversas sub-redes utilizando tecnologias diferentes.

No início da década de 1990 a ICAO aprovou o primeiro plano de desenvolvimento de sistemas aeronáuticos utilizando CNS/ATM.

A interoperabilidade entre estes sistemas utilizando tecnologias digitais, sistemas de satélites e ferramentas de automação para gerenciamento de tráfego aéreo deve ser fornecida através de uma rede de computadores ATN, que será implementada sob os princípios do Modelo OSI (Open System Interconnection) (ICAO, 2005).

O sistema CNS/ATM surgiu como uma forma de resolver o problema de congestionamento de rotas no Pacífico Sul, originado pelo grande crescimento da economia japonesa e dos tigres asiáticos. Com esse crescimento, os atuais sistemas de navegação não suportaram a demanda, tendo colocado em risco a segurança dos vôos. Ainda, como ponto de partida para a implantação do novo sistema houve o lançamento de aeronaves que poderiam navegar sem dependência de sistemas de terra, possuindo capacidade de comunicação por canal de dados e erros máximos em posicionamento de $5 \mathrm{NM}^{3}$. As mesmas considerações de implantação foram utilizadas no Atlântico Norte, formando a base para as demais implantações do sistema CNS/ATM (MINISTÉRIO DA AERONÁUTICA, 2002).

Para Siqueira (2005), a utilização do conceito CNS/ATM na navegação aérea visa proporcionar maior segurança e eficiência, bem como a cobertura global em quaisquer condições meteorológicas.

Na Figura 5, Siqueira (2005) demonstra as melhorias com a utilização dos sistemas CNS/ATM, em cuja infra-estrutura de navegação são inseridos os conceitos de RNAV (Area Navigation), RNP (Required Navigation Performance), RVSM (Minimum Reduction of Vertical Separation) e o GNSS (Global Navigation Satellite System).

${ }^{3}$ NM - Nautical Mile. Unidade de medida de comprimento ou distância, sendo 1 NM $=1852 \mathrm{~m}$. 


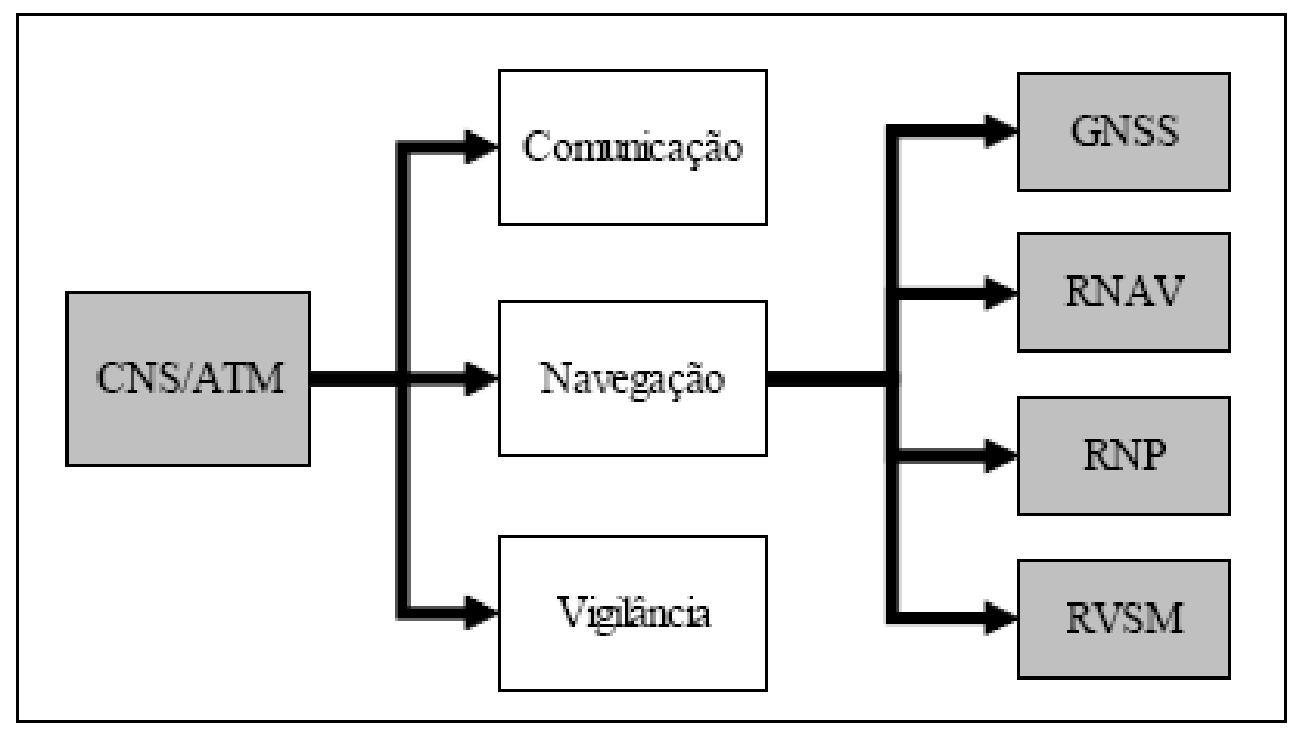

Figura 5 - Visão Utilizando os Sistemas CNS/ATM (Fonte: Siqueira, 2005)

\subsubsection{Comunicação}

As comunicações com as aeronaves deverão ser estabelecidas através de enlaces de dados, permitindo eficiência e rapidez entre os sistemas de terra e sistemas de bordo.

Nos Sistemas CNS/ATM, a transmissão de mensagens de voz utilizando freqüências na faixa de VHF irá continuar, mas será utilizada em conjunto com a transmissão digital de dados. Posteriormente, mesmo com a transmissão digital, os canais VHF continuarão a ser utilizados para a transmissão de informações, e de forma progressiva serão utilizados os sistemas de satélites nas comunicações de dados e voz, objetivando atingir uma cobertura em nível mundial.

Complementarmente, as comunicações farão uso de transmissões através de canais utilizando freqüências na faixa HF. O sistema SSR (Secondary Surveillance Radar), atualmente utilizado para a vigilância do espaço aéreo onde há áreas de alta movimentação aérea, utilizando seus modos de operação "A", "B", "C" e "S", será 
utilizado nas comunicações com aeronaves devido à sua grande capacidade de transmissão de informações digitalizadas no modo "S" (MINISTÉRIO DA AERONÁUTICA, 2002).

Os modos de comunicação são definidos por ICAO apud Vismari (2007), como:

- ADS-A (Addressing) - Possibilita 4 tipos de contato, sendo por demanda, evento período e emergência.

- ADS-B (Broadcast) - A aeronave transmite mensagens ADS de forma periódica e por rádio difusão.

- ADS-C (Contact) - A comunicação ADS é estabelecida entre a aeronave e um órgão de solo; por ser endereçável, é também denominada como ADS-A.

- ADS-S (Squiter) - A comunicação ADS é feita periodicamente através de broadcasting a 56bits por segundo e contendo endereçamento de 24 bits (BOISVERT e ORLANDO, 1993).

\subsubsection{Navegação}

A ICAO adotou o conceito de RNP (Required Navigation Performance), que estabelece a capacidade necessária de uma aeronave para se deslocar em determinadas rotas. Esta capacidade que deverá ser atingida na navegação utilizará o GNSS (MINISTÉRIO DA AERONÁUTICA, 2002).

O sistema GNSS, fundamentalmente diferente dos tradicionais sistemas de navegação baseados em auxílios em solo, fornece, através de uma navegação global, suporte a todas as fases do vôo. As atuais constelações de satélites para a navegação são o GPS (Global Positioning System) e o GLONASS (Global Navigation Satellite System) (CHUJO e WALTER, 2005).

O sistema GPS foi desenvolvido pelo DoD (American Department of Defense), é operado pelo Estados Unidos da América, possui 24 satélites distribuídos em 6 planos 
orbitais ${ }^{4}$ sendo que 21 estão operando e 3 estão ativos em reserva. Cada plano orbital é composto por 4 satélites em órbita quase circular, a uma altura de aproximadamente 20.200 km e inclinação de 55 graus em relação ao plano do Equador (LAGO, FERREIRA e KRUEGER, 2002).

O sistema GLONASS ${ }^{5}$, que está sendo desenvolvido e é operado pela Rússia possuirá, quando estiver completamente implementado, 24 satélites distribuídos em 3 planos orbitais. Cada plano orbital terá 8 satélites em órbita quase circular, a uma altura de $19.000 \mathrm{~km}$ e inclinação de 64,8 graus em relação à linha do equador (LAGO, FERREIRA e KRUEGER, 2002).

A navegação baseada no sistema GNSS tem oferecido precisão crescente, e níveis razoáveis de integridade e disponibilidade, oferecendo navegação em rota, áreas terminais e áreas de aproximação de não-precisão. Desta forma, todas as aeronaves possuirão equipamentos de igual capacidade para processamento de sinais recebidos por satélites, e poderão voar em qualquer tipo de espaço aéreo em todo o globo terrestre, podendo todos os países membros da ICAO substituir parcialmente a infraestrutura de navegação atualmente utilizada, que se baseia em terra, por uma baseada em satélites (MINISTÉRIO DA AERONÁUTICA, 2002).

\footnotetext{
${ }^{4}$ Plano orbital refere-se ao plano o qual a órbita é descrita, tendo a órbita como uma trajetória curva de um corpo no espaço.

${ }^{5}$ GLONASS é o sistema de satélite Russo, teve seu primeiro satélite em órbita em 1982, atualmente possui 17 satélites em operação. (http://www.fas.org/main/home.jsp).
} 
Quadro 2 - Quadro Comparativo entre os Sistemas GPS e GLONASS

\begin{tabular}{|c|c|c|}
\hline & GLONASS & GPS \\
\hline Número de satélites & 24 & 24 \\
\hline Número de planos orbitais & 3 & 6 \\
\hline Inclinação dos planos orbitais & $64,8^{\circ}$ & $55^{\circ}$ \\
\hline Semi-eixo maior da órbita & $25510 \mathrm{~km}$ & $26560 \mathrm{~km}$ \\
\hline Freqüência fundamental $\left(f_{0}\right)$ & $5,11 \mathrm{MHz}$ & $10,23 \mathrm{MHz}$ \\
\hline $\begin{array}{c}\text { Técnica de separação do } \\
\text { sinal }\end{array}$ & FDMA & CDMA \\
\hline $\begin{array}{l}\text { Freqüência portadoras }(\mathrm{MHz}) \\
\text { L1 } \\
\text { L2 }\end{array}$ & $\begin{array}{l}\text { de } 1602,0 \text { a } 1615,5 \\
\text { de } 1246,0 \text { a } 1256,5\end{array}$ & $\begin{array}{l}1575,42 \\
1227,60\end{array}$ \\
\hline $\begin{array}{c}\text { Freqüência códigos }(\mathrm{MHz}) \\
\mathrm{C} / \mathrm{A} \\
\mathrm{P}\end{array}$ & $\begin{array}{l}0,511 \\
5,110\end{array}$ & $\begin{array}{l}1,023 \\
10,23\end{array}$ \\
\hline $\begin{array}{l}\text { Efemérides transmitidas } \\
\text { pelos satélites }\end{array}$ & $\begin{array}{c}\text { Coordenadas Cartesianas } \\
\text { Geocêntricas e suas } \\
\text { derivadas }\end{array}$ & $\begin{array}{l}\text { Elementos Orbitais } \\
\text { Keplerianos e seus fatores de } \\
\text { Perturbação }\end{array}$ \\
\hline Tempo de referência & UTC (SU) & UTC (USNO) \\
\hline $\begin{array}{c}\text { Sistema de referência } \\
\text { Geodésico }\end{array}$ & PZ-90 & WGS-84 \\
\hline
\end{tabular}

O Quadro 2 apresenta, através de comparações, as características operacionais que diferenciam os sistemas GPS e GLONASS (LAGO, FERREIRA e KRUEGER, 2002). 


\subsubsection{Vigilância}

A ICAO adotou o conceito de ADS (Automatic Dependent Surveillance), que faz com que a aeronave transmita de forma automática sua posição e outros dados relevantes, como manobras necessárias, velocidade e condição meteorológica (MINISTÉRIO DA AERONÁUTICA, 2002). Estes dados são enviados para os órgãos que prestam Serviços de Tráfego Aéreo e utilizam para transmissão os meios de comunicação como sistemas de satélites, sistema VHF, sistemas HF ou modo "S" do transponder 6 . Os dados que são transmitidos pelas aeronaves geram, através de processamento dos mesmos, a posição da aeronave em imagem de vídeo. O contínuo e permanente conhecimento da posição das aeronaves faz com que se tenha uma utilização eficaz de todo espaço aéreo (MINISTÉRIO DA AERONÁUTICA, 2002).

A utilização do sistema ADS permite melhorias significativas ao ATM (Air Traffic Management). A utilização do transponder em modos de operações já utilizados será preservada, no entanto, complementado com a utilização gradual do modo " $\mathrm{S}$ " em áreas de tráfego denso como as áreas terminais e em espaços aéreos continentais (MINISTÉRIO DA AERONÁUTICA, 2002).

O processo ADS insere a possibilidade de transmissão de informações entre as aeronaves utilizando radiodifusão, sendo que a aeronave poderá fornecer constantemente informação sobre sua posição. A comunicação para este modo de radiodifusão é denominada como ADS-B (Automatic Dependent Surveillance Broadcast), atualmente sob responsabilidade do RTCA Inc. Special Committee 186 (RTCA, 2001).

\footnotetext{
${ }^{6}$ Transponder é um dispositivo eletrônico utilizado em aeronaves para envio e recepção de sinal, utiliza freqüência de recepção 1030Mhz e transmissão 1090 MHz. (ICA 102-9)
} 
Para a FAA (Federal Aviation Administration), o conceito sobre a troca de informações utilizando ADS-B é definido como:

The concept is simple: Aircraft (or other vehicles or obstacles) will broadcast a message on a regular basis, which includes their position (such as latitude, longitude and altitude), velocity, and possibly other information. Other aircraft or systems can receive this information for use in a wide variety of applications. Current surveillance systems must measure vehicle position, while ADS-B based systems will simply receive accurate position reports broadcast by the vehicles (RTCA, 2001).

Na Figura 6 é ilustrada a utilização do ADS-B no espaço aéreo, onde a aeronave utiliza broadcasting para enviar suas informações (HARISON, 2006).

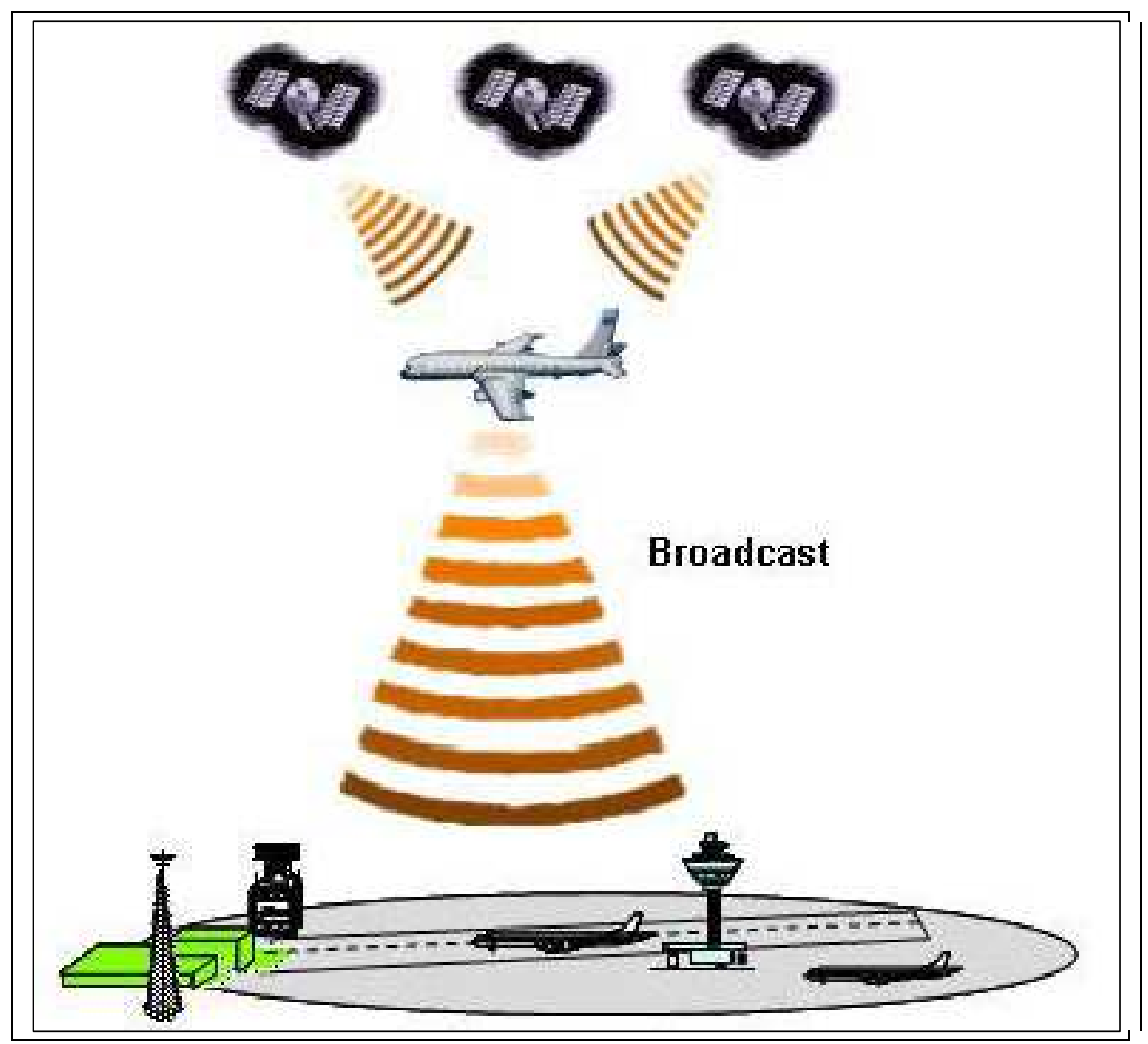

Figura 6 - Utilização do ADS-B na Vigilância (Fonte: HARISON, 2006) 
A utilização do ADS-B proporciona a todos os usuários do sistema informações em tempo real, melhor visualização do tráfego aéreo e segurança significativa nas operações de vôo (FAA, 2008).

\subsubsection{Gerenciamento de Tráfego Aéreo}

O ATM está ligado diretamente à elaboração dos novos sistemas de comunicações para navegação e vigilância. Em uma escala mais ampla o Gerenciamento de Tráfego Aéreo inclui o ATC, ATFM (Air Traffic Flow Management), e também as próprias operações aéreas (MINISTÉRIO DA AERONÁUTICA, 2002).

Para Oliveira (2005), os transportadores aéreos são divididos em diversas classes, conforme seus objetivos, sendo que a maior parte dos vôos controlados é prometido pelas linhas aéreas comerciais regulares. No entanto, todas compartilham dos mesmos recursos de infra-estrutura do transporte aéreo, que são os aeroportos e o espaço aéreo.

Assim, com a utilização simultânea destes recursos de infra-estrutura surge a necessidade de recursos inteligentes para serem utilizados pelo ATM. Como visão mundial e regional a integração dos sistemas ATM traz a necessidade de harmonização de padrões e procedimentos, a qual é obtida com a implantação das tecnologias dos sistemas CNS (Communication Navigation and Surveillance) (MINISTÉRIO DA AERONÁUTICA, 2002).

Os sistemas CNS/ATM favorecem o ATM, permitindo um maior grau de automação, e fazendo com que se tenha um sistema integrado globalmente. Desde o início da história aeronáutica, o controle de tráfego aéreo é feito de forma não homogênea, com muita variação de tecnologia, de acordo com as diversas regiões de espaço aéreo. Visa-se ter um controle unificado do espaço aéreo, permitindo um melhor desempenho no ATC e no auxílio às autoridades nas tomadas de decisões. Por outro lado, as companhias 
aéreas teriam como obter um controle efetivo de seus vôos, promovendo a agilidade e eficiência junto a seus clientes (ROSSI et al, 2005).

Através de um diagrama representado pela Figura 7, Oliveira (2005) demonstra a organização hierárquica dos serviços ATM. No entanto, é utilizado somente o sistema ATC, por servir como estrutura para os serviços ATM.

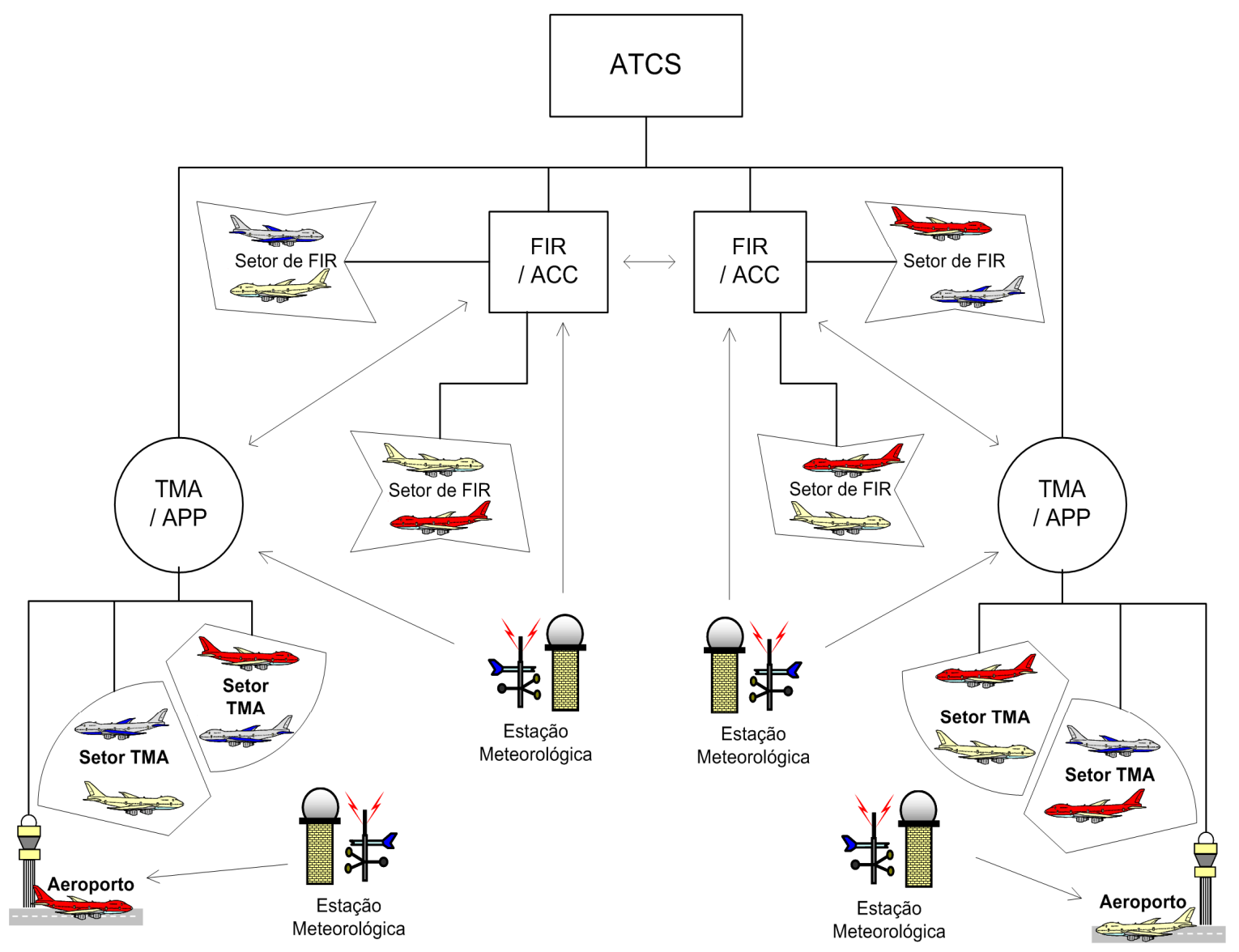

Figura 7 - Organização de um ATM (Fonte: Oliveira, 2005)

Para Oliveira (2005) as informações trocadas entre as entidades dispostas na Figura 7 podem ser categorizadas nas seguintes classes:

- Informação sobre o estado passado, atual e futuro da aeronave;

- Ações de controle; 
- Informações sobre a coordenação e ocupação do aeroporto;

- Informações meteorológicas.

Todas as informações podem provir de operadores humanos que inserem os dados nos sistemas ou também através de sensores presentes nas infra-estruturas que atendem os serviços prestados pelo ATM. 


\section{Capítulo}

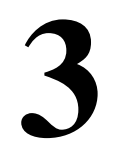

\section{REDE DE TELECOMUNICAÇÃO AERONÁUTICA (ATN)}

\subsection{O Padrão ATN}

Em janeiro de 1989 a ANC (Air Navigatin Commission), através de estudos desenvolvidos pela SICASP (Secondary Surveillance Radar Improvements and Collision Avoidance System Panel), incluiu os materiais desenvolvidos pela ICAO que tratava das necessidades mínimas requeridas para operações de serviços ATS e operações de serviços por satélites, e, assim, deu origem à ATN. No mesmo ano, em maio de 1989, a SICASP desenvolveu uma recomendação sobre a ATN e solicitou a publicação desta recomendação como manual ICAO, tendo sua primeira publicação em 1991 e a sua segunda em 1997. O SARP (Standards and Recommended Practices) e o material recomendado foram publicados no anexo 10 da Convenção da Aviação Civil Internacional (NETO, 2005).

No ano de 1993, a ANC publicou os trabalhos de estudos para recomendações sobre ATN para o ATNP (Aeronautical Telecommunication Networking Panel). No primeiro encontro do ATNP, em junho de 1994, ficou definido que seria de sua responsabilidade a elaboração do SARP e de todo material sobre orientação de implantação ATN, 
incluindo recomendações técnicas e também aplicações ar-ar e ar-terra. Assim, o primeiro conjunto de SARP para ATN foi finalizado em novembro de 1996 (SOUZA, 2004 e NETO, 2005).

A ATN é responsável pela integração da comunicação aeronáutica e também em serviços como a sub-rede AMSS (Aeronautical Mobile Satellite Service), enlace de dados VHF, SSR e enlace de dados HF. (SOUZA, 2004 e NETO, 2005).

Sendo uma rede para integração da comunicação de dados, provê benefícios como (ROSSI et al, 2005):

- Integração entre usuários de comunicação e infra-estrutura;

- Serviço seguro de comunicação;

- Escalabilidade;

- Política de roteamento; e

- Uso de infra-estrutura existente.

A ATN é baseada no padrão de arquitetura de computadores ISO (International Organization for Standardization), possibilitando o gerenciamento de tráfego aéreo através de comunicações ar-ar e ar-terra, que se integram ao conceito CNS/ATM. Os serviços de Datalink são destinados basicamente ao tráfego de mensagens (ROSSI et al, 2005), como:

- $\mathrm{ATS}=$ Air Traffic Services

Ex: PDC

- $\mathrm{AAC}=$ Administrative Aeronautical Communication

Ex: Mensagens OOOI

- $\mathrm{AOC}=$ Aeronautical Operational Communication

Ex: Monitoração de turbinas durante o vôo

As Figuras 8 e 9, HELIOS apud Souza, (2004) definem o ambiente anterior à implantação da ATN e o futuro ambiente de comunicação pretendido com a ATN, respectivamente. 


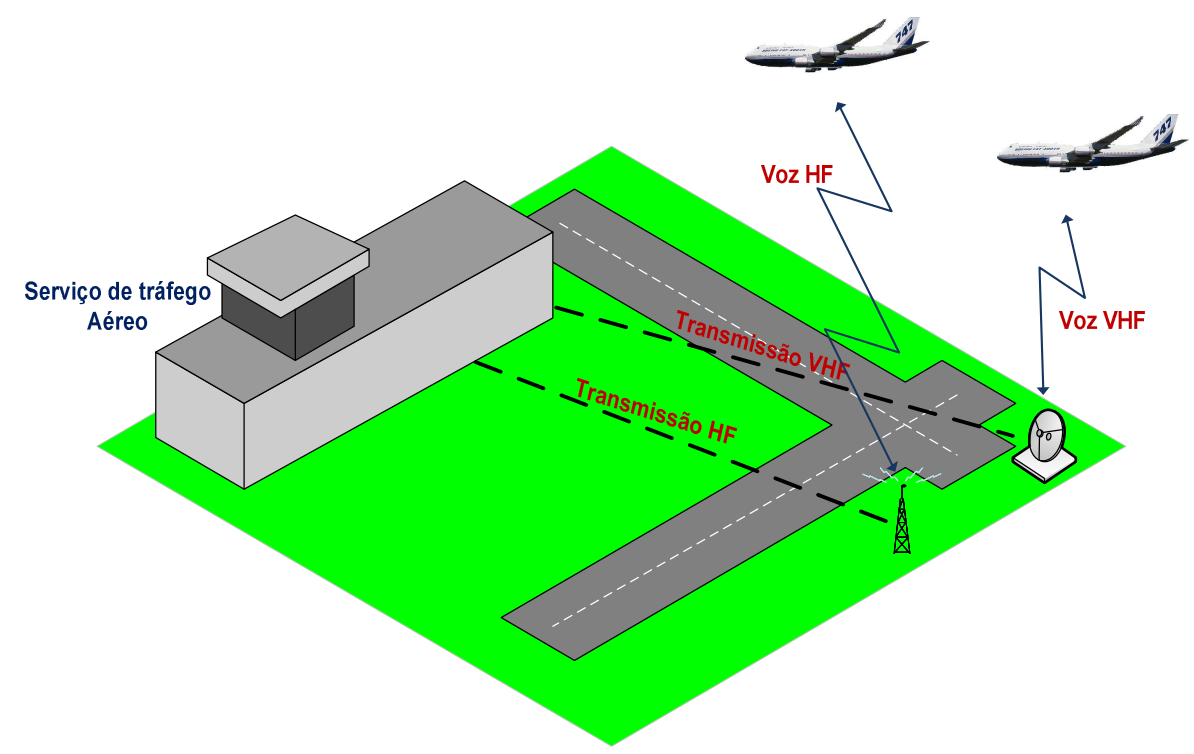

Figura 8 - Visão anterior à implantação ATN (Fonte: HELIOS apud Siqueira, 2004)

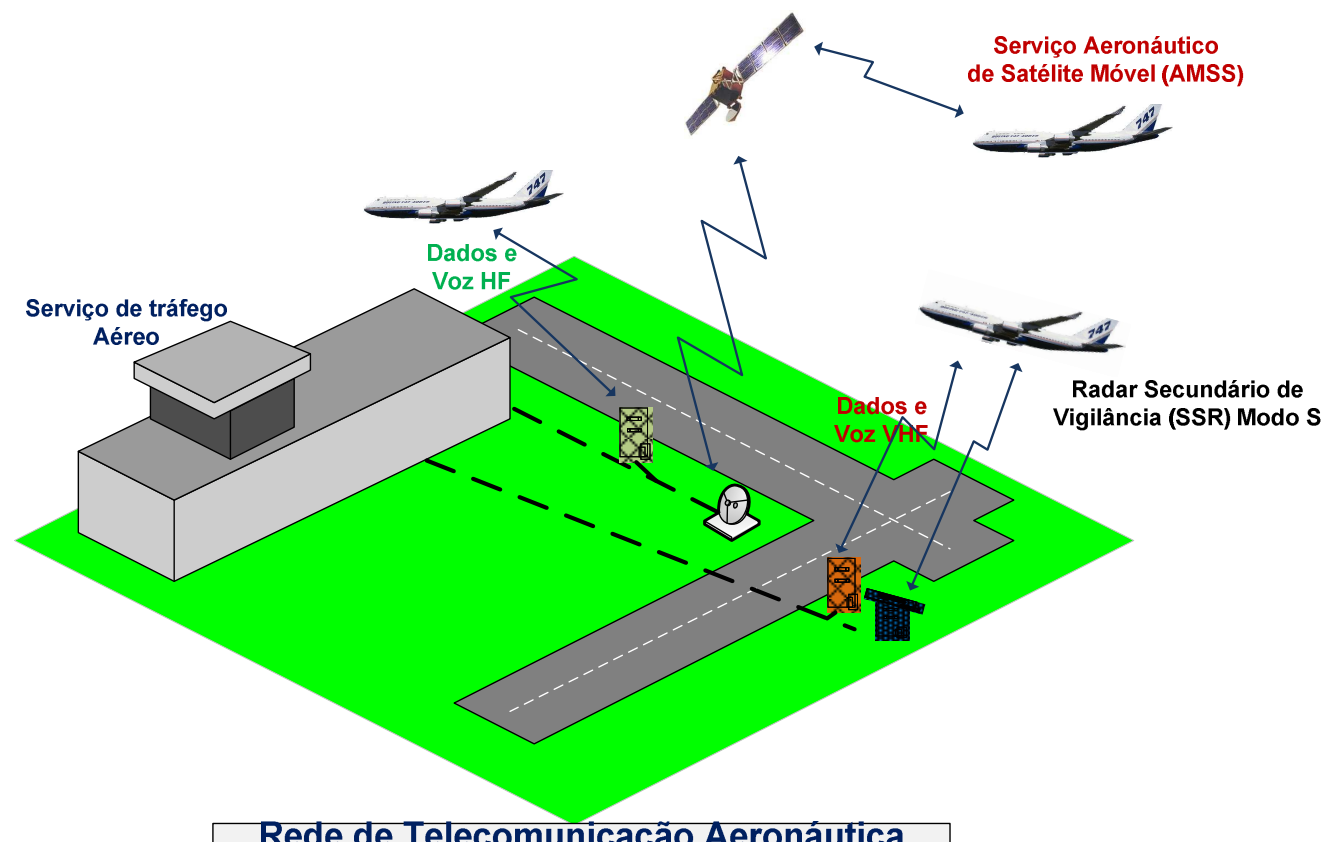

Figura 9 - Visão após implantação da ATN (Fonte: HELIOS apud Siqueira, 2004) 


\subsection{O Padrão OSI}

Em 1974 a ISO (International Organization for Standardization) desenvolveu uma arquitetura de referência para padronização de redes, que teve o nome de Modelo de Referência para Interconexão de Sistemas Abertos. Baseava-se em uma proposta de um modelo que sintetizasse de forma abstrata o funcionamento de computadores por redes de comunicação de dados, originado na experiência de funcionamento dos sistemas de teleprocessamento da rede ARPA. Entre 1978 e 1984 foi elaborado o modelo OSI (Open System Interconnection), onde pela primeira vez foi abordado o conceito de sistema aberto (GALLO e HANCOCK, 2003).

A Figura 10 ilustra o conceito de sistemas abertos proposto pelo modelo OSI.

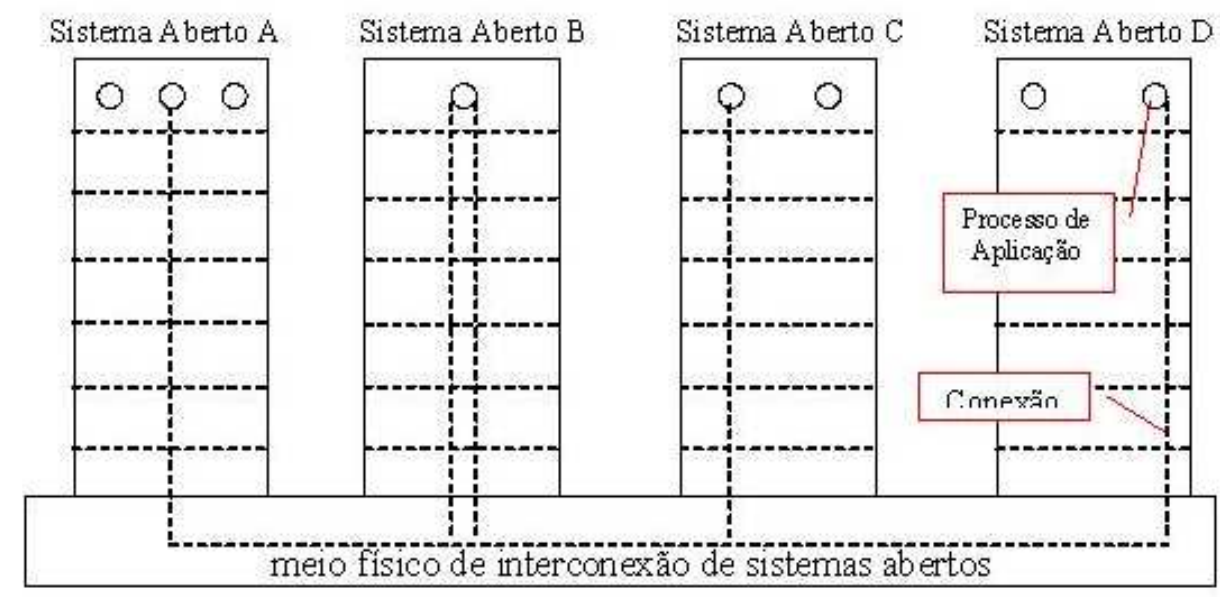

Figura 10 - Conceito OSI (Fonte: adaptado de GALLO e HANCOCK, 2003)

O conceito de sistemas abertos proposto pela ISO caracteriza-se por oferecer uma interconexão entre equipamentos fabricados por diferentes empresas. A Figura 10 representa a interconexão oferecida por quatro diferentes equipamentos, sendo definidos como Sistema Aberto A, Sistema Aberto B, Sistema Aberto C e Sistema 
Aberto D. É representada a utilização de um mesmo meio físico para que todos os sistemas possam se comunicar.

Gallo e Hancock (2003) definem o modelo OSI como um arcabouço conceitual para desenvolvimento de padrões para protocolos de redes. Em outra definição, destacam a característica do modelo OSI quanto à codificação formal do conceito de arquitetura de redes em camadas.

Gallo e Hancock (2003) também explicam que as camadas ajudam a reduzir o nível de complexidade na conectividade de uma rede por trabalharem de forma bem definida em cada estágio de processamento de dados a serem transmitidos. Desta forma, o modelo OSI baseia-se no conceito de camadas sobrepostas, onde cada uma executa um conjunto definido de funções, ajudando, desta forma, a simplificar o projeto de uma rede.

A Figura 11 ilustra as sete camadas sobrepostas do modelo OSI e quais os serviços oferecidos em cada uma. llustra onde cada camada atua durante a transmissão dos dados, podendo ser nos equipamentos ou nos programas. Outra informação demonstrada é como os dados são definidos ao serem tratados nas camadas, sendo:

- Mensagem: são definidos como mensagem os dados criados na camada de aplicação e enviados até a camada de transporte;

- Pacotes: são definidos como pacotes os dados contidos nas mensagens e quando quebrados para serem transportados pela rede;

- Quadros: são definidos como quadros os dados que chegam como pacotes na camada de enlace, ou seja, são semelhantes aos pacotes, mas existem em níveis mais baixos;

- Bits: é a transformação dos quadros em sinais para passagem no meio físico. 


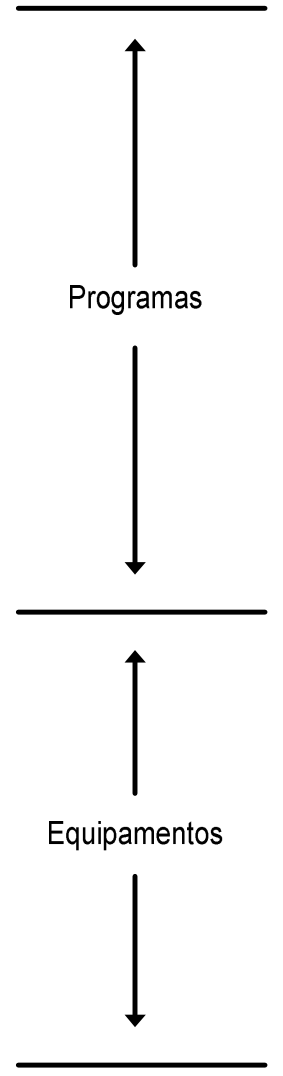

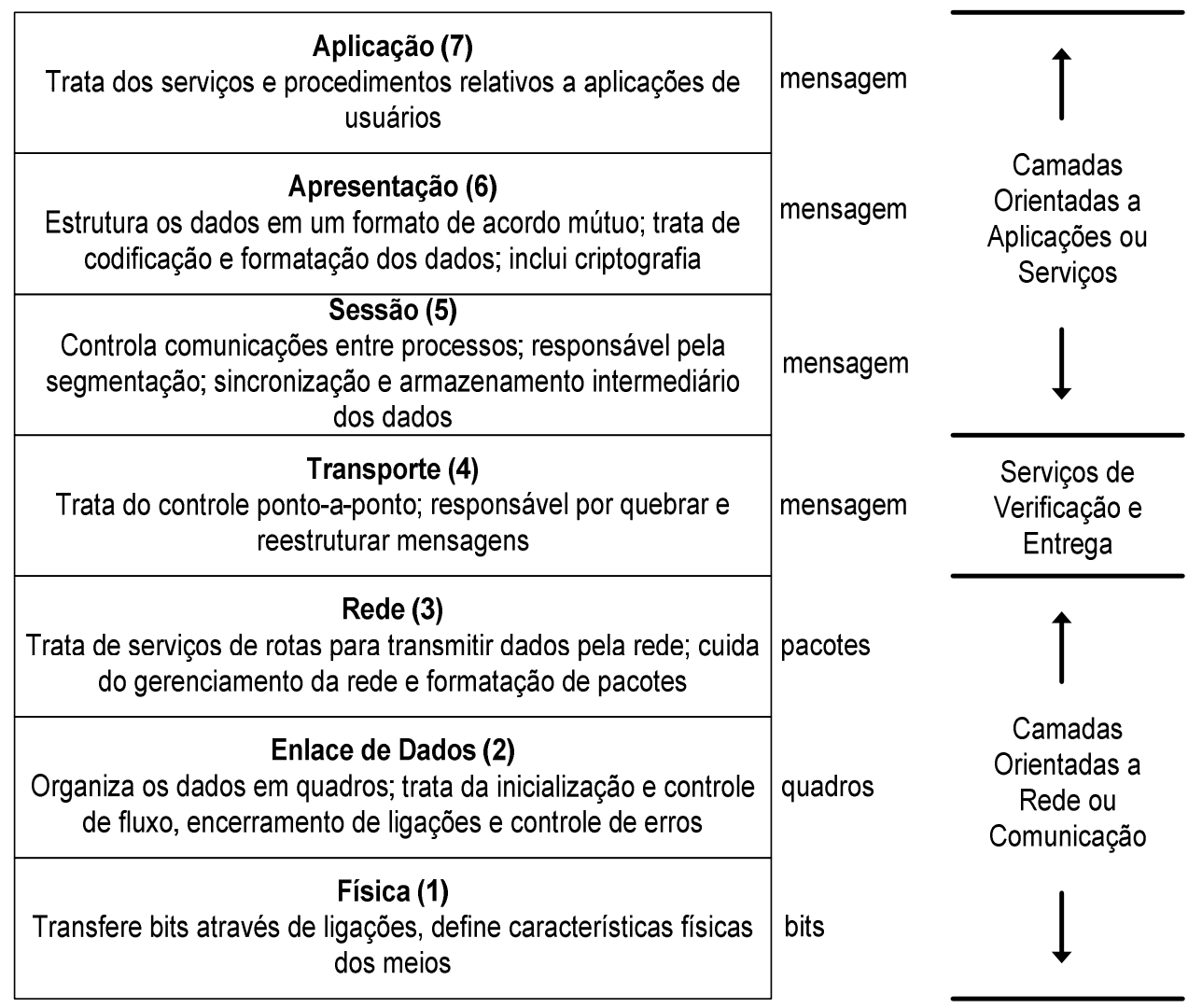

Figura 11 - Visão das Camadas do Modelo OSI (Fonte: adaptado de GALLO e HANCOCK, 2003)

A integração das camadas deve possibilitar a troca de informações entre processos de aplicação (AP - Application Process) pertencentes a sistemas abertos diferentes.

\subsubsection{Serviços do Modelo OSI}

O modelo OSI oferece dois diferentes tipos de serviços em suas camadas, que são: orientado por conexão e sem conexão.

- Serviço orientado por conexão: estabelece uma conexão física entre o nó emissor e o nó receptor antes da transferência dos dados. Após a conclusão da sessão a ligação entre os nós é removida. 
- Serviço sem conexão: não estabelece nenhuma conexão física entre o nó emissor e receptor antes da transferência dos dados. Neste tipo de serviço a mensagem é quebrada em pacotes e enviada pela rede, sendo cada pacote independente um do outro que carrega parte da mensagem e precisa carregar um endereço de destino. O serviço sem conexão pode ser confiável e não-confiável, sendo que o serviço não-confiável não requer aviso de recebimento dos dados do receptor para o emissor. Este aviso se chama serviço de datagrama. O serviço confiável, em que há a confirmação de recebimento, chama-se serviço de datagrama com confirmação.

Estes serviços ficam dispostos nos pontos de acessos de serviços (SAPs - Service Access Points), cada um com um endereço correspondente (GALLO e HANCOCK, 2003). A Figura 12 ilustra o conceito de troca de informações entre camadas com o uso de SAPs. Um serviço oferecido na camada $(\mathrm{N})$, ou simplesmente Serviço $(\mathrm{N})$, é oferecido às entidades $(\mathrm{N}+1)$ através dos Pontos de Acesso de Serviço da camada $\mathrm{N}$ ou SAP (N).

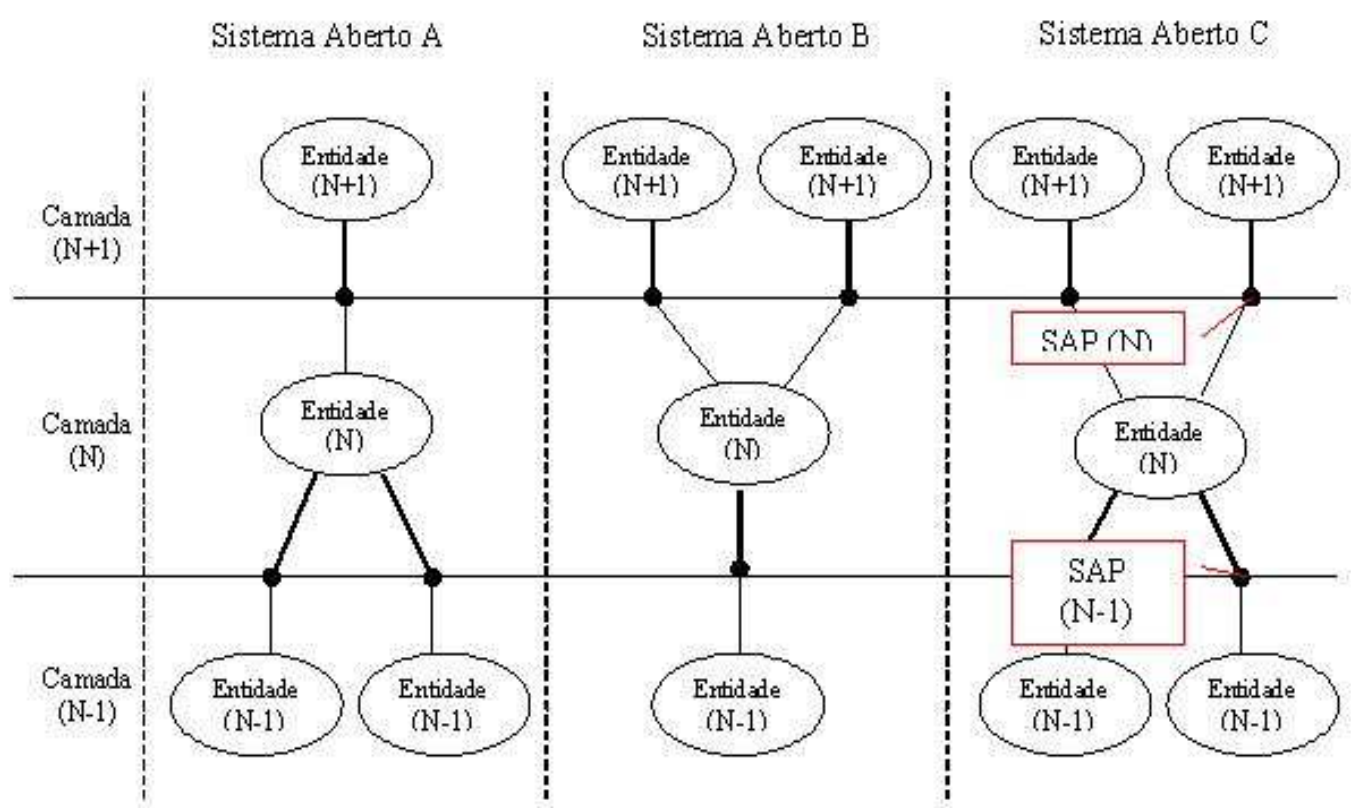

Figura 12 - Ponto de Acessos de Serviços (Fonte: adaptado de GALLO e HANCOCK, 2003) 
Desta forma, uma entidade $(\mathrm{N})$ pode oferecer serviços a várias entidades $(\mathrm{N}+1)$ através de vários SAPs $(\mathrm{N})$ e pode utilizar os serviços de várias entidades (N-1) através de vários SAPs $(\mathrm{N}-1)$.

\subsection{Arquitetura ATN}

Baseada no modelo OSI, a ATN promoverá a conexão de sub-redes e diversas tecnologias dentro do ambiente aeronáutico. A interconexão dos sistemas será baseada na comunicação ponto-a-ponto (FEIGHERY et al, 1996).

A Figura 13 ilustra a ligação na arquitetura ATN dos intermediate-systems e dos endsystems. Os intermediate-systems são os equipamentos responsáveis pela comunicação de dados na rede e os end-systems são as aplicações utilizadas no Gerenciamento do Tráfego Aéreo. Utilizando o modelo OSI, a arquitetura da rede ATN segue o conceito de camadas sobrepostas, como explicado anteriormente na Figura 11.

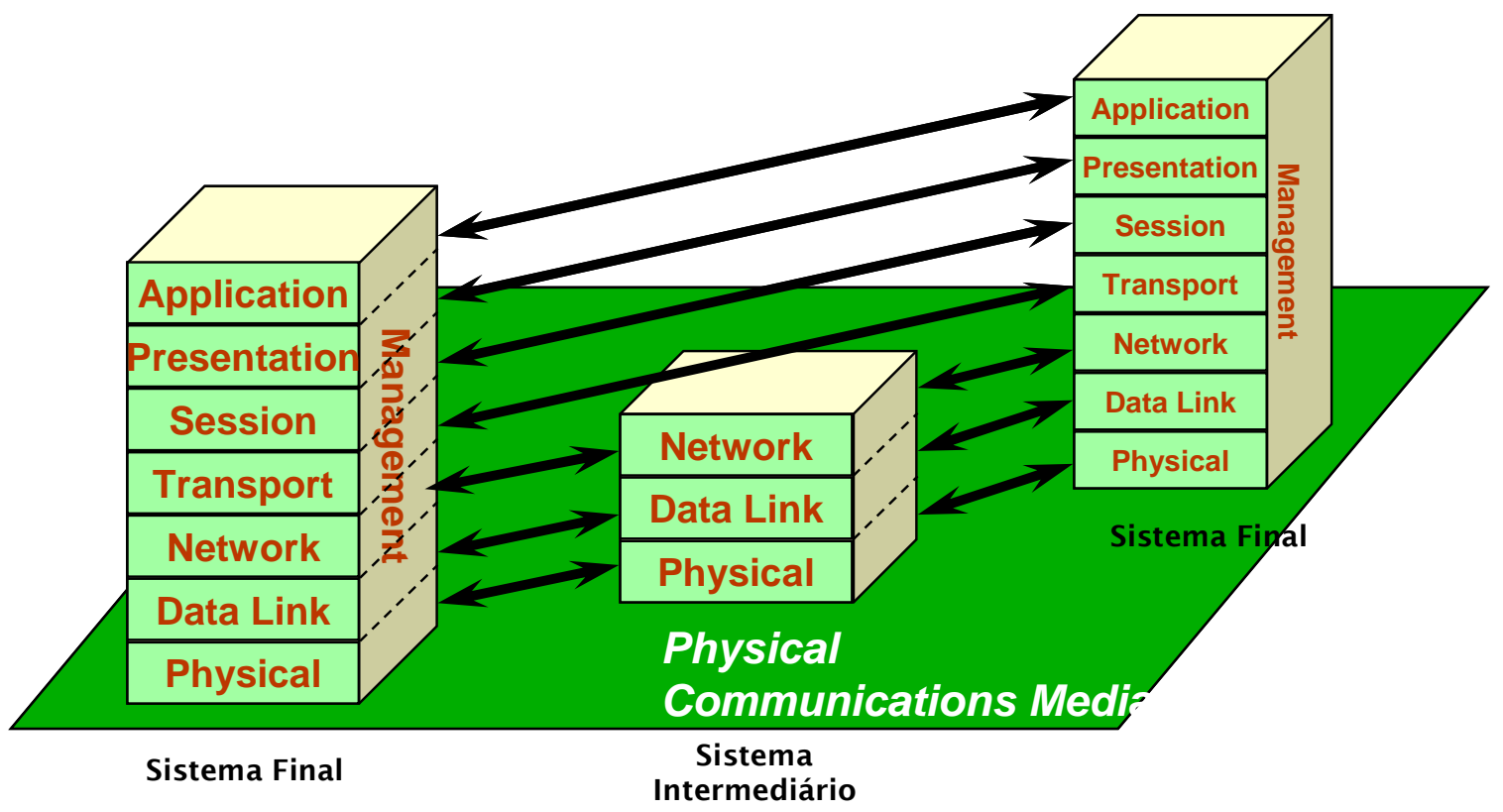

Figura 13 - Interconexão Utilizando Padrão OSI 
Segundo Signore e Girard (1998), para a ATN funcionar neste ambiente são necessários quatro elementos maiores. O primeiro é a capacidade de mobilidade no envio de dados para uma aeronave conhecendo sua localização; o segundo é a capacidade de uso simultâneo de links ar-terra instalados na aeronave; o terceiro é a verificação de larguras de bandas disponíveis hoje e as que estarão disponíveis no futuro; o quarto é a padronização de serviços requeridos em aplicações ATS.

Para o primeiro elemento, Signori e Girard (1998) definem a mobilidade da rede como a capacidade de comunicação entre dois nós existentes em diferentes redes. Quando um dos nós necessita falar com o outro, é automaticamente ligado ao mesmo através do roteamento disponível, sem precisar saber da localização do nó de destino e nem qual serviço e roteador está sendo utilizado para sua conexão.

Para o segundo elemento, demonstram a necessidade de especificação do custo das aplicações, conexão, ou preferência de velocidades que serão usadas pela ATN para o reenvio de mensagens. As exigências para o desenvolvimento das aplicações ar-terra são determinadas pelo ATNP (ATNP, 1995), como:

- Cada aplicação terá o atraso especificado em projeto;

- A taxa residual de erro será especificada como parâmetro de projeto para aplicação;

- O relatório de perda de serviço deverá ser especificado como parâmetro de projeto para cada aplicação;

- A disponibilidade da aplicação deverá ser especificada como parâmetro de projeto;

- O tempo para restauração do serviço deverá ser especificado como parâmetro de projeto.

O terceiro elemento define que para uma baixa taxa de banda nas conexões ar-terra é necessário que haja a compressão dos dados para envio na rede. $E$, para o quarto elemento, Signori e Girard (1998) demonstram a necessidade de uma padronização de aplicações que utilizam serviços ATS através das camadas de transporte, apresentação, sessão e da própria camada de aplicação, fazendo com que as aplicações sejam unificadas em todo mundo. 
Na Figura 14 é ilustrado o conceito adotado pela ICAO para a arquitetura de interconexão na rede. Neste caso o ambiente Internet ATN incorpora a utilização de roteadores, denominados IS (Intermediate-Systems), responsáveis pela interconexão gerando a transmissão de dados dentro da rede ATN, enquanto nos ES (End-Systems) ficam as aplicações utilizadas nos órgãos ATS, que são os responsáveis por gerar todo o tráfego de transmissão dados na rede (ICAO, 2001).

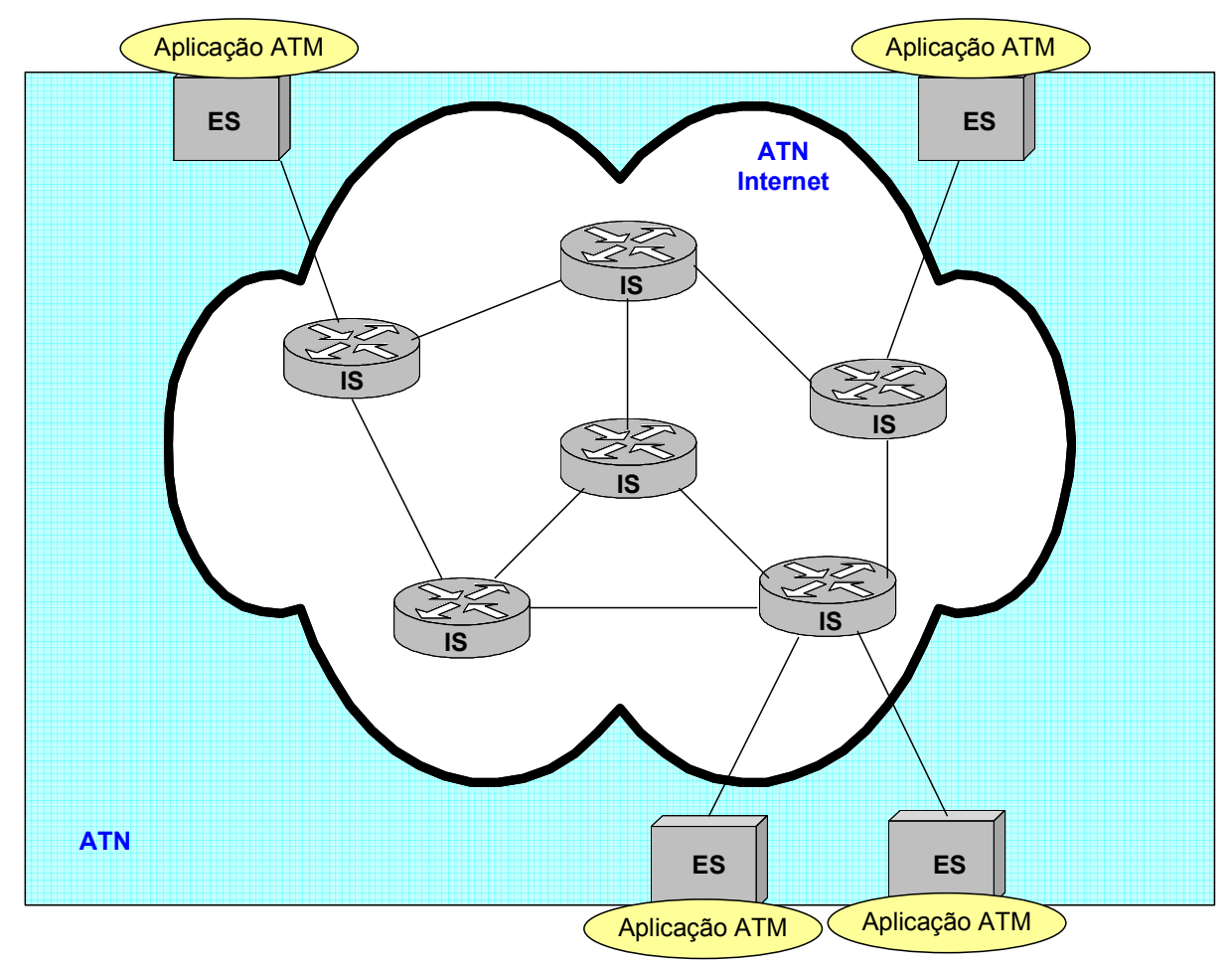

Figura 14 - Arquitetura ATN (Fonte: adaptado de ICAO, 2001)

A utilização de toda a mobilidade proposta fez com que a FAA planejasse novos rumos para as comunicações através de um novo meio de comunicação, onde utilizaria a ATN e a interconexão das demais redes de comunicação. Nestes serviços estão inclusos o ADS, CPDLC (Controller-Pilot Data Link Communications), ATIS (Automatic Terminal Information Service), e informações meteorológicas (FEIGHERY et al, 1996). 


\subsubsection{Protocolos ATN}

Segundo Farrel (2005), protocolos de computadores atendem a quatro propósitos:

- Codificam e transferem dados de um ponto ao outro;

- Podem controlar o modo como os dados são distribuídos;

- Trocam informações sobre o estado da rede;

- Podem gerenciar os recursos da rede para controle de comportamento.

Estes propósitos são caracterizados por protocolos de transferência, gerenciamento, distribuição e controle, respectivamente. Os protocolos de transferência são relativamente simples, porém são os mais importantes no nível de usuário, e caracterizam uma pequena parte dos protocolos utilizados em rede. Os protocolos de gerenciamento, distribuição e controle são mais sofisticados e complexos para serem operados.

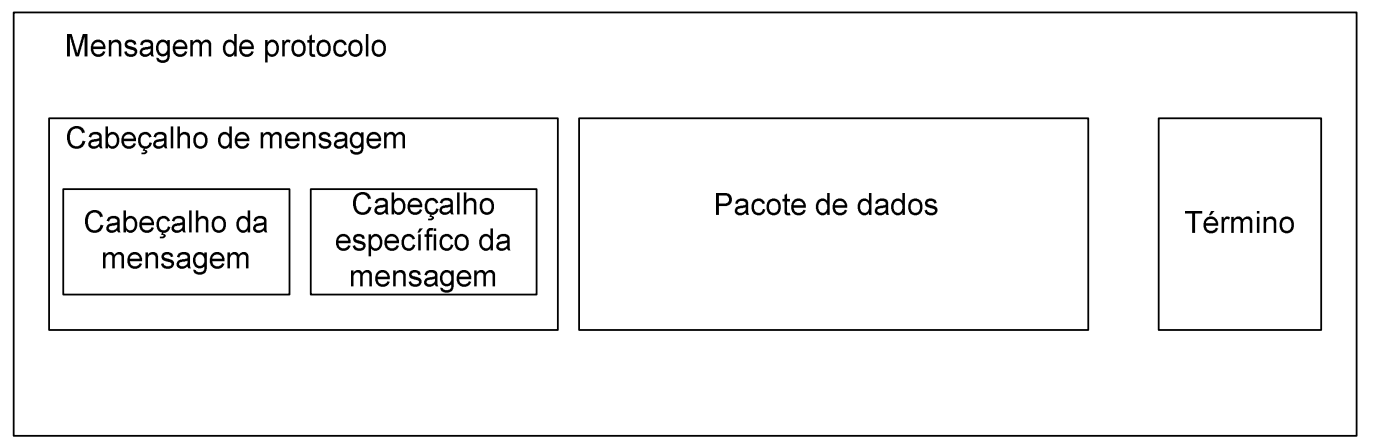

Figura 15 - Composição do Cabeçalho de uma Mensagem (Fonte: Farrel, 2005)

No entanto, para que qualquer um destes protocolos possa operar, necessita identificar a origem e o destino das mensagens. Na Figura 15, Farrel (2005) apresenta a composição de uma mensagem de protocolo. 


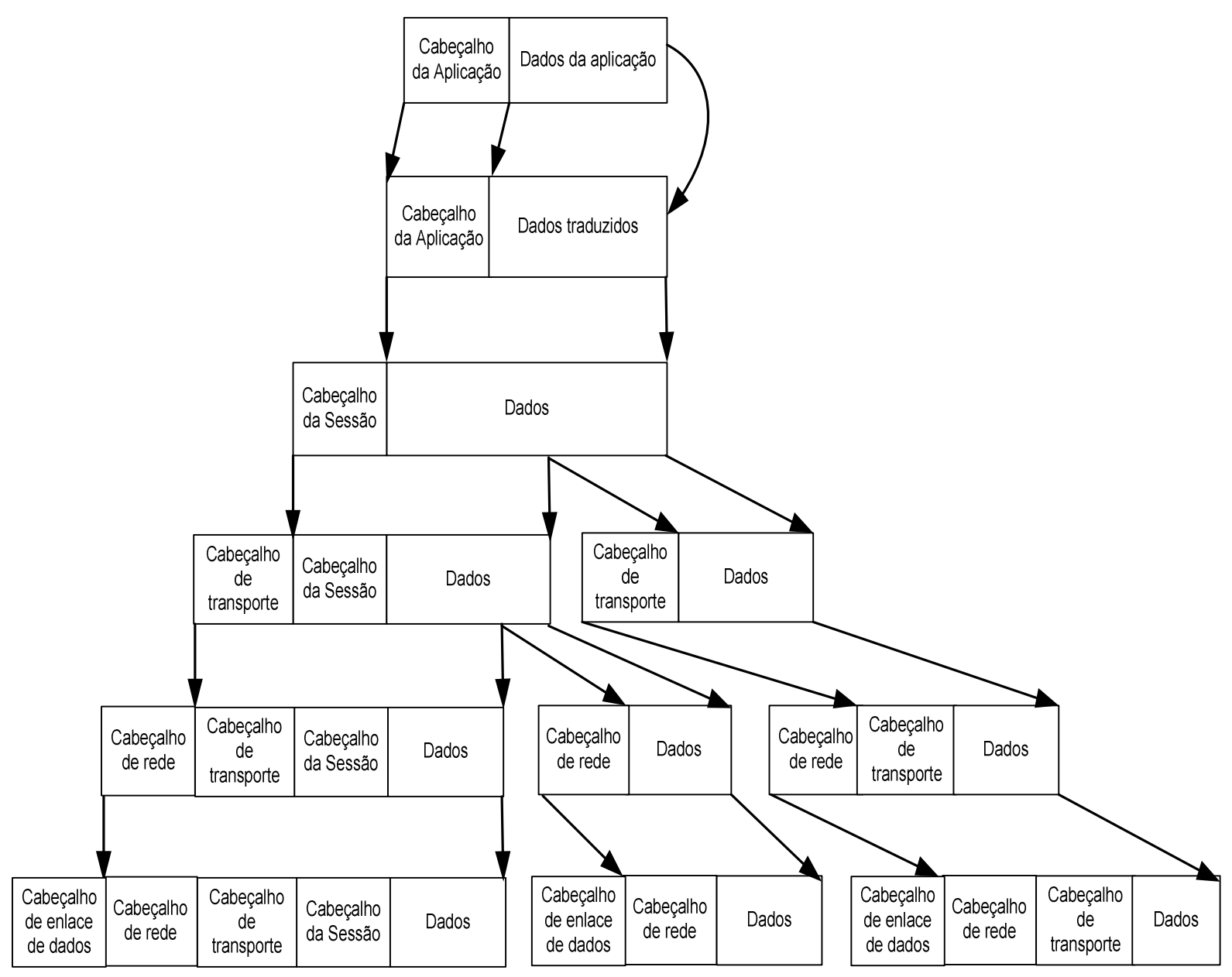

Figura 16 - Overhead em Camadas de Pilhas de Protocolos (Fonte: Farrel, 2005)

Quando trabalhado o envio de uma mensagem utilizando uma pilha de protocolos, esta se torna significativa, pois uma aplicação gera um fluxo de dados para enviar a uma aplicação remota e assim sucessivamente. Desta forma, é gerado um overhead considerável do protocolo para transmissão de dados ponto-a-ponto.

O overhead é causado pela sucessiva passagem dos dados de uma camada à outra, pois cada uma dessas camadas insere dados de identificação na mensagem que está sendo enviada. A Figura 16 demonstra o problema causado com o overhead em pilhas de protocolos (Farrel, 2005). Para resolver o problema de overhead na ATN, foi utilizado o conceito de ISO Efficiency Enhancement, fazendo com que algumas 
camadas não sejam utilizadas, minimizando substancialmente o problema.

Desta forma, a ATN se baseia na interconexão de diferentes tecnologias que devem ser implementadas através de diferentes sub-redes e protocolos específicos. Estes protocolos são necessários para a criação de endereçamento único para cada sistema em toda a rede, e fisicamente a ATN necessita de roteadores que trabalharão estes endereçamentos, que são denominados roteadores ATN. Estes equipamentos asseguram o caminho de comunicação entre todos os usuários na rede, podendo estar nas aeronaves e em terra.

Os protocolos que compõem a arquitetura de comunicação para a ATN são:

- Intra-domain Router Protocol (IDRP)

- Connectionless Network Protocol (CLNP)

- Connectionless Transport Protocol (CLTP)

- Class 4 Transport Protocol (TP4)

- Intermediate System to Intermediate System Routing Protocol (IS-IS)

- End System to Intermediate System Routing Protocol (ES-IS)

O protocolo CLNP é definido pela ISO 8473 , sendo um protocolo não orientado a conexão e sem correção de erro (ISO, 1994). Baseado no protocolo IP (Internet Protoco), para camada de rede na suíte TCP/IP (Transmission Control Protocol/Internet Protocol), possui o formato de quadros e endereçamento diferente, no entanto comum à comunicação na troca de pacotes ${ }^{7}$ dos sistemas finais e intermediários na ATN. O fato do CLNP não possuir conexão orientada transforma-o em um protocolo não confiável, pois não oferece garantia de entrega das mensagens na rede.

Desta forma, o uso do protocolo TP4 definido pela ISO 8073, oferece a conexão orientada necessária para a comunicação na ATN através da correção de erros, fragmentação e reordenamento de mensagens, além de oferecer a multiplexação e

\footnotetext{
${ }^{7}$ Pacote. Conjunto de informações que trafega pela rede onde são identificados os dados de origem, destino e conteúdo da mensagem enviada.
} 
demultiplexação de dados sobre um único circuito virtual. O protocolo TP4 é comumente utilizado para camada de transporte, similar ao protocolo TCP da suíte TCP/IP.

O protocolo CLTP definido pela ISO 8602 oferece a transmissão de pacotes onde não é requerida a garantia de entrega. Sua implementação visa à entrega de pacotes em sistemas end-to-end onde não há necessidade de alta confiabilidade no transporte dos pacotes e controle de fluxo de informações, porém implementa a correção de erros. É também implementado na camada de transporte e similar ao protocolo UDP (User Datagram Protocol) da suíte TCP/IP.

Os protocolos IDRP, IS-IS e ES-IS, definidos pelas ISO 10447, ISO 10589 e ISO 9542, respectivamente, são utilizados para roteamento. O protocolo IDRP é utilizado para fornecer o roteamento inter-domínio, o qual trabalha em conjunto com os protocolos CLNP, IS-IS e ES-IS com o objetivo de fornecer um roteamento completo para toda a rede. Todo roteador que participa do roteamento IDRP é chamado de BIS (Boundary Intermediate System), sendo considerado um roteador inteligente (FEIGHERY et al, 1996).

O protocolo ES-IS é utilizado nos usuários finais, permitindo que os end-systems saibam da existência de intermediate-systems e vice versa. Também provê informações de redirecionamento de rotas, permitindo que os intermediate-systems informem aos end-systems o melhor trajeto para envio de NPDUs (Network Protocol Data Units) a um determinado destino.

O protocolo IS-IS é utilizado nos roteadores (intermediate-systems), onde são empregados dois níveis de hierarquia:

- os roteadores do nível 1 conhecem sua topologia, roteadores e usuários inclusos, desconhecendo os demais roteadores e destinos fora de sua área.

- para os roteadores de nível 2 é conhecido todo tráfego fora de sua área, não necessitando saber a topologia existente dentro do nível 1, a não ser que o roteador 
de nível 2 pertença a uma única área como sendo um roteador de nível 1.

A Figura 17 ilustra a arquitetura de roteamento para a ATN (ICAO, 2001).

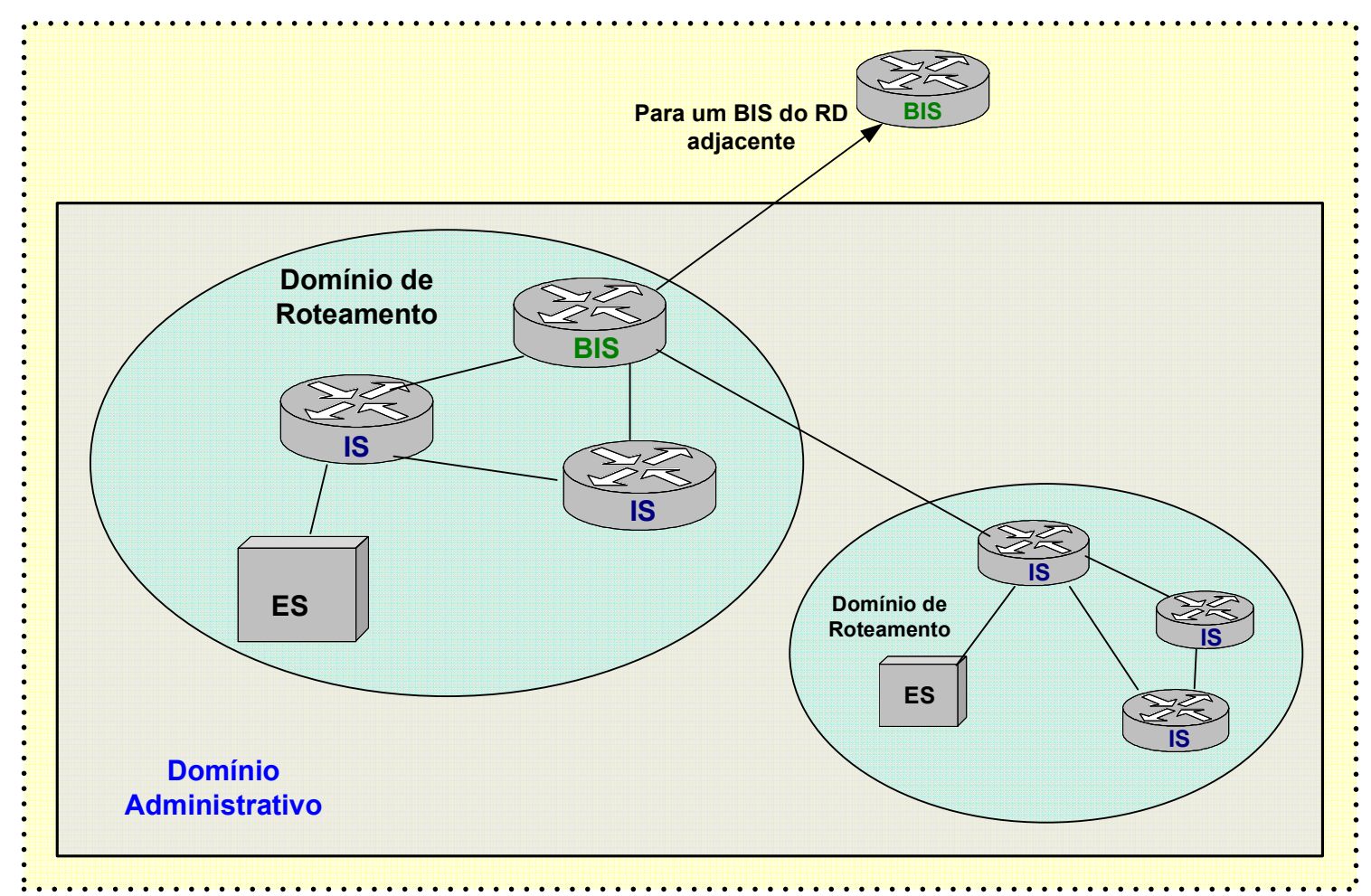

Figura 17 - Arquitetura de Roteamento ISO (Fonte: adaptado de ICAO, 2001)

Para a ICAO a política de segurança de roteamento deve seguir pela seleção de cada rota anunciada a cada BIS adjacente e a escolha entre as rotas ao mesmo destino recebidas de outro BIS adjacente (ICAO, 2001).

Um ponto importante para a ICAO, atualmente o Anexo 10 define, são as aplicações que se utilizam deste ambiente de roteamento na ATN para transferências de dados. Estas aplicações são definidas como:

Application entity (AE). Part of an application process that is concerned with communication within the OSI environment. The aspects of an application process that need to be taken into account for the purposes of OSI are represented by one or more AEs (ICAO, 2006). 
As aplicações utilizam o serviço de nível superior de comunicação, que é definido pelo Anexo 10 da ICAO como:

Upper layers (UL) communications service. A term pertaining to the session, presentation and application layers of the OSI reference model (ICAO, 2006).

Este nível superior define como todas as aplicações que são suportadas pela ATN.

Na Figura 18 é ilustrada uma visão de aplicações e em qual nível de camada cada uma se encontra. Como já definido no item 3.3 e exemplificado na Figura 13, o conceito da arquitetura ATN foi gerado sobre o modelo OSI, apresentado na Figura 18 como ATN/OSI.

No entanto, os Working Group pertencentes à ICAO vêm trabalhando no desenvolvimento de padrões para a ATN que utilizam o Internet Protocol Suíte, apresentado na Figura 18 como ATN/IPS (ICAO, 2006). 


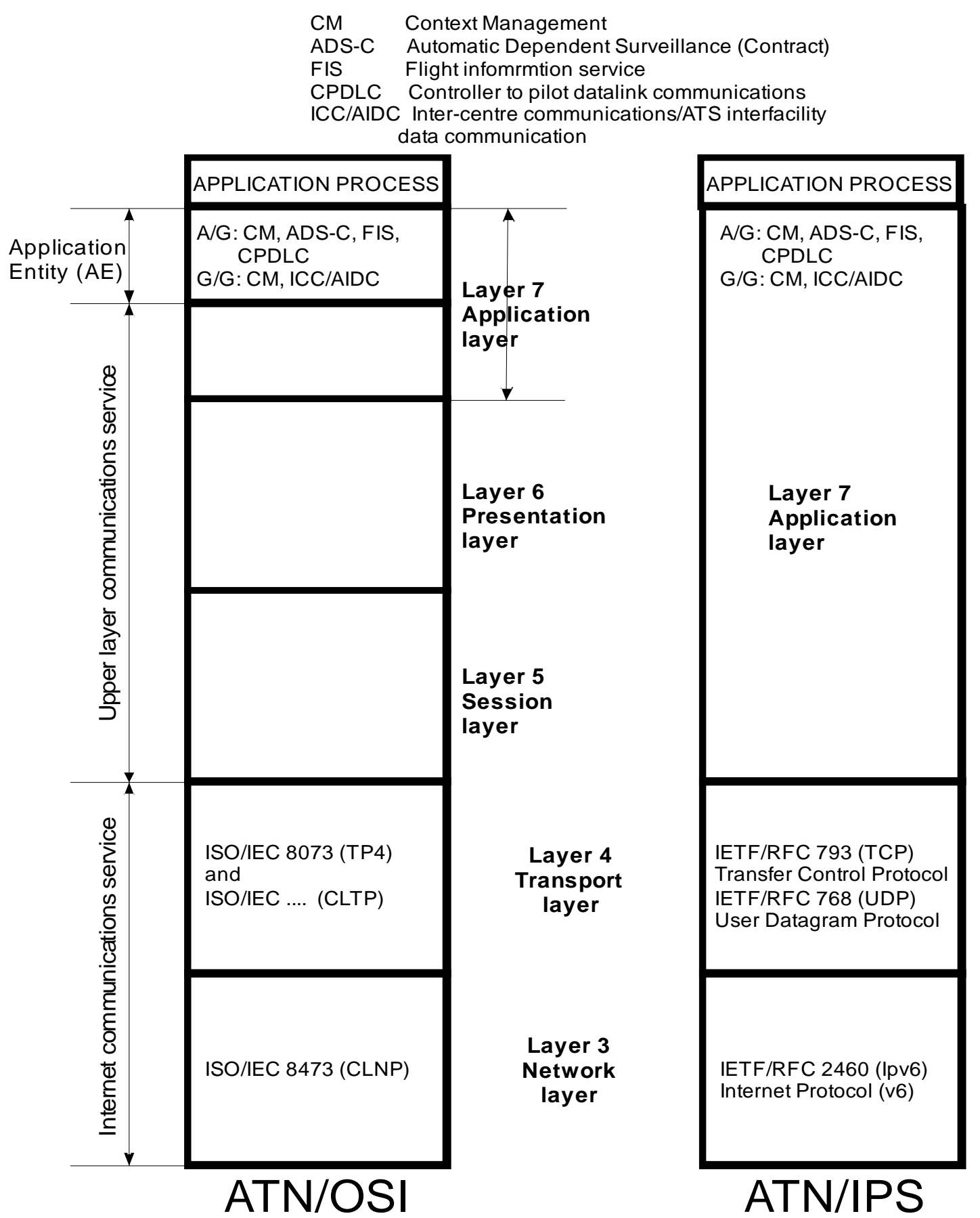

Figura 18 - Comparação de Aplicações nos modelos ATN/OSI e ATN/IPS (Fonte: adaptado de ICAO, 2006) 
A ICAO, através do Working Group $N$ define a implementação na camada de aplicação do ATN/IPS como ilustrado na Figura 19 (ICAO, 2006):

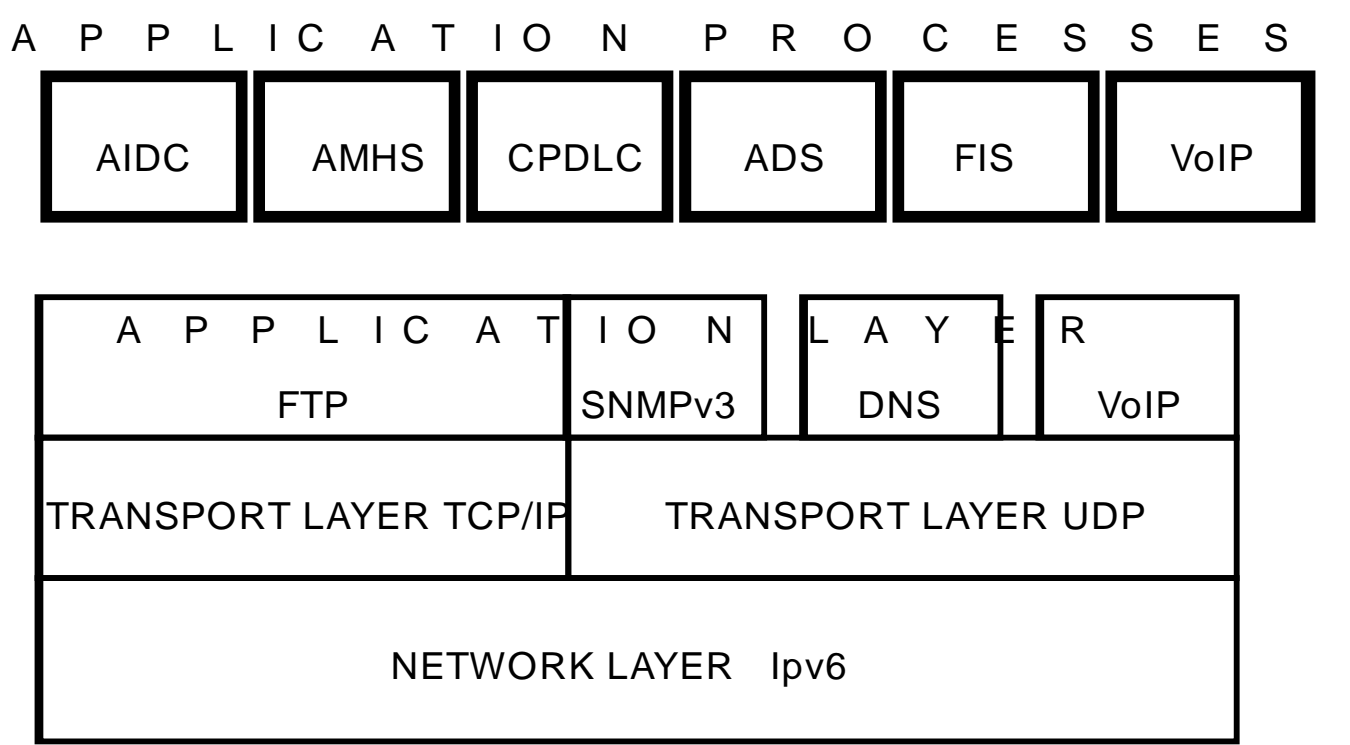

Figura 19 - Camada de Aplicação Utilizando o Conceito ATN/IPS (Fonte: adaptado de ICAO, 2006)

Figura 19 ilustra, separadamente, a camada de aplicação de nível 7, como ilustrado em conjunto com as demais camadas na Figura 18, e os processos que rodam sobre ela. Esta reestrutura na camada de aplicação é necessária para a implementação do ATN/IPS na ATN.

Os estudos desenvolvidos sobre a utilização do ATN/IPS inserem também a utilização de um novo protocolo para a camada de redes, o protocolo IPv6, como ilustrado na Figura 20. 


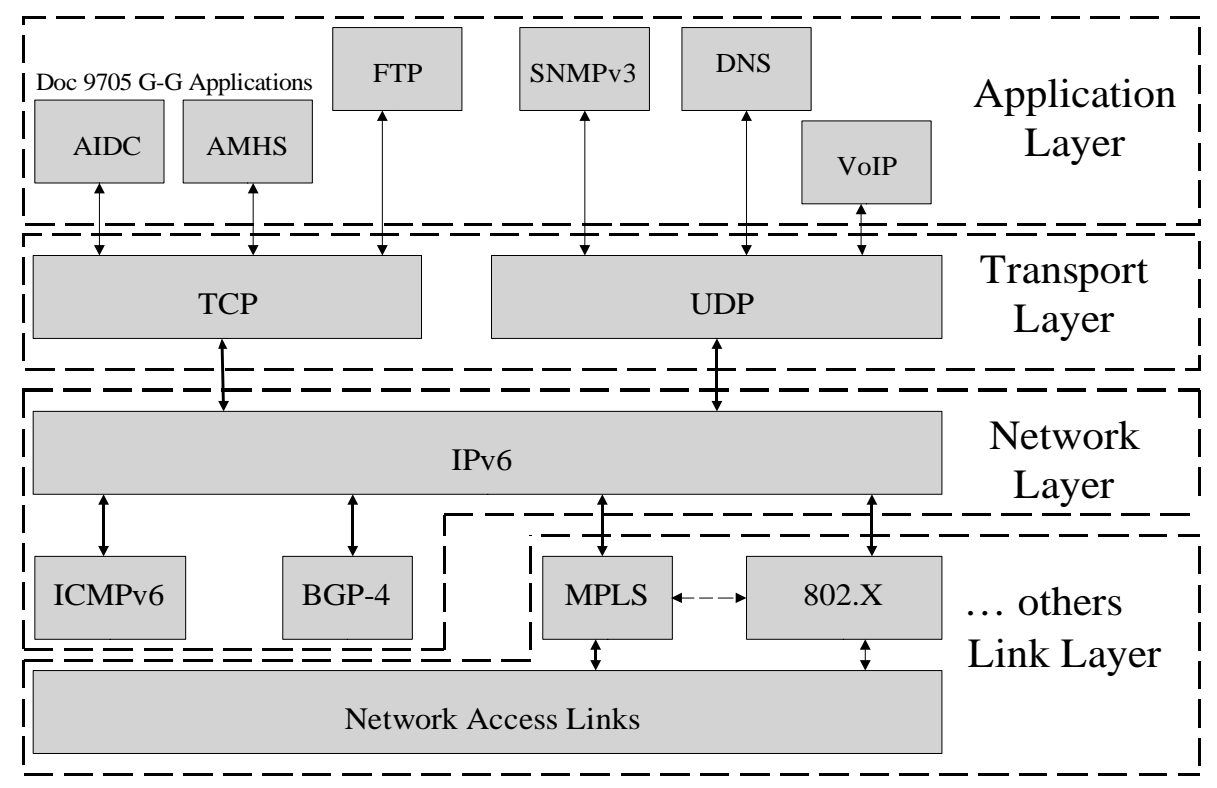

Figura 20 - Arquitetura Utilizando o Conceito ATN/IPS (Fonte: adaptado de ICAO, 2006)

O protocolo IPv6, como tratado a seguir no capítulo 4, faz parte de uma nova geração de protocolos, que traz a significativa capacidade de aumento de numeração IP, a segurança na transferência de dados em rede e o serviço de mobilidade utilizando o protocolo MIPv6. No entanto, a utilização deste novo protocolo na camada de rede necessita trabalhar com os protocolos especificados para ATN, item 3.3.1, atendendo, desta forma, as mudanças propostas na camada de aplicação.

A Figura 21 ilustra as mudanças na arquitetura do modelo OSI para atender atualmente o modelo ATN/IPS. A inclusão de novos protocolos e o tratamento de algumas camadas ocorre em um só nível. A utilização deste novo conceito de camadas para transmissão dos dados torna indispensável para atender a demanda de novas aplicações, citadas nas Figuras 18 e 19, e adequação das aplicações atualmente utilizadas, visando suprir as necessidades atuais de oferecer segurança e controle do espaço aéreo pelos Órgãos de Controle. 


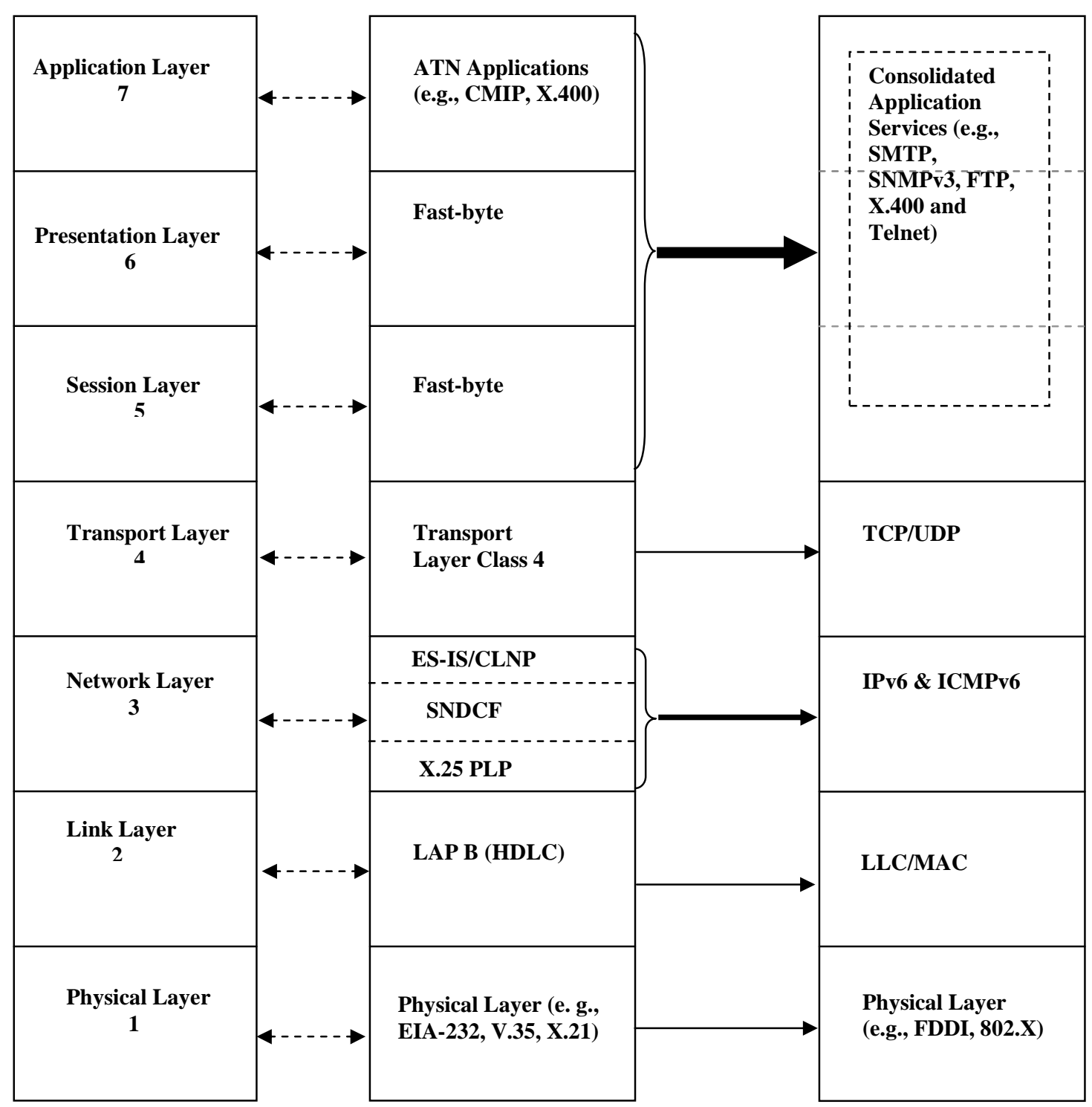

Figura 21 - Comparação entre os modelos OSI, ATN/OSI e ATN/IPS (Fonte: adaptado de ICAO, 2008a)

\subsubsection{Mobilidade ATN}

Em 2003, a ANC agregou uma composição de atividades do ATNP e do AMCP (Aeronautical Mobile Communications Panel) para serem discutidas no ACP 
(Aeronautical Communications Panel). Desde então as atividades do ATNP se concentram nos Working Groups $N$ and $M$ do ACP, sendo o Working Group $N$ responsável por desenvolver novas formas de endereçamento para ATN e o Working Group $M$ pela melhora nos atuais manuais de documentação da ATN onde são usados os protocolos e padrão OSI (ICAO, 2007).

No ano de 2007, na conferência para CNS/ATM, a ICAO apresentou os desenvolvimentos para a ATN. Nesta conferência, organizada pela AFCEA (Armed Forces Communications and Electronics Association) e pela ELSEG (Elektronic Service $\mathrm{GmbH}$ ), foi discutida a importância da mobilidade na ATN, onde foi apresentada a utilização do protocolo IPv6 como proposta para oferecer este serviço na rede.

Em 2008, o ACP realizou a sexta reunião para tratar especificamente do IPS, quando foi proposta a utilização do protocolo MIPv6 para assegurar a mobilidade na transferência de dados ar-terra na ATN. A proposta da reunião para a discussão do protocolo foi definida como (ICAO, 2008):

\footnotetext{
Proposes that Mobile IP is used as a convergence layer for air-ground communications with the intention of introducing flexibility and scalability for both airborne and ground systems.
}

Todas as discussões sobre mobilidade na ATN apresentadas pelos Working Groups seguem os padrões desenvolvidos pelo IETF/3GPP (The Internet Engineering Task Force / 3rd Generation Partnership Project), que atende a mobilidade do cliente ${ }^{8}$ e a mobilidade da rede.

\footnotetext{
${ }^{8}$ Em rede de computadores, a concepção de cliente refere-se a um determinado nó pertencente à mesma.
} 


\section{Capítulo}

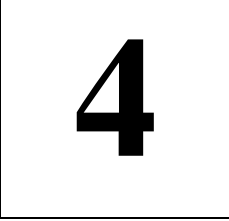

PROTOCOLO IPv6

\subsection{Histórico do Protocolo IPv6}

Em 1990, o IETF (The Internet Engineering Task Force) iniciou os estudos de um novo protocolo, o qual deveria suprir a necessidade de demanda relativa a endereçamentos na internet. Assim, o IETF convocou, através da RFC 1550, os interessados em apresentar propostas para a especificação. Após discussões, foi atribuído o nome IPv6 (Internet Protocol Version 6) para este novo protocolo (TANENBAUM, 2003).

Esta preocupação deu-se pelo fato de que o escopo máximo de $2^{32}$ endereços, que atualmente é utilizado, é dividido em classes e pode levar a um desperdício significativo de endereçamento, ocasionando um crescimento significativo de tabelas de roteamento pois os endereços atribuídos são usados parcialmente. Desses endereços, $2^{28}$ são utilizados para multicasting e $2^{27}$ para uso reservado (FARREL, 2005).

Com o aumento do uso da internet em computadores pessoais e em empresas, aumentou o comprometimento dos endereçamentos disponíveis. Outro fato foi a popularidade dos dispositivos eletrônicos que oferecem serviços diferenciados como o 
acesso à internet. O ISC (Internet Systems Consortium) publica anualmente os indicadores representativos dos hosts em todo o mundo. A Figura 22 ilustra o crescimento de hosts no mundo.

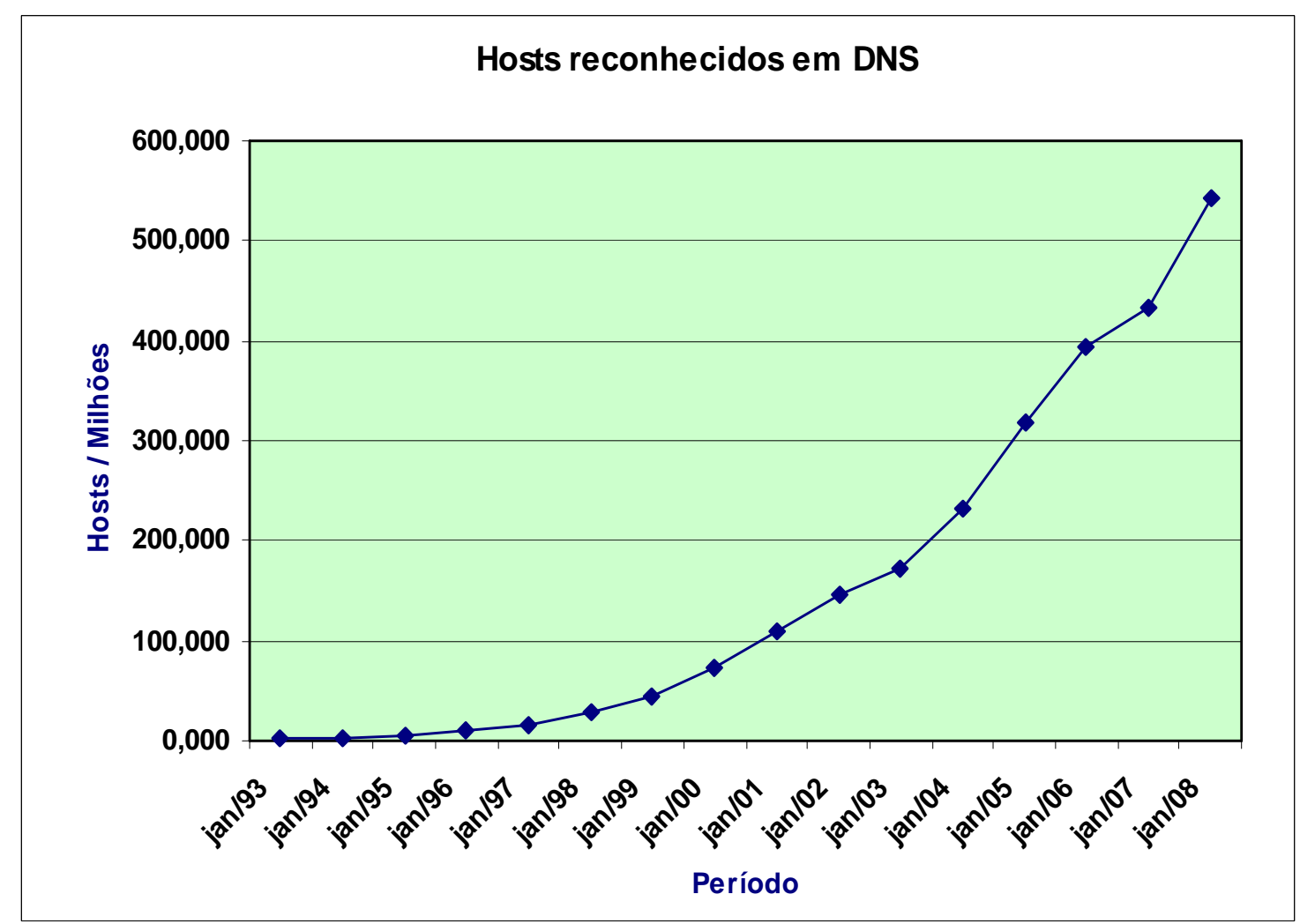

Figura 22 - Hosts reconhecidos em DNS (Fonte: www.isc.org, 2008)

O Brasil atualmente é um dos países de maior ascensão no uso de internet. Entre os motivos de tal ascensão está o crescimento de dispositivos tecnológicos à disposição do usuário, e de serviços de conexão à Internet.

A Figura 23 ilustra o aumento significativo de hosts no Brasil, que foi exorbitante a partir do ano 2000. 


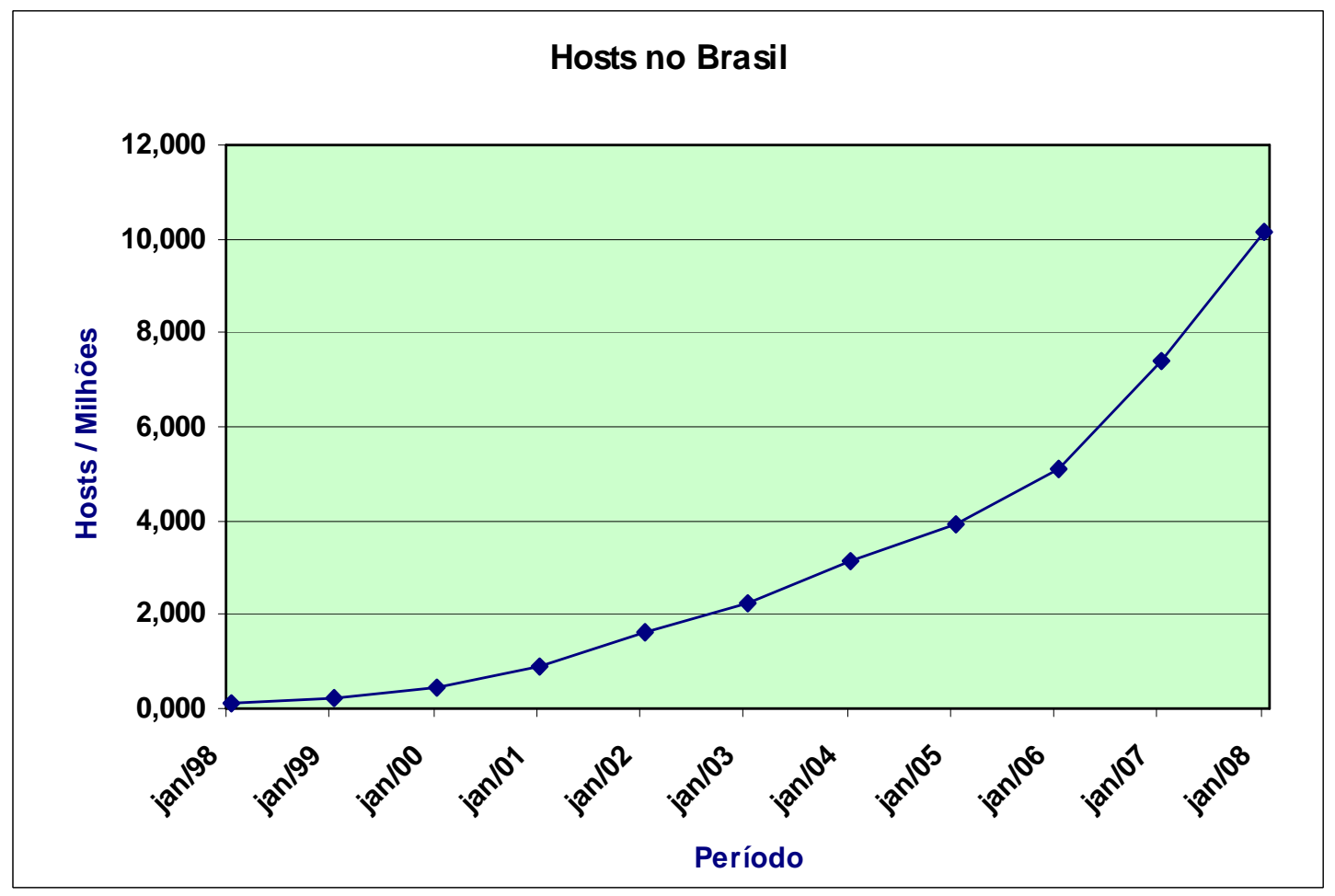

Figura 23 - Hosts no Brasil (Fonte: www.cetic.br, 2008)

Atualmente o Brasil ocupa a primeira posição entre os países da América do Sul, a segunda posição entre as Américas e a nona posição em relação ao mundo. Os Quadros 3, 4 e 5 demonstram a classificação do Brasil em relação aos demais países.

Quadro 3 - Brasil x América do Sul (Fonte: www.cetic.br, 2008)

\begin{tabular}{|l|l|r|}
\hline \multicolumn{2}{|c|}{ País } & $\begin{array}{r}\text { jan/08 } \\
\text { (mil nós) }\end{array}$ \\
\hline $\mathbf{1}^{\circ}$ & Brasil (.br) & $\mathbf{1 0 . 1 5 1 . 5 9 2}$ \\
\hline $2^{\circ}$ & Argentina (.ar) & 3.128 .975 \\
\hline $3^{\circ}$ & Colômbia (.co) & 1.299 .244 \\
\hline $4^{\circ}$ & Chile (.cl) & 816.460 \\
\hline $5^{\circ}$ & Uruguai (.uy) & 280.635 \\
\hline $6^{\circ}$ & Peru (.pe) & 271.738 \\
\hline $7^{\circ}$ & Venezuela (.ve) & 145.353 \\
\hline $8^{\circ}$ & Equador (.ec) & 42.922 \\
\hline $9^{\circ}$ & Bolívia (.bo) & 40.739 \\
\hline $10^{\circ}$ & Paraguai (.py) & 14.606 \\
\hline
\end{tabular}


Quadro 4 - Brasil x Américas (Fonte: www.cetic.br, 2008)

\begin{tabular}{|c|c|c|}
\hline \multicolumn{2}{|r|}{ País } & $\begin{array}{r}j a n / 08 \\
\text { (mil nós) }\end{array}$ \\
\hline $1^{0}$ & Estados Unidos & 302.884 .146 \\
\hline $2^{\circ}$ & Brasil (.br) & 10.151 .592 \\
\hline $3^{\circ}$ & México (.mx) & 10.071 .370 \\
\hline $4^{\circ}$ & Canadá (.ca) & 4.717 .308 \\
\hline $5^{\circ}$ & Argentina (.ar) & 3.128 .975 \\
\hline $7^{\circ}$ & Colômbia (.co) & 1.299 .244 \\
\hline $6^{\circ}$ & Chile (.cl) & 816.460 \\
\hline $8^{\circ}$ & Uruguai (.uy) & 280.635 \\
\hline $9 \stackrel{0}{9}$ & Peru (.pe) & 271.738 \\
\hline $10^{\circ}$ & Trinidad e Tobago (.tt) & 151.122 \\
\hline $11^{0}$ & Venezuela (.ve) & 145.353 \\
\hline $12^{\circ}$ & Guatemala (.gt) & 124.656 \\
\hline $13^{0}$ & República Dominicana (.do) & 84.787 \\
\hline $14^{\circ}$ & Nicaragua (.ni) & 46.764 \\
\hline $15^{\circ}$ & Equador (.ec) & 42.922 \\
\hline
\end{tabular}

Quadro 5 - Brasil x Mundo (Fonte: www.cetic.br, 2008)

\begin{tabular}{|l|l|r|}
\hline \multicolumn{2}{|c|}{ País } & $\begin{array}{r}\text { jan/08 } \\
\text { (mil nós) }\end{array}$ \\
\hline $1^{\circ}$ & Estados Unidos & 302.884 .146 \\
\hline $2^{0}$ & Japão (.jp) & 36.803 .719 \\
\hline $3^{0}$ & Alemanha (.de) & 20.659 .105 \\
\hline $4^{\circ}$ & Itália (.it) & 16.730 .591 \\
\hline $5^{\circ}$ & França (.fr) & 14.356 .747 \\
\hline $6^{\circ}$ & China (.cn) & 13.113 .985 \\
\hline $7^{\circ}$ & Austrália (.au) & 10.707 .139 \\
\hline $8^{\circ}$ & Holanda (.nl) & 10.540 .083 \\
\hline $\mathbf{9}^{\circ}$ & Brasil (.br) & $\mathbf{1 0 . 1 5 1 . 5 9 2}$ \\
\hline $10^{\circ}$ & México (.mx) & 10.071 .370 \\
\hline $11^{\circ}$ & Reino Unido (.uk) & 7.727 .550 \\
\hline $12^{\circ}$ & Polônia (pl) & 7.134 .976 \\
\hline $13^{\circ}$ & Taiwan (.tw) & 5.121 .607 \\
\hline $14^{\circ}$ & Canadá (.ca) & 4.717 .308 \\
\hline $15^{\circ}$ & Finlândia (.fi) & 3.728 .551 \\
\hline $16^{\circ}$ & Bélgica (.be) & 3.618 .495 \\
\hline $17^{\circ}$ & Rússia (.ru) & 3.577 .635 \\
\hline $18^{\circ}$ & Suécia (.se) & 3.513 .170 \\
\hline $19^{\circ}$ & Suíça (.ch) & 3.308 .684 \\
\hline $20^{\circ}$ & Dinamarca (.dk) & 3.256 .134 \\
\hline $21^{\circ}$ & Argentina (.ar) & 3.128 .975 \\
\hline $22^{\circ}$ & Espanha (.es) & 3.085 .513 \\
\hline $23^{\circ}$ & Noruega (.no) & 2.725 .031 \\
\hline $24^{\circ}$ & Áustria (.at) & 2.589 .316 \\
\hline $25^{\circ}$ & Índia (.in) & 2.584 .572 \\
\hline & & \\
\hline
\end{tabular}




\subsubsection{Arquitetura do Protocolo IPv6}

No início da década de 1990 vários estudos tratavam do novo conceito a ser especificado para o protocolo da próxima geração. Assim, o IETF escreveu a RFC 1752, onde resumia os requisitos primordiais a serem utilizados (FARREL, 2005). Atualmente, o IPv6 oferece suporte a mobilidade através do protocolo MIPv6, o qual é explicado no item 4.1.3.

Através desta especificação, foram levantadas todas as limitações que o atual protocolo IPv4 (Internet Protocol version 4) possui, então salientando as principais características que o protocolo IPv6 deveria suportar, como (FARREL, 2005):

- Prover serviço de datagrama não confiável, como o atual IPv4;

- Prover suporte unicast e multicast;

- Assegurar endereçamento para um futuro previsível;

- Compatibilidade com o protocolo IPv4;

- Suporte para autenticação e criptografia;

- Deverá adicionar recursos, acrescentados pelo decorrer do tempo, do protocolo IPv4;

- Não fazer suposições sobre topologia utilizada e capacidade de rede;

- Não afetar o desempenho de roteadores quando encaminham datagramas;

- Ser extensível para acompanhar a evolução da internet;

- Suporte para hosts móveis, redes e interconexão de redes;

- Permitir criação de interconexão de redes privadas sobre a infra-estrutura básica da internet.

Baseando-se nestas especificações, no ano de 1995 foi lançada a RFC 1883, onde foi especificado o protocolo IPv6, conhecido como protocolo de nova geração (IETF, 1995). No decorrer dos anos vários trabalhos foram desenvolvidos com objetivo de melhorar a funcionalidade do protocolo, retratando as experiências de laboratórios que possuíam Provedores de Serviços rodando o protocolo e redes experimentais 
(FARREL, 2005).

No ano de 1998, o IETF lançou a RFC 2460, que especifica a arquitetura do protocolo IPv6. A RFC especifica dados como a capacidade de endereçamento, formato do cabeçalho, opção de extensões do protocolo, identificação de fluxo com label (IETF, 1998).

A capacidade de endereçamento para transferência de dados com o uso do IPv6 é de 128 bits, possuindo quatro vezes mais capacidade de endereçamento que o protocolo IPv4, que usa para transferência de dados com 32 bits.

As figuras 24 e 25 ilustram o formato dos cabeçalhos dos protocolos IPv6 e IPv4, especificados na RFC 2460 e na RFC 791, respectivamente.

\begin{tabular}{|c|c|c|c|}
\hline Versão & Classe de Tráfego & \multicolumn{2}{|c|}{ Rótulo de Fluxo } \\
\hline \multicolumn{2}{|c|}{ Tamanho do Pacote } & $\begin{array}{l}\text { Próximo } \\
\text { Cabecalho }\end{array}$ & $\begin{array}{l}\text { Limite de Passos } \\
\text { de Rota }\end{array}$ \\
\hline \multicolumn{4}{|c|}{ Endereço de Origem } \\
\hline \multicolumn{4}{|c|}{ Endereço de Destino } \\
\hline
\end{tabular}

Figura 24 - Cabeçalho IPv6 (Fonte: adaptado IETF, 1998) 


\begin{tabular}{|c|c|c|c|c|}
\hline Versão & IHL & Tipo de Serviço & \multicolumn{2}{c|}{ Comprimento Total } \\
\hline \multicolumn{3}{|c|}{ Identificação } & $\begin{array}{c}\text { Sinaliza- } \\
\text { dores }\end{array}$ & Deslocamento do Fragmento \\
\hline Tempo de Vida & Protocolo & Verificação da Soma do Cabeçalho \\
\hline \multicolumn{4}{|c|}{ Endereço de Origem } \\
\hline \multicolumn{3}{|c|}{ Endereço de Destino } & Enchimento \\
\hline
\end{tabular}

Figura 25 - Cabeçalho IPv4 (Fonte: adaptado IETF, 1981)

Notoriamente, os campos de um cabeçalho do protocolo IPv6 mudam substancialmente em relação aos campos do protocolo IPv4. Como sua capacidade de endereçamento (que para IPv4 são 32 bits e para IPv6 são 128 bits), seu cabeçalho é totalmente variável utilizando os cabeçalhos de extensão, esta mesma versatilidade variável do cabeçalho promove a possibilidade de mudanças nos equipamentos utilizados em rede quanto à configuração, bem como nos programas. Enquanto no IPv4 os números de octetos do cabeçalho são fixos (COMER, 1998).

A especificação elaborada pela RFC 2460 determina o cabeçalho básico do protocolo IPv6 com os seguintes campos (COMER, 1998 e IETF, 1998):

- Version (versão): 4 bits, indica a versão utilizada pelo protocolo ao qual o datagrama pertence.

- Traffic Class (classe de tráfego): 8 bits, utilizado pelos nós e/ou roteadores para identificar e distinguir entre diferentes classes ou prioridades dos pacotes IPv6. Aceita QoS (quality of service) e aplicações em tempo real.

- Flow Label (rótulo de fluxo): 20 bits, contém informações que os roteadores usam para o datagrama a um fluxo e prioridade especificas. 
- Payload Length (comprimento do pacote): 16 bits, tamanho dos dados medidos em octetos.

- Next Header (próximo cabeçalho): 8 bits, identifica o tipo de encabeçamento imediatamente após o encabeçamento IPv6. Contém o número do protocolo a ser utilizado (por exemplo: sendo UDP, usará o número 17; sendo EIGPR usará o número 89). No entanto, se o cabeçalho de extensão utiliza o IPv6, este campo conterá a identificação do próximo cabeçalho de extensão ou seu nome. A especificação dos possíveis protocolos a serem utilizados consta da RFC 5237, como demonstrado no ANEXO 1 (IETF, 2008).

- Hop Limit (limites de passos de rota): 8 bits, interpreta o valor atribuindo valor estrito ao número de Hop Limit que um datagrama pode fazer antes de ser descartado. Corresponde ao campo TTL (Time to Life) no protocolo IPv4, que interpreta o tempo de vida contando os passos na rota, e o do tempo máximo.

- Source Address (endereço de origem): 16 octetos, especifica os endereços do transmissor.

- Destination Address (endereço de destino): 16 octetos, especifica os endereços do destinatário.

Houve, também, mudanças quanto ao tamanho de campos como, por exemplo, os campos Source Address e Destination Address, que passaram a ter 128 bits. Alguns campos foram substituídos, como o campo TTL, que agora passa a ser Hop Limit; o campo Type of Service, que agora passa a ser Flow Label, e o campo Protocol, que passa a ser Next Header (COMER, 1998).

Para o protocolo IPv6 outra mudança significativa foi no formato do datagrama, que passa a ter, além do cabeçalho básico, o cabeçalho de extensão e dados. Apenas o cabeçalho básico é exigido; os cabeçalhos de extensão são opcionais.

A Figura 26 ilustra um datagrama utilizado no protocolo IPv6 (COMER, 1998 e IETF, 1998). 


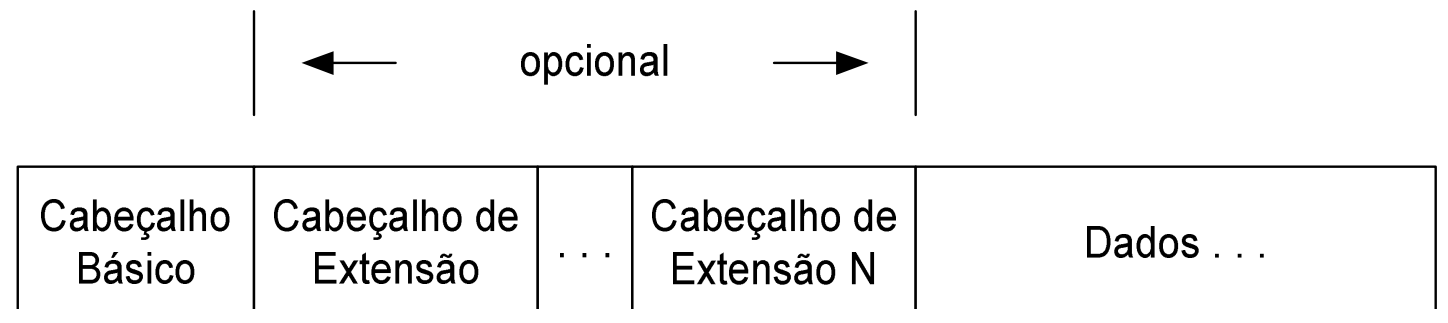

Figura 26 - Formato de Datagrama IPv6 (Fonte: COMER, 1998)

Para Comer (1998), as mudanças introduzidas no IPv6 podem ser agrupadas em cinco categorias: endereços maiores, formato flexível do cabeçalho, opções aprimoradas, suporte para alocação de recursos e previsão para extensão de protocolo.

\subsubsection{IP Móvel}

Mobilidade pode ser definida como liberdade. Em tecnologia, esta liberdade significa ter conectividade independente do local. Atualmente, com a Internet global, nem mesmo os protocolos são considerados estáticos.

Com base no sentido de mobilidade, o IETF, através de seu grupo de trabalho chamado IP Routing for Wireless/Mobile Hosts (MobileIP), lançou em 1996 a RFC 2002, que especificou as características de um IP móvel e como deve ser o roteamento transparente de um datagrama até o nó móvel da Internet (IETF, 1996). Atualmente, a especificação para mobilidade IP é definida por um conjunto de RFCs, sendo a RFC 2002, RFC 2003, RFC 2004, RFC 2005, RFC 2006 e RFC 1701. 


\subsubsection{Protocolos MIPv6 e HMIPv6}

O protocolo MIPv6 (Mobile IPv6) é caracterizado como sendo parte de um conjunto do protocolo IPv6 para conexões móveis. Trata-se de uma melhora no projeto do protocolo IPv6, também especificado, inicialmente, pela RFC 2002. No entanto, em 2004 a RFC 3775 passou a ser utilizada para a especificação de mobilidade no protocolo IPv6 (IETF, 2004). Este protocolo permite que um nó móvel migre de sua rede para outras redes, continuando sua comunicação, com os demais nós. Como o MIPv6 é um protocolo independe do meio físico, pode se mover sem perder sua conectividade ${ }^{9}$.

No MIPv6, cada MN (Mobile Node) é identificado por um endereço estático em sua rede de origem, que é sua origem de acesso à internet, chamado HA (Home Address), que recebe todos os pacotes dos nós ligados ao roteador. Quando o nó se move para uma rede externa adquire um endereço dinâmico, chamado CoA (Care-of Address), através de um roteador chamado Foreign Agent, que informa ao roteador de origem, chamado HA (Home Agent), o seu novo endereço. Este novo endereço possui um tempo de vida, que é a associação do Mobile Node com seu endereço adquirido no Home Agent e com seu novo endereço dinâmico Care-of Address. Esta associação recebe o nome de Binding Cache.

A utilização do Binding é necessária para a atualização constante do Mobile Node com o novo endereço dinâmico junto ao Home Agent, pois quando um Mobile Node entra em outra sub-rede é enviado um bit de reconhecimento e um bit que indica a atualização obrigatória do Home Agent. Esta atualização é realizada com o envio de um pacote chamado Binding Update (PERKINS e JOHNSON, 1996).

Desta forma, todos os pacotes endereçados ao Mobile Node são interceptados pelo Home Agent e redirecionados por tunneling ao Foreign Agent, que possui o atual Careof Address do nó móvel, que pode ser adquirido através do IPv6 address

\footnotetext{
${ }^{9}$ Nota de aula, professor Otto Carlos M. B. Duarte. Disponível em www.ufrj.br.
} 
autoconfiguration (PERKINS e JOHNSON, 1996).

A Figura 27 ilustra o exemplo de roteamento utilizando o conceito de mobilidade proposto pelo MIPv6, onde um Mobile Node adquire um novo endereço ao entrar em uma rede externa, onde recebe o Care-of Address, utilizando, assim, as duas rotas para efetuar toda a combinação de roteamento entre os dois nós, o Home Agent e o Mobile Node.

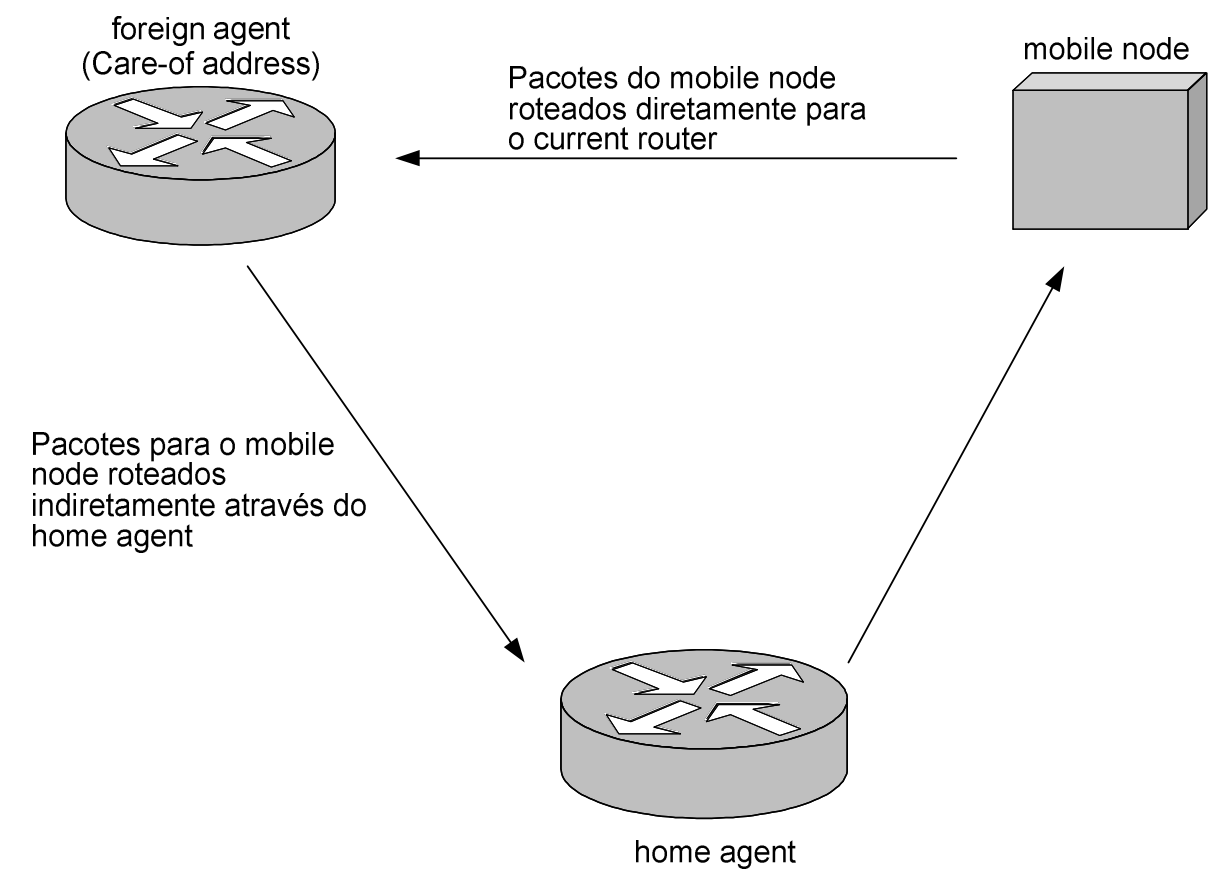

Figura 27 - Entidades utilizadas para roteamento (Fonte: adaptado de PERKINS e JOHNSON, 1996) 


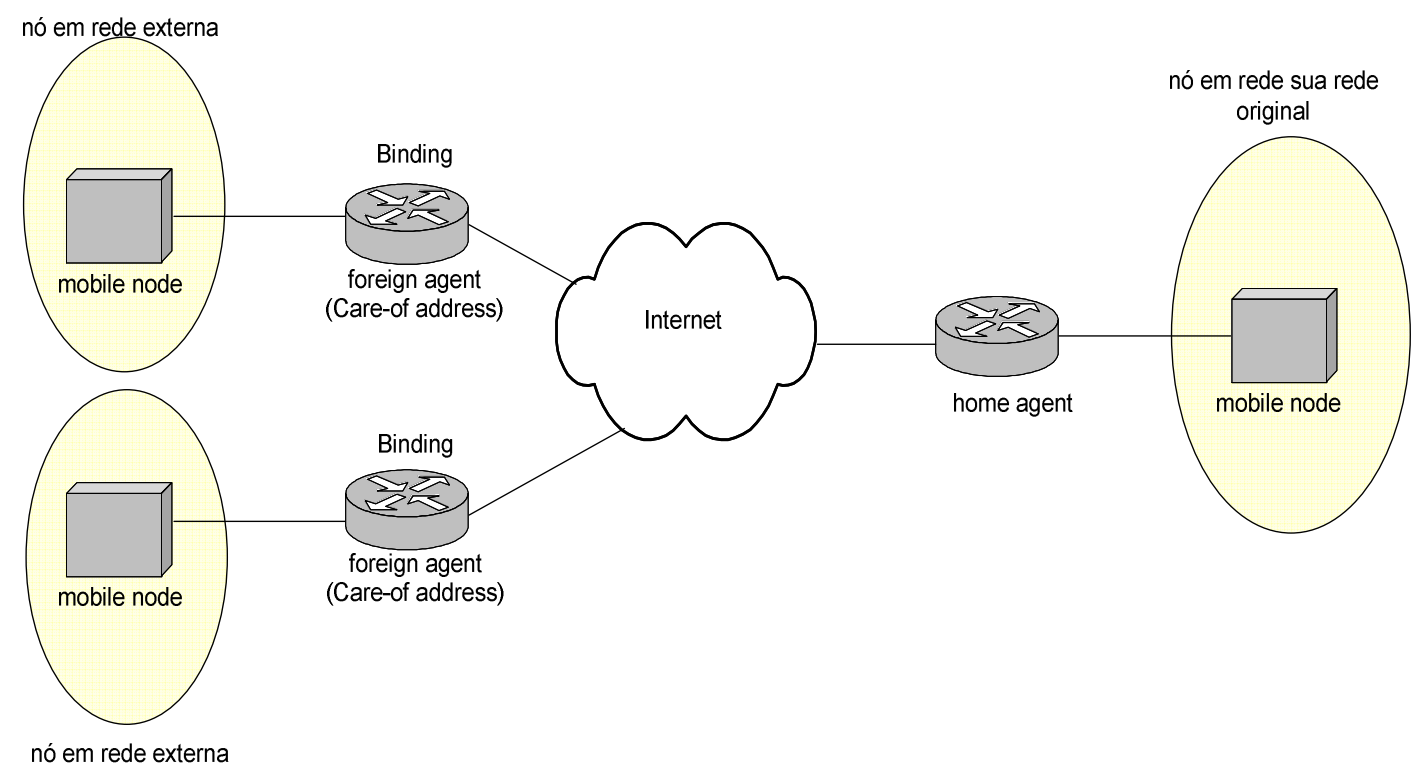

Figura 28 - Exemplo da implementação do MIPv6 em rede (Fonte: adaptado de PERKINS e JOHNSON, 1996)

A Figura 28, também ilustra o roteamento com o protocolo MIPv6, porém demonstra a utilização de duas sub-redes onde o Mobile Node adquire o endereço dinâmico, utilizando o Binding Update para atualizar sua localização no Home Agent.

No entanto, mesmo oferecendo muitas facilidades o MIPv6 traz consigo alguns problemas de desempenho quanto à sua mobilidade em rede externa, como (PERKINS e JOHNSON, 1996):

- Alto impacto na possibilidade de rompimento da rede;

- Aumento de carga na rede;

- Aumento no atraso da entrega dos pacotes.

Além destes problemas, outra preocupação é a atualização constante do nó enquanto estiver em uma rede externa, podendo ocasionar problemas, como (PERKINS e JOHNSON, 1996):

- Tempo de atualização de movimento;

- Tempo gasto para a configuração do endereço na nova rede; 
- Tempo gasto com a atualização da nova localização junto ao home agent;

- Perdas de pacotes enviados ao antigo care-of address.

Uma rede com constantes mudanças de localização de nós móveis acaba por gerar um fluxo muito grande de sinalização comprometendo sua qualidade de serviço na entrega de pacotes e na manutenção da conexão. Visando estes problemas, o IETF propôs um novo protocolo através da RFC $4140^{10}$ chamado HMIPv6 (Hierarchical Mobile IPv6), que trata de forma distinta a mobilidade global e a mobilidade local. A mudança proposta neste protocolo insere um agente chamado MAP (Mobility Anchor Point). Trata-se de um roteador responsável por gerenciar a mobilidade visando à diminuição da latência e das perdas na entrega de pacotes (IETF, 2005).

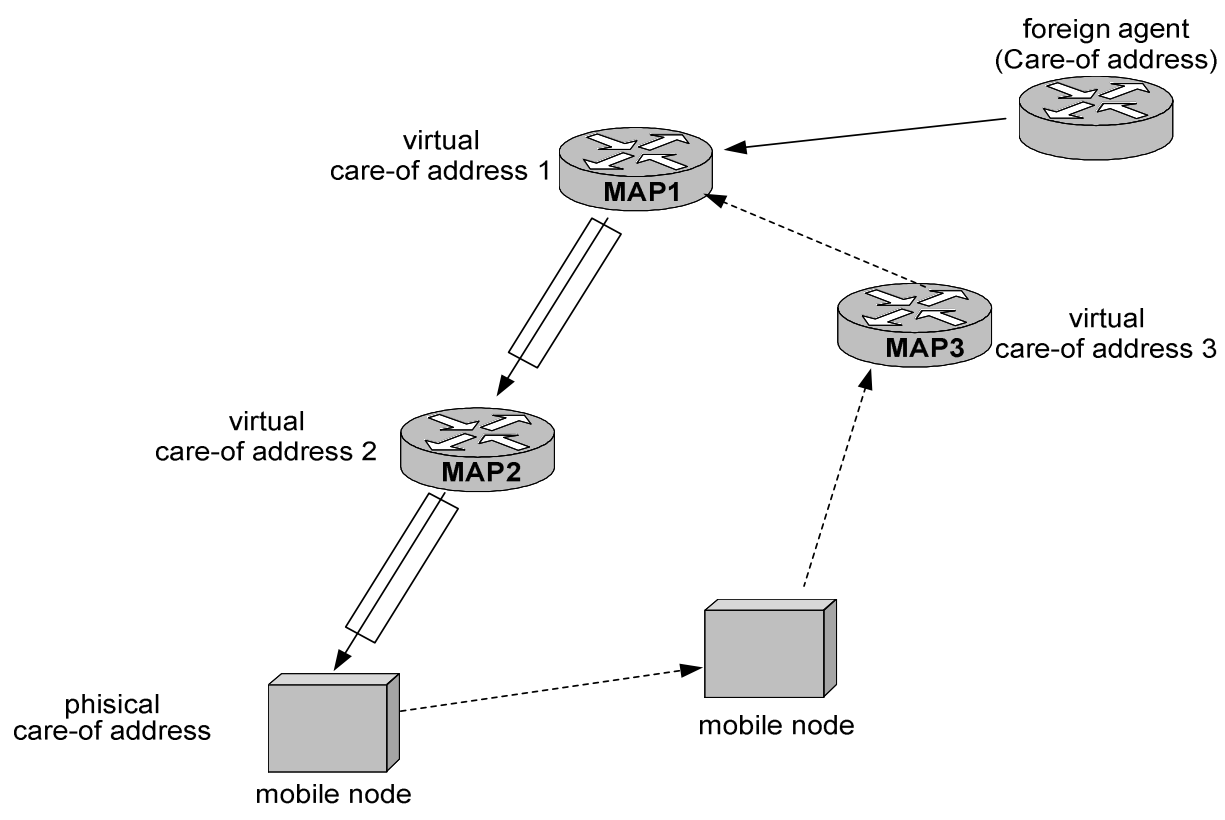

Figura 29 - Exemplo da implementação do HMIPv6 em rede. (Fonte: Adaptado de YAIZ e OZTURK, 2006)

A Figura 29 ilustra o exemplo de roteamento utilizando o conceito de mobilidade proposto pelo HMIPv6. O nó móvel inicia a movimentação com sua identificação de

${ }^{10}$ RFC 4140, esta RFC ainda está em fase experimental. 
endereçamento estático, denominado PCoA (Phisical Care-of Address) e passa por duas redes externas, onde lhe é atribuído um endereço virtual de permanência denominado VCoA (Virtual Care-of Address). No entanto, durante todo o tempo o nó carrega seu endereço estático para atualização de localização em seu Home Agent.

A atribuição dos endereços PCoA e do VCoA a cada nó é feita de forma dinâmica, como no MIPv6, que o identifica até a chegada ao destino. 


\subsection{Objetivos}

O objetivo deste capítulo é apresentar a avaliação de desempenho do protocolo MIPv6, descrito no capítulo 4, pertencente ao conjunto de protocolo IPv6, como forma de roteamento automático de aeronaves e transmissão de dados em uma rede ATN.

\subsection{Estudo de Caso Proposto no Contexto do Protocolo MIPv6}

Durante as simulações deseja-se analisar o comportamento do protocolo MIPv6 em um ambiente ATN. Para isso serão considerados os requisitos de implantação definidos pela ICAO para o sistema CNS/ATM.

Em princípio, será considerado um ambiente controlado por ACC (Centros de Controle de Área) que possui sua jurisdição em uma FIR, que no Brasil é chamado de CINDACTA (Centro Integrado de Defesa Aérea e Controle de Tráfego Aéreo). Também será considerada a quantidade de aeronaves em rota. 
A Figura 30 ilustra o cenário que será estudado.

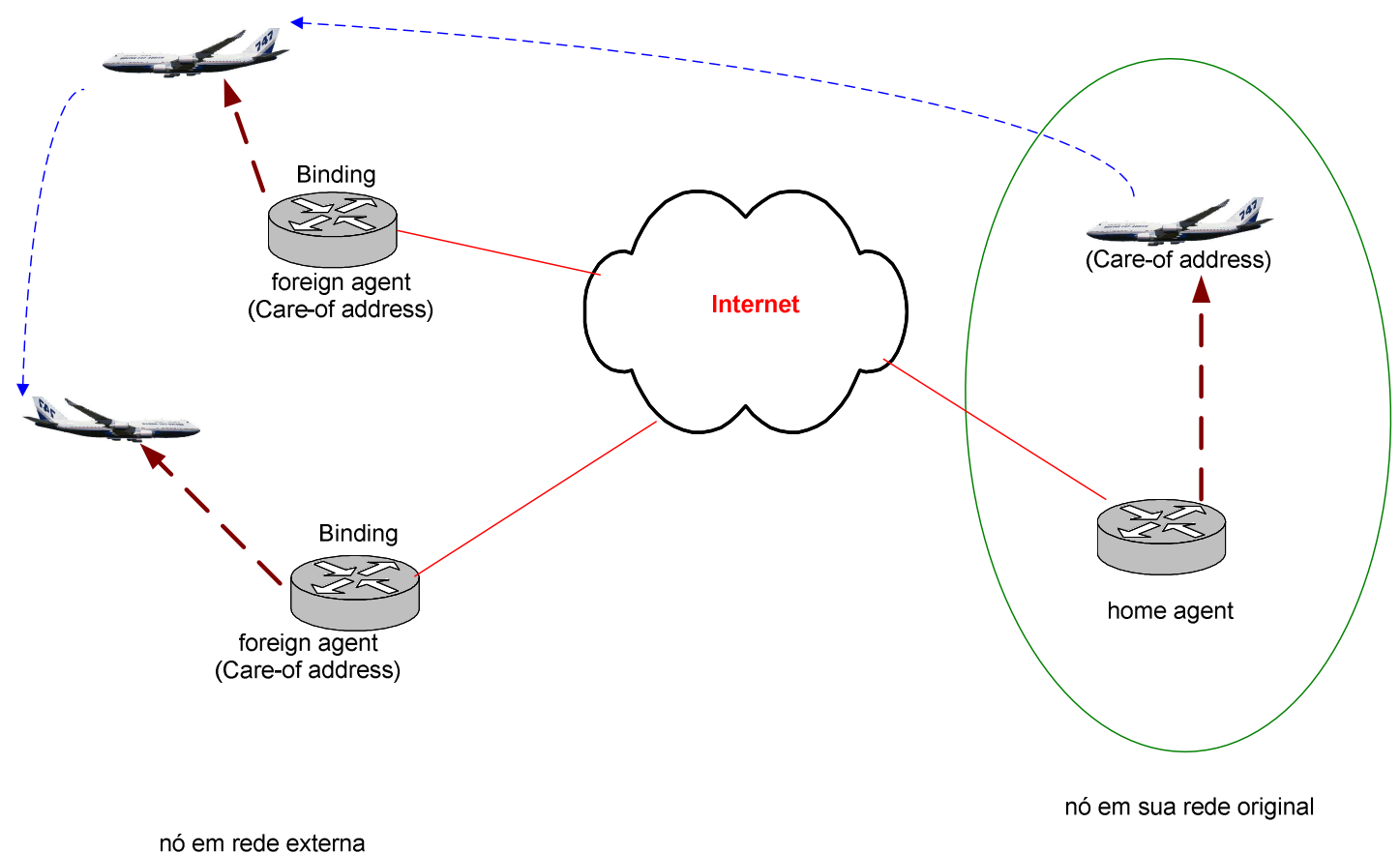

Figura 30 - Cenário estudado

Neste cenário, é representado o ambiente para simulação, onde a aeronave, que durante a simulação recebe a identificação de Mobile Node, inicia sua rota pelo Home Agent, onde recebe o endereço físico especificado como Care-of Address. Durante a rota, a mesma aeronave é identificada em duas outras sub-redes, tendo em cada uma das redes a atribuição de um novo Care-of Address virtual. Cada sub-rede utiliza-se do Binding Update para realizar a atualização de localização da aeronave.

Como descrito no item 1.2, a simulação avalia:

- Estabilidade no ambiente para a utilização da transferência dos pacotes;

- Características de roteamento;

- Tempo gasto na transmissão de dados, uma vez estipulado o tempo máximo aceitável, e, comportamento do protocolo com diferentes valores de jitter.

Ainda quanto ao ambiente, a simulação considera como já determinada a área de 
acesso administrativo de cada Home Agent, podendo assim considerar que cada aeronave dentro de seu domínio administrativo recebe um Care-of Address, que a identificará.

Outra premissa a ser considerada, quanto ao ambiente, é o fato de que a aeronave já possua o sistema de vigilância ativado, e, caso ocorra qualquer interferência na mudança de rota, o Home Agent será atualizado. A simulação considera a especificação definida pela ICAO para a ATN, sendo a utilização de roteadores móveis, denominados NEMO (Networks in Motion) e MAG (Mobile Access Gateways), necessária para a interface com o Mobile Node dentro de um domínio especificado como NETLMN Domain (Network-based Localized Mobility Management Domain).

Não é considerada a utilização de serviços Proxy denominados PMIP (Proxy Mobile IPv6) e a utilização de firewall em toda a rede.

\subsection{Ambiente de Simulação}

Nesta sessão são descritos os softwares que foram utilizados para o desenvolvimento da simulação que será apresentada neste trabalho, bem como o software utilizado na análise do canal VHF.

\subsubsection{Network Simulator 2}

A simulação é muito importante quando se deseja testar uma implementação que fisicamente torna-se inviável ou complexa. Quando surge esta necessidade é utilizado o que chamamos de simulador, um software que permite criar um ambiente igual ao ambiente físico real.

Para este trabalho será utilizado o simulador NS2. Trata-se de um software muito 
difundido no meio acadêmico para a realização de simulações em Redes de Computadores. Oferece simulação em diversos protocolos e também protocolos multicasting, redes cabeadas ou redes wireless, e também simula o roteamento destes pacotes (FALL, 2000).

Por ser um programa com o código aberto, permite a inclusão das alterações necessárias para simularmos o ambiente desejado. Sua primeira versão surgiu em 1989 através do software Real Network Simulator, e então passou a ter apoio para desenvolvimento do DARPA (Defense Advanced Research Projects Agency) através do projeto VINT (Virtual Network Testbed), e atualmente continua com o apoio do DARPA através do SAM (Simulation Augmented by Measurement and Analysis for Networks) e através do COSER (Collaborative Simulation for Education and Research), ambos com colaboração de pesquisadores incluindo o ACIRI (International Computer Science Institute). As contribuições inseridas no simulador também são oriundas de pesquisadores em todo mundo (ESTRIN, 1998).

Atualmente o NS encontra-se na versão 2, atribuindo o nome NS2, e mantido pela Universidade de Berkeley. Utiliza as linguagens $\mathrm{C}_{++}$e OTcl, sendo a linguagem OTcl uma linguagem de script orientada a objeto (FALL, 2000).

As linguagens utilizadas na arquitetura do NS2 podem ser entendidas como:

- $\mathrm{C}++$ para tratamento dos dados.

- ação por pacote;

- desempenho de memória.

- OTcl para a parte de controle.

- Tcl orientado a objeto;

- ações periódicas ou disparadas por eventos.

- TclCl.

- fusão $\mathrm{C}++$ e OTcl.

Uma importante característica de trabalho do NS2 é a separação das implementações 
de caminho de dados e tempo de processamento do evento. Utiliza dois componentes, que são ${ }^{11}$ :

- escalonador de eventos discretos;

- componentes de redes.

- camada de enlace e superiores;

- suporte a emulação.

O scheduler de eventos (escalonador de eventos discretos) e os objetos (componentes de redes) são escritos e compilados em C++. Após a compilação, os objetos são disponibilizados para o interpretador OTcl por uma ligação OTcl, o qual cria a correspondência entre este objeto OTcl para cada um dos objetos $\mathrm{C}_{++}$.

Esta correspondência faz com que as variáveis de configuração e as funções de controle ajam como funções de membros e variáveis de membros de objetos OTcl correspondentes a elas. Desta forma, conseguem fazer com que o controle de objetos C++ sejam dados pela OTcl. (FALL, 2000).

Toda implementação da simulação é produzida através de códigos, baseada no projeto MobiWan iniciado pelo Motorola Labs Paris em colaboração com o INRIA PLANETE Team. Depois que esses códigos são compilados, é gerado um arquivo contendo os resultados para análise. No entanto, o NS possui uma ferramenta de simulação gráfica chamada NAM (Network Animator). Esta ferramenta demonstra, por exemplo, a simulação das rotas e o tráfego dos pacotes em tempo real.

\subsubsection{Multi-speech 3700}

$\mathrm{Na}$ análise espectral foi utilizado o programa Multi-speech 3700 da empresa norteamericana KAY Elemetrics Corporation, que é um software para tratamento de sinal

\footnotetext{
${ }^{11}$ Simulador de redes NS, notas de aulas Professor José Resende. GTA/COOPE/UFRJ.
} 
acústico, baseado na plataforma Windows, que utiliza placas de som para captura de voz. 


\section{Capítulo}

\section{6}

INTERFERÊNCIAS GERADAS NO CANAL VHF

\subsection{Canal VHF}

A utilização do canal VHF possibilita interferências na comunicação entre a aeronave e os controles em terra. Neste capítulo é apresentado, por amostragem, um tipo de ocorrência por interferências com a utilização de uma comunicação por voz.

Com a análise apresentada neste trabalho sobre o canal VHF, é verificada a necessidade de se dispor de uma nova tecnologia para a comunicação e controle das aeronaves em rota. Atualmente, para atender a esta necessidade a ICAO estuda fortemente a implementação de serviços para Controle de Tráfego Aéreo sobre protocolos de Internet.

Assim, inserindo-se neste contexto atendendo o projeto que envolve a implantação da ATN, sob o conceito CNS/ATM com uso de protocolos de Internet, é apresentado a utilização do protocolo MIPv6 como forma de possível substituição do controle das aeronaves por voz, como discutido no Capítulo 3. Desta forma, a utilização do controle por voz seria aconselhável apenas em situações de emergência, onde há necessidade 
de intervenção imediata pelos órgãos de controle.

\subsubsection{Caracterização do Ambiente}

O ambiente analisado é um aeroporto com capacidade de aproximadamente 26.000 pousos e decolagens mensais, entre vôos internacionais e domésticos (PRGP, 2007), sendo que a análise é feita em um intervalo limitado de tempo.

A Figura 31 ilustra a movimentação das aeronaves estudadas. Nessa figura, as aeronaves em controle de solo são representadas pelas barras sólidas, enquanto que as aeronaves que estejam em controle de torre são representadas pelas barras hachuradas. A extensão ou tamanho de cada barra indica a janela de tempo de comunicação entre cada aeronave e os controles de terra. As cores verde, marrom e amarela representam as diferentes companhias aéreas.

As comunicações podem ser regulares ou irregulares. Quando uma aeronave efetua uma comunicação regular significa que ela está identificada em um dos controles por estar sob a responsabilidade deste. Nas comunicações irregulares a aeronave pode ainda não ter entrado em contato com o controle responsável pela sua posição ou ter saído da responsabilidade de um controle e aguardando o contato com outro controle que passará ser responsável pela aeronave.

Foram examinados os registros de comunicação das aeronaves desde 01:14:00h até 01:49:00h. Ao delimitar o ambiente, foram selecionadas as aeronaves que efetuaram comunicação com qualquer um dos três controles de terra, que são as posições de tráfego, solo ou torre, dentro deste espaço de tempo. São várias as situações das aeronaves analisadas, porém todos os ambientes tinham a característica da freqüência fundamental de $400 \mathrm{~Hz}$, o que caracteriza o ruído de fundo típico da cabine de uma aeronave, considerando que a mesma não disponha de dispositivos de cancelamento eletrônico de ruído (DOD, 1997). 


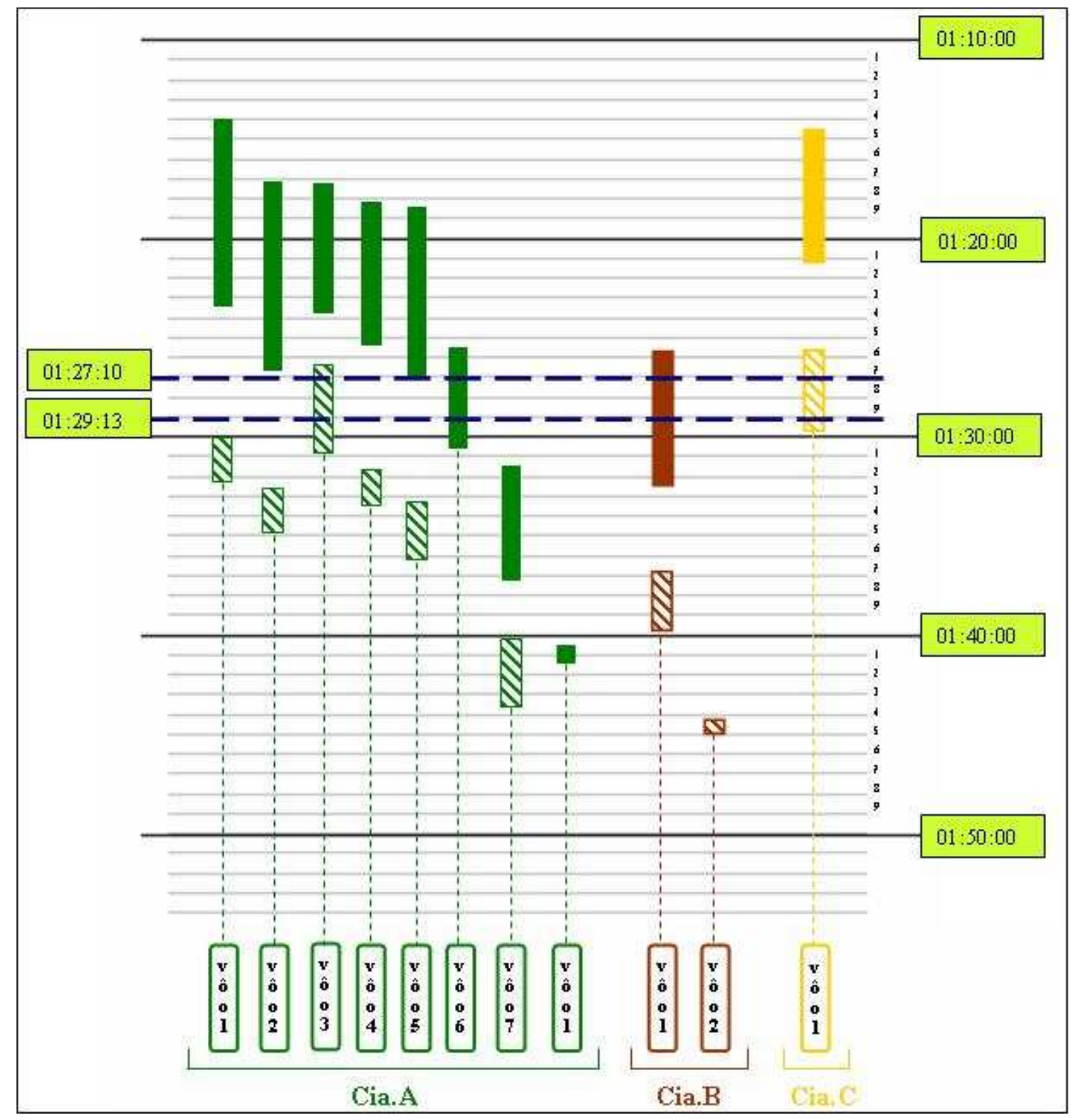

Figura 31 - Diagrama de Movimentação das Aeronaves

Em geral, esta freqüência é produzida pelo gerador de energia da aeronave, denominado A.P.U. (Auxiliary Power Unit), que produz um sinal acústico local por ficar ligado, fornecendo energia aos demais equipamentos da aeronave (GAMA, SLAMAB e NOGUEIRA, 2004). As situações analisadas são:

- Algumas aeronaves já estavam em contato com o controle de solo; 
- Outras aeronaves ainda não haviam feito contato com o controle de solo;

- Outras aeronaves já se encontravam em controle de torre;

- Outras aeronaves já haviam feito o último contato com o controle de solo, mas ainda não estavam em controle de torre.

Onde constata-se que:

- As aeronaves da Cia.A - vôo6 e da Cia.B - vôo1, já estavam em controle de solo;

- As aeronaves da Cia.A - vôo1, vôo2, vôo4 e vôo5, já tinham feito sua última transmissão regular para o controle de solo e ainda não tinham iniciado as transmissões para controle de torre;

- As aeronaves da Cia.A - vôo3 e da Cia.C - vôo1, já estavam sob controle de torre; e

- As aeronaves da Cia.A - vôo7 e da Cia.B - vôo2, ainda não tinham feito comunicação com o controle de solo.

No caso apresentado na Figura 31 registrou-se uma transmissão irregular, cuja análise demonstrou que ocorreu entre os horários de 01:27:10h e 01:29:12h, delimitando, desta forma, um conjunto das comunicações efetuadas pelas aeronaves junto aos controles de terra, o qual deve ser analisado. As linhas tracejadas azuis, na horizontal, mostram o instante das duas transmissões irregulares, ocorridas à 01:27:10h e à 01:29:12h.

\subsubsection{Métodos Utilizados para Este Estudo}

Para estudo foram utilizados os padrões de análise de freqüência de voz, dos quais foram extraídos espectrogramas das comunicações realizadas pelas aeronaves junto aos controles de terra. Através desta extração há condições de realizar uma comparação do ambiente onde há uma transmissão regular identificada, além do ambiente utilizado para uma transmissão irregular. A análise baseou-se nos ruídos de fundo que compunham o ambiente e a voz do locutor. 
Este análise utiliza o conceito demonstrado pelo Teorema de Fourier, que define um sinal periódico qualquer como sendo composto ou decomposto em uma série de ondas senoidais com freqüências múltiplas inteiras da freqüência fundamental. Cada onda possui uma determinada amplitude e uma determinada fase (SCHAWARZ e FRIEDLAND, 1972 e BREGMAN, 1990).

Porém, a análise de Fourier pressupõe a análise de sinais estacionários, ou seja, que não possuem alteração em sua freqüência no decorrer do tempo: a decomposição do sinal em senóide. Neste caso, para utilizar a análise de Fourier em sinais dinâmicos empregaram-se os espectrogramas.

\subsubsection{Análise dos Espectros}

As aeronaves selecionadas para análise espectrográfica são somente as aeronaves das quais possivelmente tenha ocorrido a transmissão irregular. Os espectrogramas apresentados nas figuras 32 a 35 demonstram, do lado esquerdo de cada uma das posições, a comunicação irregular que está sendo analisada, e no lado direito de cada uma das posições, uma transmissão efetuada de forma regular, devidamente identificada pelas aeronaves em cada posição de controle de terra. Na parte superior da figura é apresentado o sinal acústico. Tal lógica é apresentada para as posições de tráfego, de solo e de torre. 


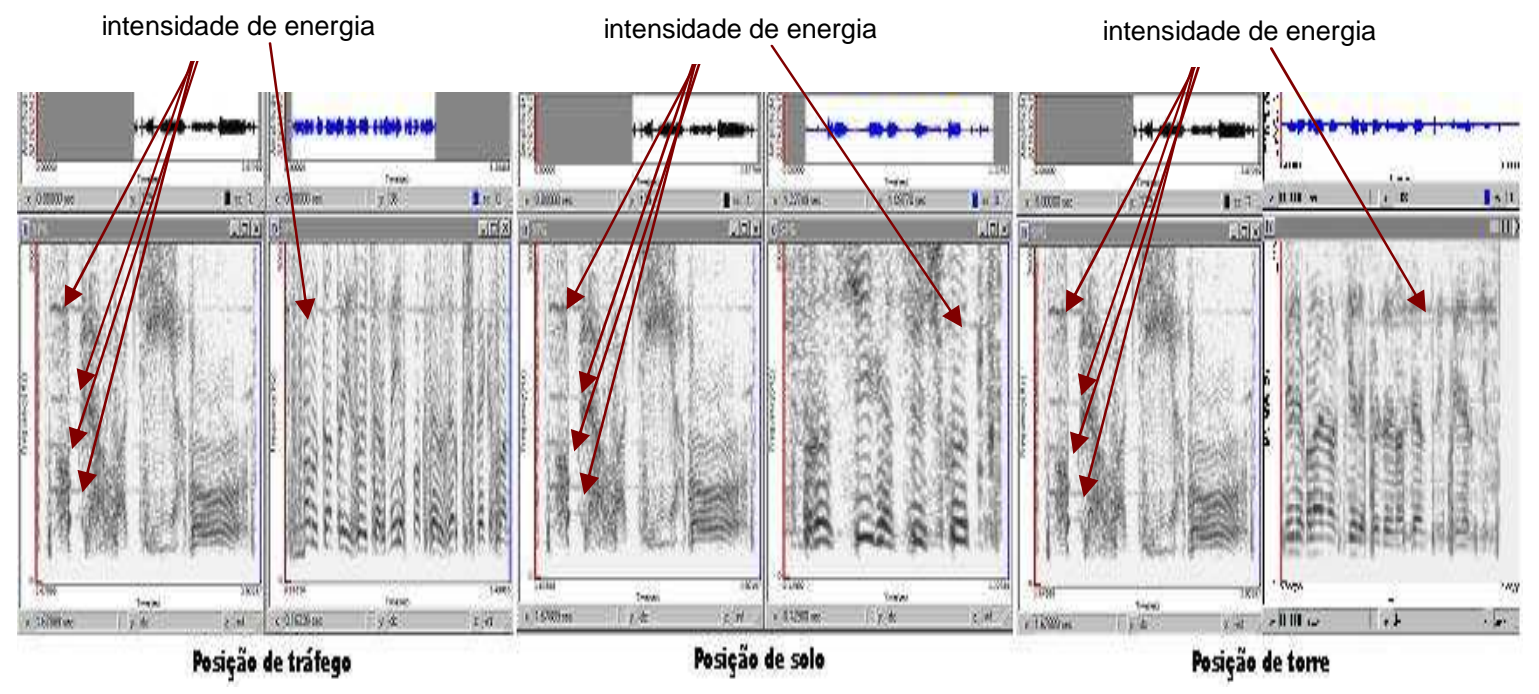

Figura 32 - Espectrograma do Vôo 1

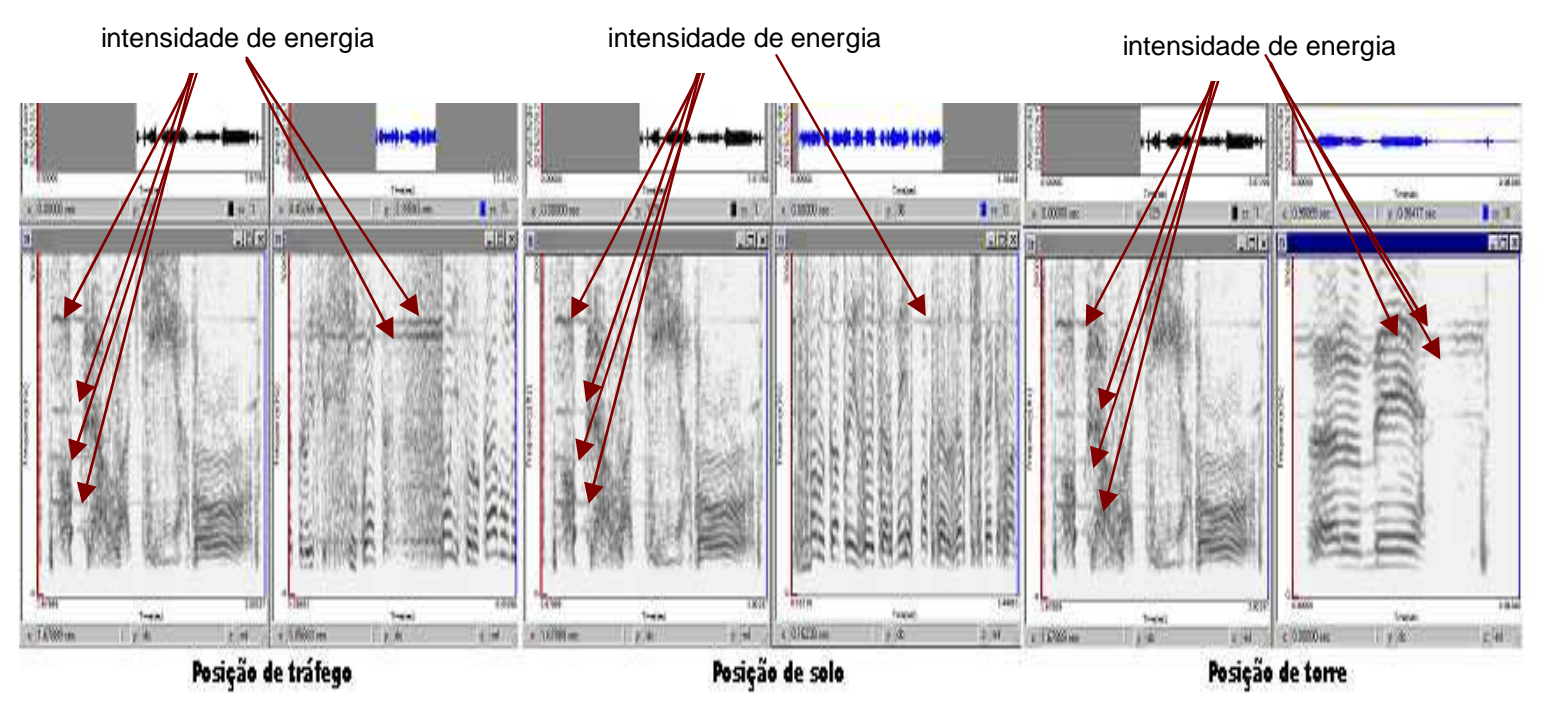

Figura 33 - Espectrograma do Vôo 2 


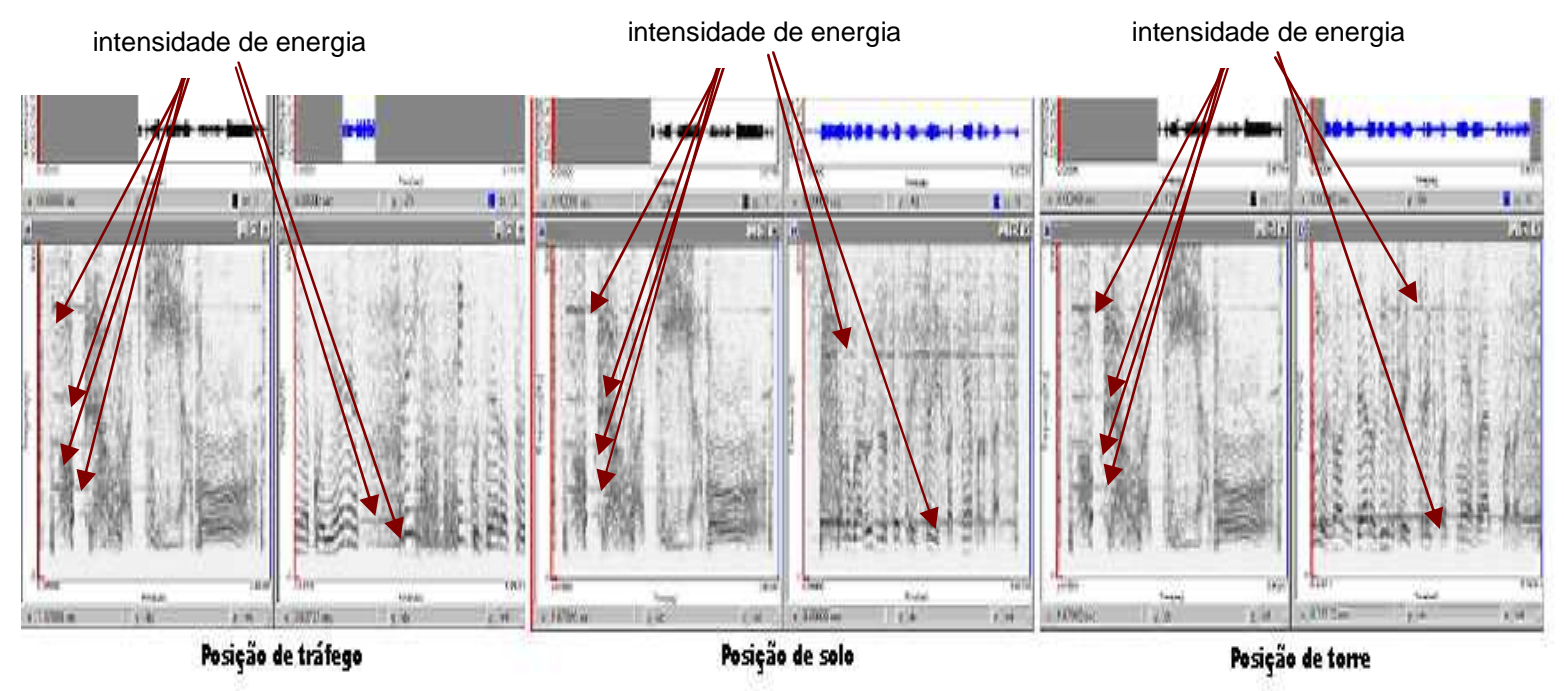

Figura 34 - Espectrograma do Vôo 4

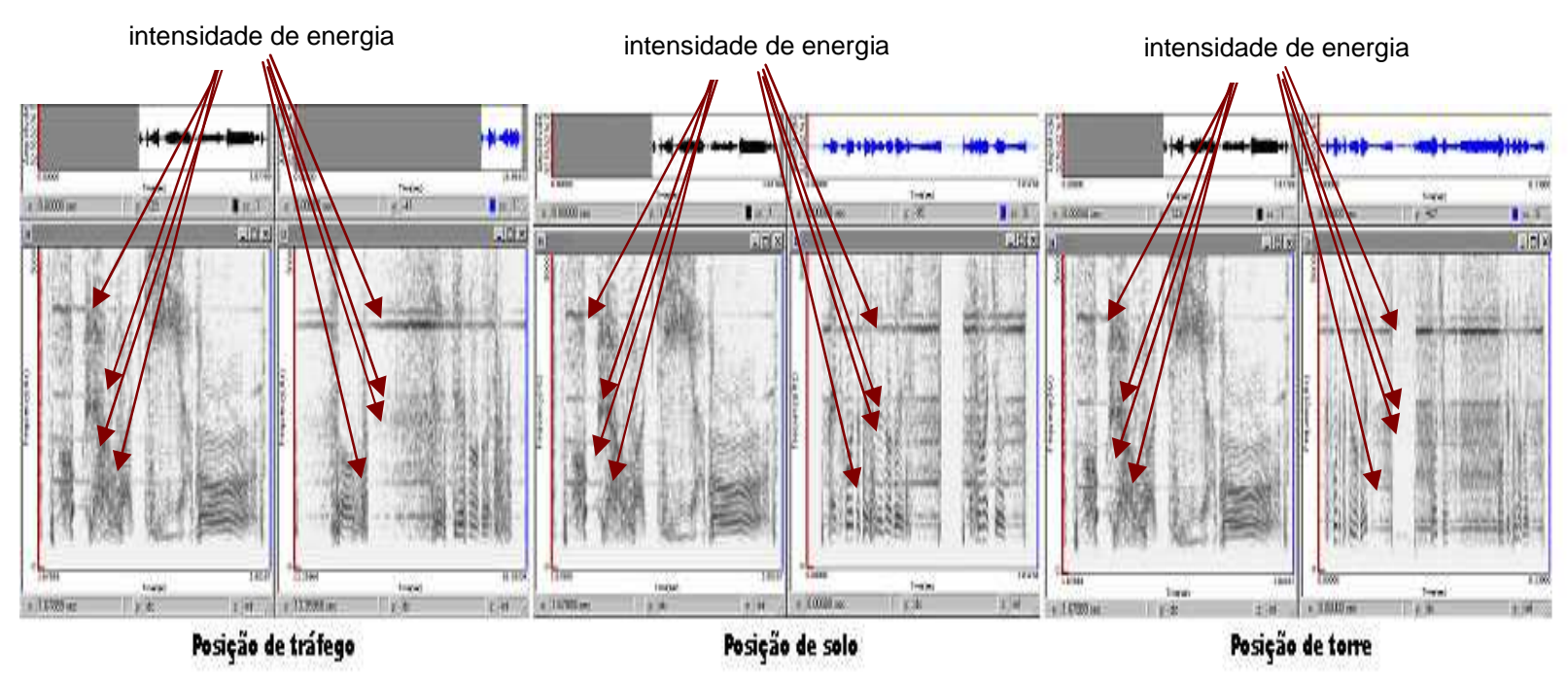

Figura 35 - Espectrograma do Vôo 5

Assim, podem ser percebidas as intensidades de energia em cada intervalo de tempo do espectrograma, representadas pelas intensidades espectrais horizontais mais escuras em cada figura. Estas manchas representam a fala do locutor na utilização do Canal VHF. Através destas manchas é possível formular a comparação das extrações 
efetuadas durante as comunicações das aeronaves junto aos controles de terra. Para comparação foram medidas as freqüências e os tempos em cada espectrograma nos eixos x e y, respectivamente.

Para este estudo, considera-se que uma determinada fonte tenha sido identificada se as faixas compostas pelos harmônicos estiverem representadas tanto na comunicação irregular, quanto na comunicação sob análise, fato este que recebe a denominação de representação simétrica, possibilitando a identificação da aeronave responsável pela transmissão irregular. Esta simetria define a igualdade na intensidade de energia entre as falas. Mesmo com os ruídos de fundo ou com alteração proposital da fala, as intensidades não se desfazem.

Nos casos onde as faixas são representadas de forma assimétrica, ou seja, onde não há a representação simultânea das faixas de harmônicos entre os espectrogramas da comunicação irregular e da comunicação sob análise, não é possível se estabelecer a origem da mensagem.

Nas Figuras 32, 33 e 34, foram notadas estas diferenças nas freqüências em relação ao tempo, fazendo com que as intensidades dos sinais sejam demonstradas de forma assimétrica entre os espectrogramas de cada posição.

Na Figura 35, pode-se notar que esta intensidade das freqüências em relação ao tempo possui uma simetria em todos os espectrogramas de cada posição. Desta forma, podese apontar como resultado que nenhuma das aeronaves analisadas nas Figuras 32, 33 e 34 poderia ter sido a responsável pela emissão irregular ocorrida. A ocorrência de uma transmissão irregular junto ao controle de terra é indicada na Figura 35. 


\section{ANÁLISE DE RESULTADOS}

Neste capítulo apresentam-se os resultados obtidos pelas simulações realizadas.

\subsection{Ambiente de Simulação}

A construção de um ambiente real torna-se algo complexo, pois implica em uma infraestrutura robusta e instalada em vários pontos do território nacional. Desta forma, para as simulações foram utilizados dois equipamentos com diferentes características e rodando o simulador NS2 de forma independente.

A utilização de dois computadores não impede a obtenção dos resultados, uma vez que é mantida a mesma programação no código executado. As especificações dos dois computadores utilizados são:

1. Processador T2370 Pentium Dual-Core da Intel com velocidade de 1,73 gigahertz, 1 GB de memória, sistema operacional Ubuntu LTS 8.04 - kernel 2.6.24.21.

2. Processador ADM Semprom 3000+ com velocidade de 1,80 gigahertz, 512MB de memória, sistema operacional Ubuntu LTS 8.04 - kernel 2.6.24.21. 
Estes equipamentos, em conjunto com o simulador NS2, constroem um ambiente com as características do ambiente necessário para simulação.

\subsection{Ambiente de Simulação}

A área disposta para a topologia é composta de todo território nacional, especificada em 8.514.205 km² e o espaço aéreo sobrejacente à área oceânica, que se estende até o meridiano $10^{\circ} \mathrm{W}$, perfazendo um total de 22 milhões de $\mathrm{Km}^{2}$. Os roteadores e os gateways são localizados seguindo a divisão das FIRs, e possuem comunicação entre si para transmissão dos dados.

Os nós, que representam as aeronaves, são dispostos de forma aleatória em toda a rede. A transmissão dos pacotes é iniciada logo que os nós são reconhecidos na rede. Todos os nós móveis são considerados como fontes constantes de bits para a geração do tráfego na rede durante o serviço de navegação. Os destinos dos nós são previamente determinados na simulação, bem como o endereçamento que será atribuído a cada nó durante a rota.

Para preparação do ambiente de simulação utiliza-se o projeto MobiWan, originalmente desenvolvido pelo Motorola Labs Paris em em colaboração com o INRIA PLANETE Team, utilizando a versão NS-2.1b6 do Networking Simulator.

A adaptação para a versão ns-2-allinone-2.33 foi gerada através do script ns-233mobiwan-1.patch, uma adaptação para nova versão do Networking Simulator, desenvolvido pelo NICTA - Australia's ICT Research Centre of Excellence. O script pode ser analisado no ANEXO 2.

A figura 36 ilustra a localização dos routers e dos gateways utilizados para transmissão dos dados. 


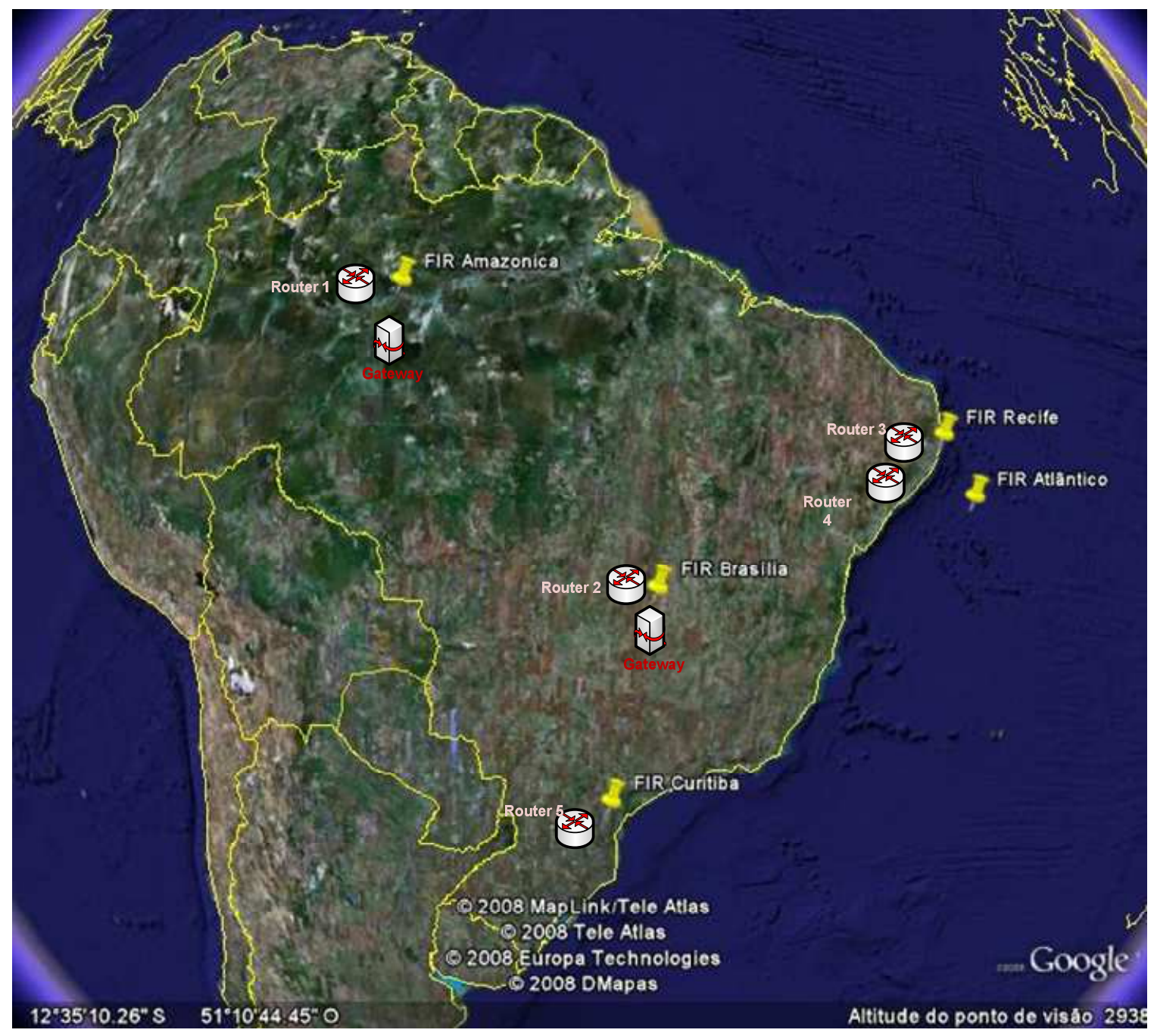

Figura 36 - Localização dos Routers (Fonte: Adaptado de Google Earth, 2008)

A figura 37 ilustra a localização dos routers e dos gateways utilizados para transmissão dos dados e a interconexão entre os router e os gateways, demonstrando o ambiente onde são vistos os links utilizados para a transmissão dos dados entre os nós. Os gateways são utilizados para definir a interface entre o MN (Mobile Node) e o MAG (Mobility Access Gateway) no NETLMN Domain (Network-based Localized Mobility Management Domain). Para o ATN/IPS, o Mobile Node é a aeronave, o Mobility Access Gateway é o roteador ar-terra e o Network-based Localized Mobility Management Domain é um Provedor de Serviços, com um único prefixo de sub-rede arterra (ICAO, 2007a). 


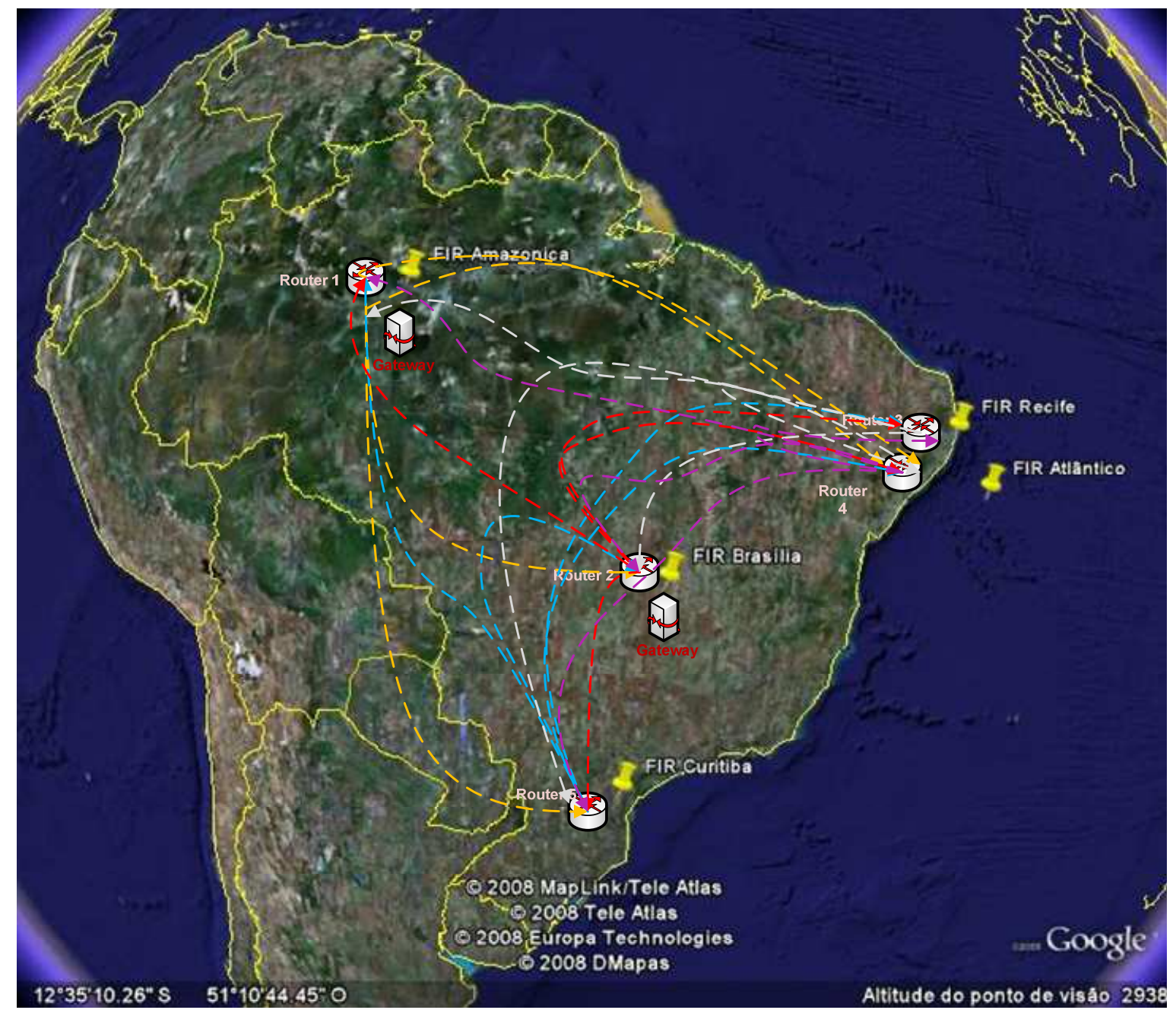

Figura 37 - Ligação Lógica entre os Routers (Fonte: Adaptado de Google Earth, 2008)

A arquitetura utilizando Mobile IPv6 para os nós da rede já é padronizada pelo IETF e inserida em produtos COTS (Commercial of the Shelf). Os roteadores baseados no padrão IP móvel são considerados dispositivos provedores de serviços móveis ou um roteador móvel, definidos como roteador móvel NEMO (Networks Mobility). No entanto, a implementação de serviços como o PMIP (Proxy Mobile IPv6) ainda está em estudo, o que deverá ser definido pelo Working Group responsável por adotar a gerência de mobilidade para o ATN/IPS. Assim, a Figura 36 representa os roteadores sem a utilização de serviços PMIP (ICAO, 2008). 


\subsubsection{Topologia de Rede Utilizada}

O método utilizado permite que seja estudado o comportamento do protocolo MIPv6 em um ambiente simulando a ATN. O cenário para a simulação é composto por 5 roteadores que estão distribuídos da seguinte forma:

- 1 roteador localizado na FIR Brasília;

- 1 roteador localizado na FIR Amazônica;

- 1 roteador localizado na FIR Curitiba;

- 1 roteador localizado na FIR Recife;

- 1 roteador localizado na FIR Atlântico.

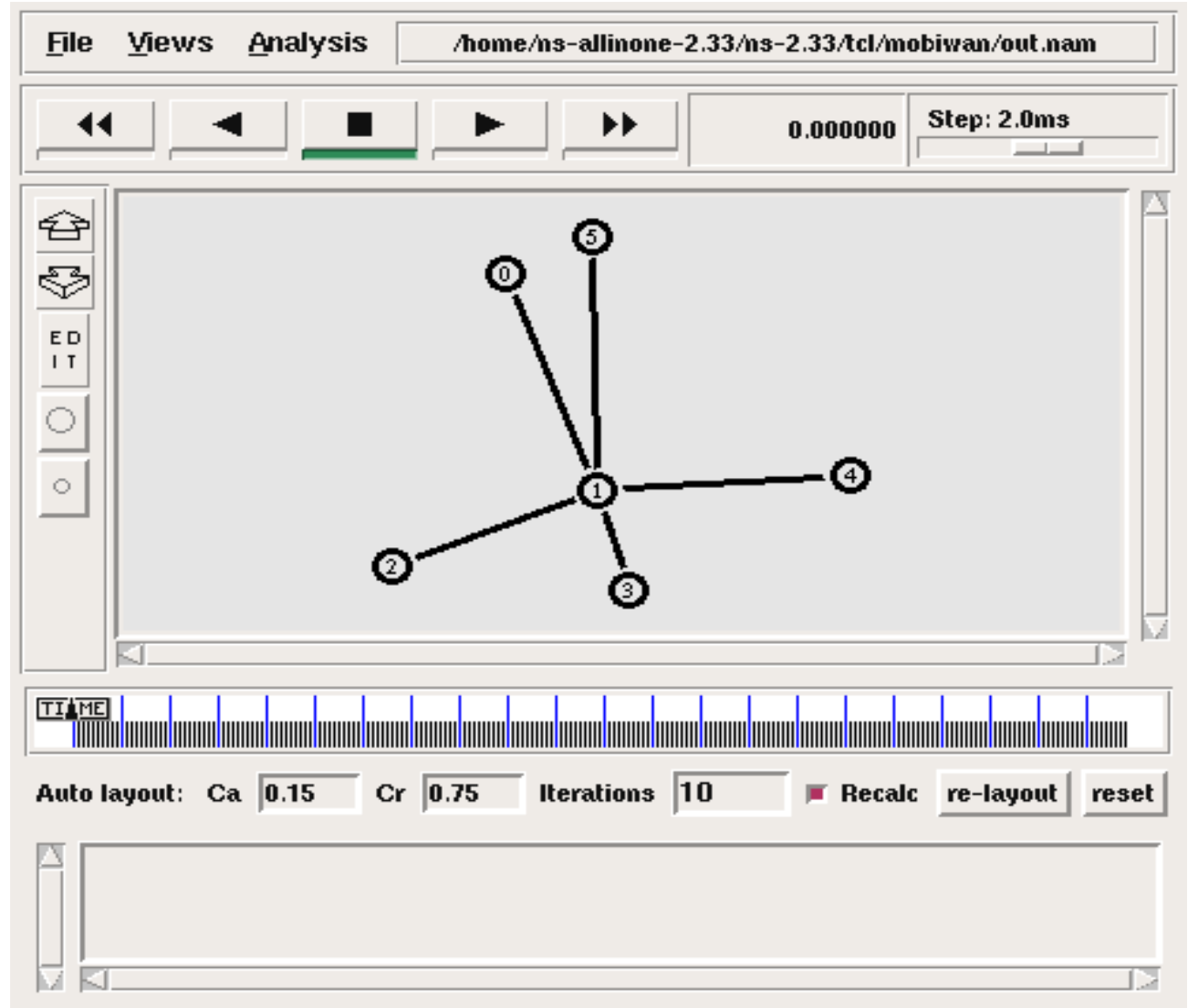

Figura 38 - Topologia da Rede 
Na Figura 38 é ilustrado o ambiente com os roteadores, onde o círculo representando o Mobile Node é definido pelo número 1, e os círculos possuindo os números $0,2,3,4$ e 5 representam os roteadores definidos nas Figuras 36 e 37.

Os resultados obtidos serão apresentados de forma gráfica, devendo ser definidas as métricas utilizadas para cada tipo de análise. Utiliza-se de métrica comum a todas as simulações que serão apresentadas, sendo o emprego de Vetor de Distância para topologia. É também definido o uso de filas FIFO (First in First Out) e a utilização do link CDMA/CD (Carrier Sense Multiple Access with Collision Detection).

Os tempos obtidos na simulação seguem os padrões de operações no ar ou no solo. Através da rede RACAM (Rede Administrativa de Comutação Automática de Mensagens) o tempo máximo de 30 segundos para entrega da mensagem e após este tempo a mensagem passa a ser inconsistente (ICA, 2001). Em operações onde há a necessidade da missão ser abortada o tempo para recebimento da mensagem e tomada de ação do piloto é de 3 segundos (MINISTÉRIO DA AERONÁUTICA, 2001).

Outras medidas de tempos são consideradas através das regulamentações da RBAC 01 (Regulamento Brasileiro de Aviação Civil) e RBHA (Regulamento Brasileiro de Homologação Aeronáutica), ambas seguem as normas de medias ABNT NBR 7324 que define as unidades de medidas de uso em aeronáutica.

\subsection{Análise dos Resultados por Tipo de Alteração na Rede}

A seguir são apresentados os resultados obtidos pela transmissão dos dados na rede, com variações na banda, no tamanho do pacote e no tempo de jitter que será explicado na seção 7.3.3. 


\subsubsection{Utilização de Banda}

Esta primeira métrica está relacionada à largura do link utilizado para o envio de dados na rede. Os links estão relacionados diretamente com os roteadores utilizados na topologia. Os links são determinados como duplex-link, que permitem o envio e o recebimento de dados ao mesmo tempo. Os valores de \$router_ Mb determinam a largura do link a ser utilizado na rede, em cada um dos roteadores. A definição DropTail determina o tipo de fila que o sistema utiliza para a vazão dos dados; neste caso, é utilizado o tipo de fila FIFO.

Outro fator essencial para análise é a definição do tipo de propagação e antena utilizado. Assim, para esta simulação foi definida a propagação Two-ray Ground $\left(1 / r^{4}\right)$ e antena Omni-directional. $\mathrm{O}$ algoritmo abaixo representa a especificação da propagação e antena utilizada.

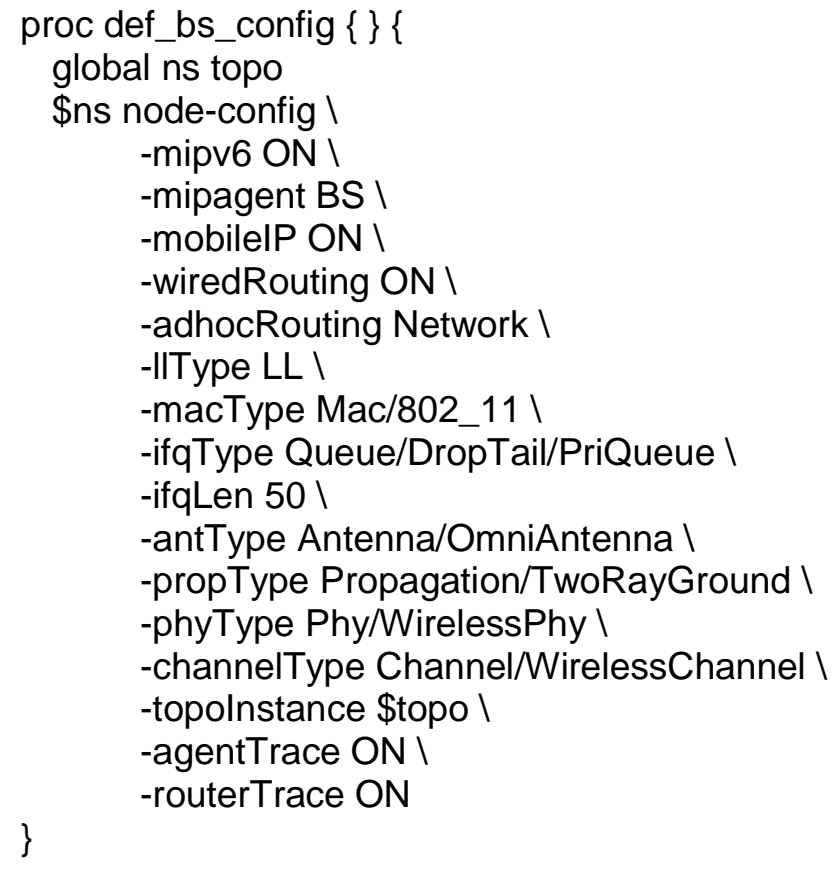

A propagação Two-ray Ground é definida pela equação: 


$$
P_{r}(d)=\frac{P_{t} G_{t} G_{r} h_{t}{ }^{2} h_{r}{ }^{2}}{d^{4} L}
$$

onde,

- $\mathrm{P}_{r}$ e $\mathrm{P}_{t}$ são as potências;

- $d$ é a distância entre o transmissor e o receptor;

- $\mathrm{G}_{t}$ e $\mathrm{G}_{r}$ são os ganhos;

- $\quad h_{t}$ é a altura de envio e $h_{r}$ é a altura recepção e envio das antenas;

- L é o fator de perda, adotando L=1 para consistir com o modelo de espaço livre.

O modelo OnmiAntena é um sistema de antena que envia sinais para todas as direções. O modelo da antena é definido pela equação:

$$
D=10 \log _{10}\left(\frac{\text { Watts }}{H P B W-\text { Watts }(H P B W)^{2}}\right) d B
$$

onde,

- D é o máximo ganho direto, que mede o poder de alcance da antena e a densidade de emissão;

- $\quad \mathrm{dB}$ é a relação da densidade de radiação de energia constante;

- HPBW (Half-Power BeamWidth) é a medida da direção da antena, ou seja, a separação angular dos pontos de radiação;

- Watts é a potência da antena;

Nas Tabelas 1 e 3 são definidos os parâmetros da análise. Através de um tempo máximo para entrega do pacote, é analisado o desempenho do protocolo na banda disponível para envio dos dados. Os resultados obtidos com os parâmetros apresentados nas Tabelas 1 e 3 são demonstrados nas Tabelas 2 e 4, 
respectivamente.

Tabela 1 - Parâmetro para Análise da Banda 10MB

\begin{tabular}{c|c|c|c|c|c|c}
\hline Pacote & Link & Banda & $\begin{array}{c}\text { Jitter } \\
(\mathbf{s})\end{array}$ & $\begin{array}{c}\text { Intervalo } \\
(\mathbf{m s})\end{array}$ & $\begin{array}{c}\text { Simulação } \\
(\mathbf{m s})\end{array}$ & Fila \\
\hline $1000 \mathrm{k}$ & Duplex & $10 \mathrm{MB}$ & 1,8 & 0,05 & 2000 & DropTail \\
\hline
\end{tabular}

Tabela 2 - Resultado: Pacote 1000k e Largura de Banda 10MB

\begin{tabular}{|c|c|c|c|c|}
\hline \multicolumn{5}{|c|}{ Binding Cache - Node 1.1.0 } \\
\hline Node & CoA & Local & $\begin{array}{c}\text { Tempo de Entrega do } \\
\text { Pacote }(\mathrm{ms})\end{array}$ & $\begin{array}{l}\text { Atualização } \\
(\mathrm{ms})\end{array}$ \\
\hline 1.1 .1 & 1.3 .6 & MN & 1993,36 & 0 \\
\hline \multicolumn{5}{|c|}{ Binding Cache - Node 0.0.0 } \\
\hline Node & $\operatorname{CoA}$ & Local & $\begin{array}{l}\text { Tempo de Entrega do } \\
\text { Pacote }(\mathrm{ms})\end{array}$ & $\begin{array}{l}\text { Atualização } \\
(\mathrm{ms})\end{array}$ \\
\hline 1.1 .1 & 1.3 .6 & MN & 1993,36 & 0 \\
\hline \multicolumn{5}{|c|}{ Binding Update List - Node 1.1.1 } \\
\hline Node & CoA & Local & $\begin{array}{c}\text { Tempo de Entrega do } \\
\text { Pacote }(\mathrm{ms})\end{array}$ & $\begin{array}{l}\text { Atualização } \\
(m s)\end{array}$ \\
\hline 0.0 .0 & 1.3 .6 & $\mathrm{CN}$ & 1993,35 & 2009,97 \\
\hline 1.1 .0 & 1.3 .6 & HA & 1993,35 & $2.68435 \mathrm{e}+08$ \\
\hline \multicolumn{5}{|c|}{ Base Station List - Node 1.1.1 } \\
\hline Node & CoA & Local & $\begin{array}{c}\text { Tempo de Entrega do } \\
\text { Pacote }(\mathrm{ms})\end{array}$ & $\begin{array}{l}\text { Atualização } \\
(\mathrm{ms})\end{array}$ \\
\hline 1.3 .0 & 1.3 .6 & BS & 1999,93 & 0 \\
\hline
\end{tabular}


Tabela 3 - Parâmetro para Análise de Banda 2MB

\begin{tabular}{c|c|c|c|c|c|c}
\hline Pacote & Link & Banda & $\begin{array}{c}\text { Jitter } \\
(\mathbf{s})\end{array}$ & $\begin{array}{c}\text { Intervalo } \\
(\mathbf{m s})\end{array}$ & $\begin{array}{c}\text { Simulação } \\
(\mathbf{m s})\end{array}$ & Fila \\
\hline $1000 \mathrm{k}$ & Duplex & $2 \mathrm{MB}$ & 1,8 & 0,05 & 2000 & DropTail \\
\hline
\end{tabular}

Tabela 4 - Resultado: Pacote 1000k e Largura de Banda 2MB

\begin{tabular}{|c|c|c|c|c|}
\hline \multicolumn{5}{|c|}{ Binding Cache - Node 1.1.0 } \\
\hline Node & CoA & Local & $\begin{array}{c}\text { Tempo de Entrega do } \\
\text { Pacote }(\mathrm{ms})\end{array}$ & $\begin{array}{l}\text { Atualização } \\
(\mathrm{ms})\end{array}$ \\
\hline 1.1 .1 & 1.4 .6 & $\mathrm{MN}$ & 1995,65 & 0 \\
\hline \multicolumn{5}{|c|}{ Binding Cache - Node 0.0.0 } \\
\hline Node & CoA & Local & $\begin{array}{c}\text { Tempo de Entrega do } \\
\text { Pacote }(\mathrm{ms})\end{array}$ & $\begin{array}{l}\text { Atualização } \\
(\mathrm{ms})\end{array}$ \\
\hline 1.1 .1 & 1.4 .6 & $\mathrm{MN}$ & 1995,65 & 0 \\
\hline \multicolumn{5}{|c|}{ Binding Update List - Node 1.1.1 } \\
\hline Node & CoA & Local & $\begin{array}{c}\text { Tempo de Entrega do } \\
\text { Pacote }(\mathrm{ms})\end{array}$ & $\begin{array}{l}\text { Atualização } \\
(\mathrm{ms})\end{array}$ \\
\hline 1.2 .0 & 1.4 .6 & BS & 1790,64 & 1800,64 \\
\hline 0.0 .0 & 1.4 .6 & $\mathrm{CN}$ & 1995,64 & 2009,97 \\
\hline 1.1.0 & 1.4 .6 & HA & 1995,64 & $2.68435 e+08$ \\
\hline \multicolumn{5}{|c|}{ Base Station List - Node 1.1.1 } \\
\hline Node & CoA & Local & $\begin{array}{c}\text { Tempo de Entrega do } \\
\text { Pacote }(\mathrm{ms})\end{array}$ & $\begin{array}{l}\text { Atualização } \\
(\mathrm{ms})\end{array}$ \\
\hline 1.4 .0 & 1.4 .6 & $\mathrm{BS}$ & 1999,58 & 0 \\
\hline
\end{tabular}

$\mathrm{Na}$ simulação baseada nos dados da Tabela 1, nota-se que o tempo estipulado para a execução de Binding Cache pelo Node 1.1.1 não se aproxima de seu limite, trabalhando com o tempo de 1993,36ms.

No entanto, nota-se a diminuição no tempo gasto quando o Node 1.1.1 executa o Binding Update para a atualização do Correpondent Node no tempo de 1993,35ms e no envio de dados sobre sua posição ao seu Home Agent, que utiliza também o mesmo tempo $1993,35 \mathrm{~ms}$.

Considerando os testes realizados, os dados representados na Tabela 3 apontam diferentes pontos no desempenho do protocolo. 
Utilizando a capacidade de banda em 2MB, o Binding Cache para o Node 1.1.1 passa a ser realizado no tempo de 1995,65ms. A execução do Binding Update do Node 1.1.1, apresenta um bom desempenho na atualização da Base Station, que é realizada no tempo de $1790,64 \mathrm{~ms}$, mas o mesmo desempenho não ocorre na atualização do Correspondente Node, que ocorre no tempo de 1995,64ms e do Home Agent que ocorre no tempo de 1995,64ms.

Quando comparados os tempos gastos na entrega de pacotes com o mesmo tamanho, mas utilizando diferentes capacidades de banda, o desempenho torna-se comprometido em banda de baixa capacidade na taxa de transferência.

\subsubsection{Tamanho do Pacote}

Esta métrica está relacionada ao tamanho do pacote de dados que é enviado na rede. O valor definido em \$src set packetSize_ determina qual o tamanho do pacote que será enviado pela rede, da mesma forma que o valor determinado em \$src set interval_ indica o valor do intervalo entre os pacotes.

Os pacotes transmitidos são encapsulados no protocolo de transporte para serem enviados por tunelamento entre os roteadores. O envio dos pacotes na rede requer a inserção de um cabeçalho de roteamento para que haja entrega correta dos pacotes. As implementações do momento deste encapsulamento e da inserção do cabeçalho de roteamento são apresentadas a seguir:

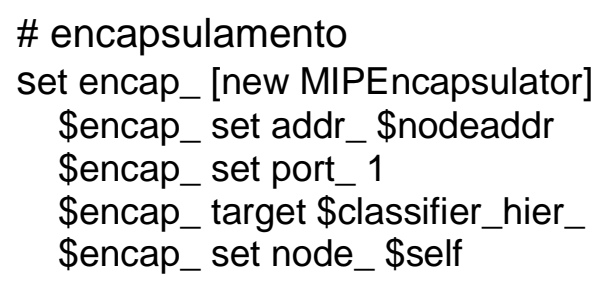


\# cabeçalho de roteamento

set src_routing_[new SrcRouting]

\$src_routing_set port_[Simulator set RT_HDR_PORT]

\$src_routing_set node_\$self

\$self attach \$src_routing_[Simulator set RT_HDR_PORT]

\$src_routing_node \$self

Nas Tabelas 5 e 7 são apresentados os valores para análise com diferentes tamanhos de pacotes.

Tabela 5 - Parâmetros para Análise de Pacotes 1200k

\begin{tabular}{c|c|c|c|c|c|c}
\hline Pacote & Link & Banda & $\begin{array}{c}\text { Jitter } \\
(\mathbf{s})\end{array}$ & $\begin{array}{c}\text { Intervalo } \\
(\mathbf{m s})\end{array}$ & $\begin{array}{c}\text { Simulação } \\
(\mathbf{m s})\end{array}$ & Fila \\
\hline $1200 \mathrm{k}$ & Duplex & $10 \mathrm{MB}$ & 1,8 & 0,05 & 2000 & DropTail \\
\hline
\end{tabular}

Tabela 6 - Resultado: Pacote 1200k e Largura de Banda de 10MB

\begin{tabular}{l|l|l|l|l}
\hline \multicolumn{5}{c}{ Binding Cache - Node 1.1.0 } \\
\hline Node & COA & Local & $\begin{array}{c}\text { Tempo de Entrega do } \\
\text { Pacote (ms) }\end{array}$ & Atualização (ms) \\
\hline 1.1 .1 & 1.3 .6 & MN & 1991,82 & 0 \\
\hline \multicolumn{6}{c}{ Binding Cache - Node 0.0.0 } \\
\hline Node & COA & Local & $\begin{array}{c}\text { Tempo de Entrega do } \\
\text { Pacote (ms) }\end{array}$ & Atualização (ms) \\
\hline 1.1 .1 & 1.3 .6 & MN & 1991,83 & 0 \\
\hline \multicolumn{7}{c}{ Binding Update List - Node 1.1.1 } \\
\hline Node & COA & Local & $\begin{array}{c}\text { Tempo de Entrega do } \\
\text { Pacote (ms) }\end{array}$ & Atualização (ms) \\
\hline 1.4 .0 & 1.3 .6 & BS & 1836,82 & 1846,82 \\
\hline 0.0 .0 & 1.3 .6 & CN & 1991,82 & 2009,97 \\
\hline 1.1 .0 & 1.3 .6 & HA & 1991,82 & $2.68435 \mathrm{e}+08$ \\
\hline \multicolumn{7}{|c}{ Base Station List - Node 1.1.1 } \\
\hline Node & COA & Local & $\begin{array}{c}\text { Tempo de Entrega do } \\
\text { Pacote (ms) }\end{array}$ & Atualização (ms) \\
\hline 1.3 .0 & 1.3 .6 & BS & 1999,45 & 0 \\
\hline
\end{tabular}


Tabela 7 - Resultado: Pacote 150k e Largura de Banda de 10MB

\begin{tabular}{c|c|c|c|c|c|c}
\hline Pacote & Link & Banda & $\begin{array}{c}\text { Jitter } \\
(\mathbf{s})\end{array}$ & $\begin{array}{c}\text { Interval } \\
\mathbf{o}(\mathbf{m s})\end{array}$ & $\begin{array}{c}\text { Simulação } \\
(\mathbf{m s})\end{array}$ & Fila \\
\hline $150 \mathrm{k}$ & Duplex & $10 \mathrm{MB}$ & 1,8 & 0,05 & 2000 & DropTail \\
\hline
\end{tabular}

Tabela 8 - Resultado: Pacote 150k e Largura de Banda de 10MB

\begin{tabular}{|c|c|c|c|c|}
\hline \multicolumn{5}{|c|}{ Binding Cache - Node 1.1.0 } \\
\hline Node & CoA & Local & $\begin{array}{c}\text { Tempo de Entrega do } \\
\text { Pacote }(\mathrm{ms})\end{array}$ & $\begin{array}{l}\text { Atualização } \\
(\mathrm{ms})\end{array}$ \\
\hline 1.1 .1 & 1.3 .6 & $\mathrm{MN}$ & 1994,51 & 0 \\
\hline \multicolumn{5}{|c|}{ Binding Cache - Node 0.0.0 } \\
\hline Node & CoA & Local & $\begin{array}{c}\text { Tempo de Entrega do } \\
\text { Pacote }(\mathrm{ms})\end{array}$ & $\begin{array}{l}\text { Atualização } \\
(\mathrm{ms})\end{array}$ \\
\hline 1.1 .1 & 1.3 .6 & $\mathrm{MN}$ & 1994,51 & 0 \\
\hline \multicolumn{5}{|c|}{ Binding Update List - Node 1.1.1 } \\
\hline Node & CoA & Local & $\begin{array}{l}\text { Tempo de Entrega do } \\
\text { Pacote }(\mathrm{ms})\end{array}$ & $\begin{array}{l}\text { Atualização } \\
(\mathrm{ms})\end{array}$ \\
\hline 0.0 .0 & 1.3 .6 & $\mathrm{CN}$ & 1994,5 & 2009,96 \\
\hline 1.1 .0 & 1.3 .6 & HA & 1994,5 & $2.68435 \mathrm{e}+08$ \\
\hline \multicolumn{5}{|c|}{ Base Station List - Node 1.1.1 } \\
\hline Node & CoA & Local & $\begin{array}{c}\text { Tempo de Entrega do } \\
\text { Pacote (ms) }\end{array}$ & $\begin{array}{l}\text { Atualização } \\
(\mathrm{ms})\end{array}$ \\
\hline 1.3 .0 & 1.3 .6 & $\mathrm{BS}$ & 1999,4 & 0 \\
\hline
\end{tabular}

Os valores foram obtidos pela simulação com diferentes tamanhos de pacotes utilizando sempre a mesma capacidade na taxa de transferência da banda e o mesmo tamanho de jitter.

Pode ser observado nas Tabelas 6 e 8 que o tamanho do pacote não interfere no desempenho do Node, uma vez que na primeira simulação o tamanho do pacote é de 1200k, o tempo para execução de Binding Cache foi de 1991,82ms, o Binding Update foi realizado para a Base Station no tempo de $1836,82 \mathrm{~ms}$, para o Correspondent Node o tempo foi de 1991,82ms e a atualização do Home Agente também ocorreu em $1991,82 \mathrm{~ms}$.

Nota-se que somente o tamanho do pacote não interfere no desempenho da rede, uma vez que o roteamento é determinado pelo melhor caminho. 


\subsubsection{Jitter}

Esta métrica está relacionada com o atraso aceitável para a entrega dos pacotes de dados na rede. Também é definida como a medida de variação do atraso entre os pacotes sucessivos de dados. Os valores de jitter são determinados para cada roteador por $\boldsymbol{s}$ (segundos). No entanto, os valores podem ser repetidos igualmente a todos. O valor de jitter é determinado por:

$$
\text { Jitter }=T_{2}-T_{1}-T_{p}
$$

onde,

- $T_{2}$ representa o tempo de chegada do pacote anterior;

- $T_{1}$ representa o tempo de chegada do pacote atual;

- $T_{p}$ indica o valor de tempo para geração do pacote no roteador.

Nas Tabelas 9 e 11 são apresentados os valores para análise com o mesmo tamanho de jitter. Para a análise são consideradas as mesmas capacidades para as bandas, diferentes tamanhos de pacotes, intervalos iguais e mesmos tempos de simulação.

Tabela 9 - Parâmetro para Análise de Jitter 3,8s e Pacote de 500k

\begin{tabular}{c|c|c|c|c|c|c}
\hline Pacote & Link & Banda & $\begin{array}{c}\text { Jitter } \\
(\mathbf{s})\end{array}$ & $\begin{array}{c}\text { Intervalo } \\
(\mathbf{m s})\end{array}$ & $\begin{array}{c}\text { Simulação } \\
(\mathbf{m s})\end{array}$ & Fila \\
\hline $500 \mathrm{k}$ & Duplex & $10 \mathrm{MB}$ & 3,8 & 0,05 & 2000 & DropTail \\
\hline
\end{tabular}


Tabela 10 - Resultado: Pacote 500k e Jitter 3,8s

\begin{tabular}{|c|c|c|c|c|}
\hline \multicolumn{5}{|c|}{ Binding Cache - Node 1.1.0 } \\
\hline Node & $\operatorname{CoA}$ & Local & $\begin{array}{c}\text { Tempo de Entrega do } \\
\text { Pacote }(\mathrm{ms})\end{array}$ & $\begin{array}{l}\text { Atualização } \\
(\mathrm{ms})\end{array}$ \\
\hline 1.1 .1 & 1.1 .1 & MN & 1985,89 & 0 \\
\hline \multicolumn{5}{|c|}{ Binding Cache - Node 0.0.0 } \\
\hline Node & CoA & Local & $\begin{array}{c}\text { Tempo de Entrega do } \\
\text { Pacote }(\mathrm{ms})\end{array}$ & $\begin{array}{l}\text { Atualização } \\
(\mathrm{ms})\end{array}$ \\
\hline 1.1 .1 & 1.1 .1 & $\mathrm{MN}$ & 1985,91 & 0 \\
\hline \multicolumn{5}{|c|}{ Binding Update List - Node 1.1.1 } \\
\hline Node & CoA & Local & $\begin{array}{c}\text { Tempo de Entrega do } \\
\text { Pacote }(\mathrm{ms})\end{array}$ & $\begin{array}{l}\text { Atualização } \\
(\mathrm{ms})\end{array}$ \\
\hline 1.2 .0 & 1.1 .1 & $\mathrm{BS}$ & 1985,89 & 1995,89 \\
\hline 0.0 .0 & 1.1 .1 & $\mathrm{CN}$ & 1985,89 & 1995,91 \\
\hline 1.1 .0 & 1.1 .1 & HA & 1985,89 & $2.68435 \mathrm{e}+08$ \\
\hline \multicolumn{5}{|c|}{ Base Station List - Node 1.1.1 } \\
\hline Node & $\operatorname{CoA}$ & Local & $\begin{array}{c}\text { Tempo de Entrega do } \\
\text { Pacote }(\mathrm{ms})\end{array}$ & $\begin{array}{l}\text { Atualização } \\
(\mathrm{ms})\end{array}$ \\
\hline 1.1 .0 & 1.1 .1 & $\mathrm{BS}$ & 1999,97 & 0 \\
\hline 1.2 .0 & 1.2 .6 & $\mathrm{BS}$ & 1999,21 & 0 \\
\hline
\end{tabular}

Tabela 11 - Parâmetro para Análise de Jitter 3,8s e Pacote de 1000k

\begin{tabular}{c|c|c|c|c|c|c}
\hline Pacote & Link & Banda & $\begin{array}{c}\text { Jitter } \\
(\mathbf{s})\end{array}$ & $\begin{array}{c}\text { Interval } \\
\mathbf{o}(\mathbf{m s})\end{array}$ & $\begin{array}{c}\text { Atualização } \\
(\mathbf{m s})\end{array}$ & Fila \\
\hline $1000 \mathrm{k}$ & Duplex & $10 \mathrm{MB}$ & 3,8 & 0,05 & 2000 & DropTail \\
\hline
\end{tabular}


Tabela 12 - Resultado: Pacote 1000k e Jitter 3,8s

\begin{tabular}{|c|c|c|c|c|}
\hline \multicolumn{5}{|c|}{ Binding Cache - Node 1.1.0 } \\
\hline Node & CoA & Local & $\begin{array}{c}\text { Tempo de Entrega do } \\
\text { Pacote }(\mathrm{ms})\end{array}$ & $\begin{array}{l}\text { Atualização } \\
(\mathrm{ms})\end{array}$ \\
\hline 1.1 .1 & 1.4 .6 & $\mathrm{MN}$ & 1990,78 & 0 \\
\hline \multicolumn{5}{|c|}{ Binding Cache - Node 0.0.0 } \\
\hline Node & CoA & Local & $\begin{array}{c}\text { Tempo de Entrega do } \\
\text { Pacote }(\mathrm{ms})\end{array}$ & $\begin{array}{l}\text { Atualização } \\
(\mathrm{ms})\end{array}$ \\
\hline 1.1 .1 & 1.4 .6 & MN & 1990,79 & 0 \\
\hline \multicolumn{5}{|c|}{ Binding Update List - Node 1.1.1 } \\
\hline Node & CoA & Local & $\begin{array}{c}\text { Tempo de Entrega do } \\
\text { Pacote }(\mathrm{ms})\end{array}$ & $\begin{array}{l}\text { Atualização } \\
(\mathrm{ms})\end{array}$ \\
\hline 1.3 .0 & 1.4 .6 & $\mathrm{BS}$ & 1945,77 & 1955,77 \\
\hline 0.0 .0 & 1.4 .6 & $\mathrm{CN}$ & 1990,77 & 2009,97 \\
\hline 1.1 .0 & 1.4 .6 & HA & 1990,77 & $2.68435 \mathrm{e}+08$ \\
\hline \multicolumn{5}{|c|}{ Base Station List - Node 1.1.1 } \\
\hline Node & CoA & Local & $\begin{array}{c}\text { Tempo de Entrega do } \\
\text { Pacote }(\mathrm{ms})\end{array}$ & $\begin{array}{l}\text { Atualização } \\
(\mathrm{ms})\end{array}$ \\
\hline 1.4 .0 & 1.4 .6 & BS & 1999,83 & 0 \\
\hline 1.3.0 & 1.3 .6 & BS & 1999,87 & 0 \\
\hline
\end{tabular}

Comparando as Tabelas 10 e 12, pode ser observado que as utilizações do mesmo valor de jitter, em diferentes tamanhos de pacotes, geram uma considerável diferença na rede quanto à entrega dos pacotes. Considerando o tamanho do pacote em 500k, obteve-se como Binding Cache para o Node 1.1.1 o tempo de 1985,89ms e o Binding Cache para o Node 0.0 .0 o tempo for de 1985,91ms. Avaliando o tempo de Binding Update para o Node 1.1.1 os valores foram de $1985,89 \mathrm{~ms}$, sendo iguais para Base Station, Correspondent Node e Home Agent.

Para o tamanho de pacote em 1000k, considerando o mesmo jitter, o valor de Binding Cache para o Node 1.1 .1 foi de $1990,78 \mathrm{~ms}$ e para o Node $1.1 .1 \mathrm{com}$ atualização do roteador 0.0.0 o valor foi de 1990,79ms. O tempo de Binding Update para o Node 1.1.1 ficou em 1945,77ms para Base Station, a atualização no Correspondent Node foi no tempo de 1990,77ms e o mesmo tempo de 1990,77ms para Home Agent.

Observando os resultados, vale ressaltar que, se inserido um valor muito alto para jitter, o desempenho da rede fica comprometido quando se trabalha com grandes pacotes. 


\section{Capítulo}

\section{8}

CONCLUSÃO E FUTUROS TRABALHOS

Neste capítulo são apresentadas a conclusões finais do estudo realizado, destacando futuras linhas de pesquisas que podem vir a dar continuidade a esta dissertação.

\subsection{Conclusões}

Neste trabalho foi analisado o comportamento do protocolo MIPv6 em um ambiente ATN. O estudo iniciou-se com a análise da rede, na qual foi apresentado um estudo sobre as falhas decorrentes da utilização do Canal VHF, seguida pela apresentação dos novos estudos para e arquitetura ATN apresentadas pela ICAO, em particular a utilização do protocolo IPv6 no novo conceito de ATN/IPS. Finalizando, foi estudado o envio de dados na ATN utilizando como base o protocolo MIPv6.

Uma das principais contribuições deste trabalho foi demonstrar o bom desempenho do uso do MIPv6 para transmissão de dados. A utilização do protocolo como forma de roteamento das aeronaves traz a possibilidade de oferecer ao Órgão de Controle, como complemento aos serviços de navegação, informação exata da localização da aeronave em qualquer domínio que esteja sobrevoando ou em qualquer momento de conexão. 
Neste estudo demonstra-se a viabilidade de implantação da suíte de protocolos IPv6, trazendo para a ATN serviços seguros e podendo trabalhar com o aspecto de confidencialidade na troca de mensagens, o que atualmente não é oferecido pela ATN.

Com os resultados obtidos durante a simulação para a utilização de banda, sendo, na banda de 10MB a atualização do Home Agent é de 1993,35ms e com a utilização da banda de 2MB o valor de atualização ficou em 1995,64. Os resultados por tamanho de pacote com 1200k em 1991,82ms e o pacote de 150k em 1994,5ms, tendo para ambos os valores uma banda com capacidade de 10MB. E, com o uso de jitter com valor elevado os resultados foram para um pacote 500k o tempo para atualização no Home Agente foi de $1985,89 \mathrm{~ms}$, já utilizando um pacote $1000 \mathrm{k}$ a atualização foi de 1990,77ms, ambos os resultados utilizando o jitter de 3,8s e banda de 10MB de capacidade.

Analisando os resultados obtidos neste trabalho de pesquisa, pode-se concluir que a utilização do protocolo passa a ter um bom desempenho em redes com capacidades mais elevadas e com menor tempo utilizado na geração entre os pacotes que sairão pelo roteador. Já com os tamanhos de pacotes não houve degradação, pois o emprego do vetor de distância trabalha sempre com o melhor caminho para entrega dos datagramas.

Tratando-se dos valores de Binding Cache para os Mobile Nodes 1.1.0 e 0.0.0 os valores conseguidos ficaram todos abaixo dos $2000 \mathrm{~ms}$ definidos para testes de simulação. Resultando na análise de banda com capacidade de 10MB ambos os Nodes o tempo de 1993,36ms e utilizando uma banda de $2 \mathrm{MB}$ os valores de ambos foram de 1995,65ms. Para análise de pacotes com utilização da banda de 10MB, os pacotes de 1200k tiveram o tempo de $1991,82 \mathrm{~ms}$ para o Node 1.1 .0 e o tempo de $1991,83 \mathrm{~ms}$ para o Node 0.0.0. Com o envio de pacotes de 150k o tempo de atualização para ambos os Nodes foram de $1994,51 \mathrm{~ms}$. Quanto a utilização de jitter os valores para os pacotes de 500k foram de 1985,89ms para o Node 1.1.0 e no valor de 1985,91 para o Node 0.0.0. 
Enquanto, para os pacotes de 1000k o valor de atualização do Node 1.1 .0 foi de $1990,78 \mathrm{~ms}$ e para o Node 0.0 .0 foi de $1990,79 \mathrm{~ms}$.

Com os resultados obtidos durante o Binding Cache, demonstra-se que a movimentação dos Mobile Nodes não é afetada durante todo o percurso dentro da rede, mesmo em pontos onde a atualização do Node na rede em que está obtendo um endereço virtual tenha um atraso de $10 \mathrm{~ms}$.

Outro ponto de grande relevância deste trabalho, que merece atenção, é a relativa facilidade de trabalhar com uma arquitetura IPS. A implementação de uma pilha de protocolos voltada à Internet facilita a integração de diversas aplicações e serviços a rede.

Finalizando, o estudo desenvolvido para a realização deste trabalho com a implementação de métricas específicas para controle em um ambiente móvel traz uma importante contribuição para futuros estudos em ambiente móvel utilizando a suíte IPv6.

\subsection{Trabalhos Futuros}

Os trabalhos futuros aqui apresentados estão relacionados diretamente aos resultados obtidos durante este estudo. Trata-se de novas linhas de pesquisas relacionadas diretamente aos novos protocolos móveis para comunicação.

Uma linha de grande abrangência é o estudo da navegação com os novos protocolos HMIPv6 e FHMIPv6. O desenvolvimento de novos ambientes de testes com estes protocolos proporcionará um elevado e importante trabalho para a navegação.

A injeção de falhas nos ambientes testados também pode vir a ser uma nova e importante linha de pesquisa. Estas falhas podem envolver diretamente a taxa de 
comunicação do ambiente, fazendo com que a injeção de falhas altere a comunicação oferecida e o ambiente ofereça uma solução imediata ao problema.

Ainda como injeção de falhas pode-se envolver as configurações de hardware, como tabela de roteamento e interrupção de serviços, que o tornam linhas bastante interessantes a serem pesquisadas.

Com a mesma importância apresenta-se o estudo direcionado à implementação de firewall, esta linha de pesquisa é justificada para o caso dos serviços oferecidos, utilizando protocolos de Internet, necessitar de segurança para transmissão dos dados. 


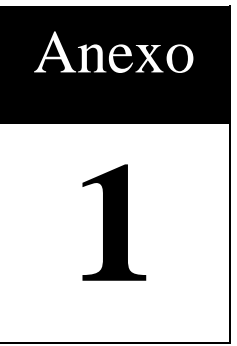

Anexo 1: Quadro de Protocolos

\begin{tabular}{|c|c|c|c|}
\hline Decimal & Keyword & Protocol & References \\
\hline 0 & HOPOPT & IPv6 Hop-by-Hop Option & [RFC1883] \\
\hline 1 & ICMP & Internet Control Message & [RFC792] \\
\hline 2 & IGMP & Internet Group Management & [RFC1112] \\
\hline 3 & GGP & Gateway-to-Gateway & [RFC823] \\
\hline 4 & IP & IP in IP (encapsulation) & [RFC2003] \\
\hline 5 & ST & Stream & [RFC1190][RFC1819] \\
\hline 6 & TCP & Transmission Control & [RFC793] \\
\hline 7 & CBT & CBT & [Ballardie] \\
\hline 8 & EGP & Exterior Gateway Protocol & [RFC888][DLM1] \\
\hline 9 & IGP & $\begin{array}{l}\text { any private interior gateway } \\
\text { (used by Cisco for their IGRP) }\end{array}$ & [IANA] \\
\hline 10 & BBN-RCC-MO & BBN RCC Monitoring & [SGC] \\
\hline 11 & NVP-II & Network Voice Protocol & [RFC741,SC3] \\
\hline 12 & PUP & PUP & [PUP,XEROX] \\
\hline 13 & ARGUS & ARGUS & [RWS4] \\
\hline 14 & EMCON & EMCON & [BN7] \\
\hline 15 & XNET & Cross Net Debugger & [IEN158,JFH2] \\
\hline 16 & CHAOS & Chaos & [NC3] \\
\hline 17 & UDP & User Datagram & [RFC768,JBP] \\
\hline 18 & MUX & Multiplexing & {$[$ IEN90,JBP] } \\
\hline 19 & DCN-MEAS & $\begin{array}{l}\text { DCN Measurement } \\
\text { Subsystems }\end{array}$ & [DLM1] \\
\hline 20 & HMP & Host Monitoring & {$[\mathrm{RFC869, \textrm {RH }}$ ] } \\
\hline 21 & PRM & Packet Radio Measurement & [ZSU] \\
\hline
\end{tabular}




\begin{tabular}{|c|c|c|c|}
\hline 22 & XNS-IDP & XEROX NS IDP & [ETHERNET,XEROX] \\
\hline 23 & TRUNK-1 & Trunk-1 & [BWB6] \\
\hline 24 & TRUNK-2 & Trunk-2 & [BWB6] \\
\hline 25 & LEAF-1 & Leaf-1 & [BWB6] \\
\hline 26 & LEAF-2 & Leaf-2 & [BWB6] \\
\hline 27 & RDP & Reliable Data Protocol & {$[\mathrm{RFC} 908, \mathrm{RH} 6]$} \\
\hline 28 & IRTP & Internet Reliable Transaction & {$[\mathrm{RFC938,TXM]}$} \\
\hline 29 & ISO-TP4 & ISO Transport Protocol Class 4 & [RFC905,RC77] \\
\hline 30 & NETBLT & Bulk Data Transfer Protocol & [RFC969,DDC1] \\
\hline 31 & MFE-NSP & MFE Network Services Protocol & [MFENET,BCH2] \\
\hline 32 & MERIT-INP & MERIT Internodal Protocol & {$[\mathrm{HWB}]$} \\
\hline 33 & DCCP & $\begin{array}{l}\text { Datagram Congestion Control } \\
\text { Protocol }\end{array}$ & [RFC4340] \\
\hline 34 & $3 P C$ & Third Party Connect Protocol & [SAF3] \\
\hline 35 & IDPR & $\begin{array}{l}\text { Inter-Domain Policy Routing } \\
\text { Protocol }\end{array}$ & [MXS1] \\
\hline 36 & XTP & XTP & [GXC] \\
\hline 37 & DDP & Datagram Delivery Protocol & {$[\mathrm{WXC}]$} \\
\hline 38 & IDPR-CMTP & $\begin{array}{l}\text { IDPR Control Message } \\
\text { Transport Proto }\end{array}$ & [MXS1] \\
\hline 39 & TP++ & TP++ Transport Protocol & [DXF] \\
\hline 40 & IL & IL Transport Protocol & [Presotto] \\
\hline 41 & IPv6 & Ipv6 & [Deering] \\
\hline 42 & SDRP & $\begin{array}{l}\text { Source Demand Routing } \\
\text { Protocol }\end{array}$ & [DXE1] \\
\hline 43 & IPv6-Route & Routing Header for IPv6 & [Deering] \\
\hline 44 & IPv6-Frag & Fragment Header for IPv6 & [Deering] \\
\hline 45 & IDRP & Inter-Domain Routing Protocol & [Sue Hares] \\
\hline 46 & RSVP & Reservation Protocol & [Bob Braden] \\
\hline 47 & GRE & General Routing Encapsulation & [Tony Li] \\
\hline 48 & DSR & $\begin{array}{l}\text { Dynamic Source Routing } \\
\text { Protocol }\end{array}$ & [RFC4728] \\
\hline 49 & BNA & BNA & [Gary Salamon] \\
\hline 50 & ESP & Encap Security Payload & [RFC2406] \\
\hline 51 & $\mathrm{AH}$ & Authentication Header & [RFC2402] \\
\hline 52 & I-NLSP & $\begin{array}{l}\text { Integrated Net Layer Security } \\
\text { TUBA }\end{array}$ & [GLENN] \\
\hline 53 & SWIPE & IP with Encryption & [JI6] \\
\hline 54 & NARP & $\begin{array}{l}\text { NBMA Address Resolution } \\
\text { Protocol }\end{array}$ & [RFC1735] \\
\hline 55 & MOBILE & IP Mobility & [Perkins] \\
\hline 56 & TLSP & $\begin{array}{l}\text { Transport Layer Security } \\
\text { Protocol }\end{array}$ & [Oberg] \\
\hline
\end{tabular}




\begin{tabular}{|c|c|c|c|}
\hline & & $\begin{array}{l}\text { using Kryptonet key } \\
\text { management }\end{array}$ & \\
\hline 57 & SKIP & SKIP & [Markson] \\
\hline 58 & IPv6-ICMP & ICMP for IPv6 & [RFC1883] \\
\hline 59 & IPv6-NoNxt & No Next Header for IPv6 & [RFC1883] \\
\hline 60 & IPv6-Opts & Destination Options for IPv6 & [RFC1883] \\
\hline 61 & & any host internal protocol & [IANA] \\
\hline 62 & CFTP & CFTP & [CFTP,HCF2] \\
\hline 63 & & any local network & [IANA] \\
\hline 64 & SAT-EXPAK & $\begin{array}{l}\text { SATNET and Backroom } \\
\text { EXPAK }\end{array}$ & [SHB] \\
\hline 65 & KRYPTOLAN & Kryptolan & {$[\mathrm{PXL1}]$} \\
\hline 66 & RVD & $\begin{array}{l}\text { MIT Remote Virtual Disk } \\
\text { Protocol }\end{array}$ & [MBG] \\
\hline 67 & IPPC & Internet Pluribus Packet Core & [SHB] \\
\hline 68 & & any distributed file system & [IANA] \\
\hline 69 & SAT-MON & SATNET Monitoring & {$[\mathrm{SHB}]$} \\
\hline 70 & VISA & VISA Protocol & [GXT1] \\
\hline 71 & IPCV & Internet Packet Core Utility & [SHB] \\
\hline 72 & CPNX & $\begin{array}{l}\text { Computer Protocol Network } \\
\text { Executive }\end{array}$ & [DXM2] \\
\hline 73 & CPHB & Computer Protocol Heart Beat & [DXM2] \\
\hline 74 & WSN & Wang Span Network & [VXD] \\
\hline 75 & PVP & Packet Video Protocol & [SC3] \\
\hline 76 & BR-SAT-MON & Backroom SATNET Monitoring & {$[\mathrm{SHB}]$} \\
\hline 77 & SUN-ND & $\begin{array}{l}\text { SUN ND PROTOCOL- } \\
\text { Temporary }\end{array}$ & [WM3] \\
\hline 78 & WB-MON & WIDEBAND Monitoring & [SHB] \\
\hline 79 & WB-EXPAK & WIDEBAND EXPAK & {$[\mathrm{SHB}]$} \\
\hline 80 & ISO-IP & ISO Internet Protocol & [MTR] \\
\hline 81 & VMTP & VMTP & [DRC3] \\
\hline 82 & SECURE-VMT & SECURE-VMTP & [DRC3] \\
\hline 83 & VINES & VINES & {$[\mathrm{BXH}]$} \\
\hline 84 & TTP & TTP & {$[\mathrm{JXS}]$} \\
\hline 85 & NSFNET-IGP & NSFNET-IGP & [HWB] \\
\hline 86 & DGP & Dissimilar Gateway Protocol & [DGP,ML109] \\
\hline 87 & TCF & TCF & [GAL5] \\
\hline 88 & EIGRP & EIGRP & [CISCO,GXS] \\
\hline 89 & OSPFIGP & OSPFIGP & [RFC1583,JTM4] \\
\hline 90 & Sprite-RPC & Sprite RPC Protocol & [SPRITE,BXW] \\
\hline 91 & LARP & $\begin{array}{l}\text { Locus Address Resolution } \\
\text { Protocol }\end{array}$ & {$[\mathrm{BXH}]$} \\
\hline 92 & MTP & Multicast Transport Protocol & [SXA] \\
\hline
\end{tabular}




\begin{tabular}{|c|c|c|c|}
\hline 93 & AX.25 & AX.25 Frames & [BK29] \\
\hline 94 & IPIP & $\begin{array}{l}\text { IP-within-IP Encapsulation } \\
\text { Protocol }\end{array}$ & [JI6] \\
\hline 95 & MICP & $\begin{array}{l}\text { Mobile Internetworking Control } \\
\text { Pro. }\end{array}$ & [JI6] \\
\hline 96 & SCC-SP & $\begin{array}{l}\text { Semaphore Communications } \\
\text { Sec. Pro. }\end{array}$ & {$[\mathrm{HXH}]$} \\
\hline 97 & ETHERIP & \begin{tabular}{|l|} 
Ethernet-within-IP \\
Encapsulation
\end{tabular} & [RFC3378] \\
\hline 98 & ENCAP & Encapsulation Header & [RFC1241,RXB3] \\
\hline 99 & & any private encryption scheme & [IANA] \\
\hline 100 & GMTP & GMTP & [RXB5] \\
\hline 101 & IFMP & $\begin{array}{l}\text { Ipsilon Flow Management } \\
\text { Protocol }\end{array}$ & [Hinden] \\
\hline 102 & PNNI & PNNI over IP & [Callon] \\
\hline 103 & PIM & Protocol Independent Multicast & [Farinacci] \\
\hline 104 & ARIS & ARIS & [Feldman] \\
\hline 105 & SCPS & SCPS & [Durst] \\
\hline 106 & QNX & QNX & [Hunter] \\
\hline 107 & $A / N$ & Active Networks & [Braden] \\
\hline 108 & IPComp & $\begin{array}{l}\text { IP Payload Compression } \\
\text { Protocol }\end{array}$ & [RFC2393] \\
\hline 109 & SNP & Sitara Networks Protocol & [Sridhar] \\
\hline 110 & Compaq-Pee & Compaq Peer Protocol & [Volpe] \\
\hline 111 & IPX-in-IP & IPX in IP & [Lee] \\
\hline 112 & VRRP & $\begin{array}{l}\text { Virtual Router Redundancy } \\
\text { Protocol }\end{array}$ & [RFC3768] \\
\hline 113 & PGM & $\begin{array}{l}\text { PGM Reliable Transport } \\
\text { Protocol }\end{array}$ & [Speakman] \\
\hline 114 & & any 0-hop protocol & [IANA] \\
\hline 115 & L2TP & Layer Two Tunneling Protocol & [Aboba] \\
\hline 116 & DDX & D-II Data Exchange (DDX) & [Worley] \\
\hline 117 & IATP & $\begin{array}{l}\text { Interactive Agent Transfer } \\
\text { Protocol }\end{array}$ & [Murphy] \\
\hline 118 & STP & Schedule Transfer Protocol & [JMP] \\
\hline 119 & SRP & SpectraLink Radio Protocol & [Hamilton] \\
\hline 120 & UTI & UTI & [Lothberg] \\
\hline 121 & SMP & Simple Message Protocol & [Ekblad] \\
\hline 122 & SM & SM & [Crowcroft] \\
\hline 123 & PTP & $\begin{array}{l}\text { Performance Transparency } \\
\text { Protocol }\end{array}$ & [Welzl] \\
\hline 124 & ISIS over IPv4 & & [Przygienda] \\
\hline 125 & FIRE & & [Partridge] \\
\hline
\end{tabular}




\begin{tabular}{|c|c|c|c|}
\hline 126 & CRTP & $\begin{array}{l}\text { Combat Radio Transport } \\
\text { Protocol }\end{array}$ & [Sautter] \\
\hline 127 & CRUDP & Combat Radio User Datagram & [Sautter] \\
\hline 128 & SSCOPMCE & & [Waber] \\
\hline 129 & IPLT & Secure Packet Shield & [Hollbach] \\
\hline 130 & SPS & $\begin{array}{l}\text { Private IP Encapsulation within } \\
\text { IP }\end{array}$ & [Mclntosh] \\
\hline 131 & PIPE & $\begin{array}{l}\text { Stream Control Transmission } \\
\text { Protocol }\end{array}$ & [Petri] \\
\hline 132 & SCTP & Fibre Channel & [Stewart] \\
\hline 133 & FC & & [Rajagopal] \\
\hline 134 & $\begin{array}{l}\text { RSVP-E2E- } \\
\text { IGNORE }\end{array}$ & & [RFC3175] \\
\hline 135 & Mobility Header & & [RFC3775] \\
\hline 136 & UDPLite & & [RFC3828] \\
\hline 137 & MPLS-in-IP & & [RFC4023] \\
\hline 138 & manet & MANET Protocols & $\begin{array}{l}\text { [RFC-ietf-manet-iana- } \\
\text { 07.txt] }\end{array}$ \\
\hline 139 & HIP & Host Identity Protocol & $\begin{array}{l}\text { [RFC-ietf-hip-base- } \\
\text { 10.txt] }\end{array}$ \\
\hline $140-252$ & Unassigned & & [IANA] \\
\hline 253 & $\begin{array}{l}\text { Use for } \\
\text { experimentation } \\
\text { and testing }\end{array}$ & & [RFC3692] \\
\hline 254 & $\begin{array}{l}\text { Use for } \\
\text { experimentationan } \\
\text { d testing }\end{array}$ & & [RFC3692] \\
\hline 255 & & Reserved & [IANA] \\
\hline
\end{tabular}




\section{Anexo}

\section{2}

Anexo 2: Código de Preparação do Ambiente

Este Anexo permite a análise do código para a preparação do ambiente, originalmente desenvolvido para utilização da versão ns-2.1b6, para a versão mais atualizada do simulador, a versão ns-2-allinone-2.33. Além disso serve como fonte de consulta para novas implementações em versões que devem surgir futuramente do Networking Simulator.

Conteúdo disponível em CD. 


\section{REFERÊNCIAS}

ATNP. Requirements placed on the ATN Communication Service by Air/Ground Applications. Appendix D, 1995.

BOISVERT, R. E; ORLANDO, V.A. ADS-Mode S system overview. IEEE Digital Avionics Systems Conference. 12th DASC, AIAA/IEEE, p104 a 109, 1993.

BREGMAN, Albert S. The Perceptual Organization of Sound. Auditory Scene Analysis. The MIT Press. 1990. Leitura complementar: MARTINS, Luis Gustavo. "Representação de Sinais Sonoros". Acessado em 28 de junho de 2008. Disponível em <http://www.porto.ucp.pt>

CHUJO, Amália M.; WALTER, Fernando. Atividades do Laboratório GNSS do ITA Relacionadas com CNS/ATM. IV Simpósio de Transporte Aéreo, São José dos Campos, Brasil, p219 a 229, 2005.

COMER, D. E. Interligação em Rede com TCP/IP. Rio de Janeiro: Editora Campus, 1998.

DOD. Design Criteria Standard - Limit Noise. Department of Defense, MIL-STD-1474D. 1997. Leitura complementar: BRUNT, Chris. "Speech Interfrence Levels in Aircraft Interior Noise Measurement: Their Use and Interpretation" . Acessado em: 28 de junho 2008. Disponível em: <ttp://www.armchair.com/sci/brunt1.html>.

ESTRIN, Deborah. VINT: Status and Plans. DARPA Networking PI Meeting, 1998. Leitura Complementar: ISI. Network Simulator NS). Disponível em: 〈http://www.isi.edu/nsnam/ns/>. Último acesso: em 08 de Março de 2008. 2008.

FAA. Merging and Spacing Enabling Continuous Descent Arrivals - An Update. ASAS-TN 2.5: Towards an ASAS-Global Network: Next Steps. Itália. 2008. Leitura complementar: Surveillance and Broadcast Services Disponível em: < http://www.faa.gov/about/office_org/headquarters_offices/ato/service_units/enroute/surveillance _broadcast/>. Último Acesso: em 12 de Dezembro de 2008.

FALL, K. The ns Manual (formerly ns Notes and Documentation). UC Berkeley. 2000

FARREL, Adrian. A Internet e seus Protocolos. São Paulo: Editora Campus, 2005. 
FEIGHERY, Patrick et al. The Aeronautical Telecomunications Network (ATN) Testbed. IEEE Digital Avionics Systems Conference. 15th AIAA/IEEE, p187 a 122, 1996.

GALLO, Michel A. e HANCOCK, William M. Comunicação entre Computadores e Tecnologias de Rede. São Paulo: Pioneira Thomson Learning, 2003.

GAMA, Ana. P., SLAMAB, Jules G., NOGUEIRA, Rita. "Caracterização de Ruído de Equipamentos de Apoio em Solo de Aeroportos". IV Congresso Ibero-Americano de Acústica. 2004. Portugal.

HARISON, Michael J. ADS-X The Next Gen Approach For The Next Generation Air Transportation System. IEEE Digital Avionics Systems Conference. 25th, 2006. Leitura complementar: SITA. ADS-X Extended ADS-B Surveillence: sítio na internet. Disponível em: < http://www.sita.aero>. Último acesso: em 20 de Fevereiro de 2007. 2006.

ICAO. ATN Internet Communication Architecture. ATNS - ATN Seminar and Third ATN Transition Task Force Meeting, 2001.

ICAO. Third Meeting of the Air Traffic Management / Communications, Navigation and Surveillance Subgroup (ATM/CNS/SG/4) - CNS Committee. México, 2005.

ICAO. Applications in the ATN/OSI and the ATN/IPS. Aeronautical Communications Panel (ACP) - Working Group N (Networking) Sixt Meeting -. Belgium, 2006.

ICAO. Presentation to the 2007 CNS/ATM - Developments on the ICAO - Aeronautical Telecommunication Network (ATN). Conference Organized by the AFCEA and ELSG, 2007.

ICAO. Recommendations for Local and Global Mobility Management for ATN IPS Mobility. Aeronautical Communications Panel (ACP) - WG I - Internet Protocol Suite. Denmark, 2007a.

ICAO. Air Ground ATN/IPS. Aeronautical Communications Panel (ACP) - WG I - Internet Protocol Suite - 6th Meeting. Canada, 2008.

ICAO. ATN IPS Guidance Material. Aeronautical Communications Panel (ACP) - 6th Meeting of Working Group I - Canada, 2008a. 
IETF. RFC 2460 - Internet Protocol Version 6 (IPv6). 1998.

IETF. RFC 791 - Internet Protocol. 1981.

IETF. RFC 1883 - Internet Protocol, version 6 (Ipv6). 1995.

IETF. RFC 5237 - IANA Allocation Guidelines for the Protocol Field. 2008.

IETF. RFC 2002 - IP Mobility Support. 1996.

IETF. RFC 3775 - Mobility Support in IPv6. 2004.

IETF. RFC 4140 - Hierarchical Mobile IPv6 Mobility Management (HMIPv6). 2005.

ISO. Information technology - Protocol for providing the connectionless-mode network service. Second Edition, 1994.

LAGO, Isabel F.; FERREIRA, Luiz D. D.; KRUEGER, Claudia P. GPS and GLONASS: Theorical Aspects and Pratical Applications. II Colóquio Brasileiro de Ciências Geodésias, Curitiba, Brasil, v8, no 2, p37 a 53, 2001.

MINISTÉRIO DA AERONÁUTICA. Regras do Ar e Serviços de Tráfego Aéreo. IMA 10012. 1999.

MINISTÉRIO DA AERONÁUTICA. Telecomunicações Aeronáuticas e Controle do Tráfego Aéreo - Diretrizes Básicas para Situação de Degradação. IMA 63-1. 1999a.

MINISTÉRIO DA AERONÁUTICA. Serviços Radiotelefônicos de Operações. FMA 102-2. 1999b.

MINISTÉRIO DA AERONÁUTICA. Manual do Especialista em Informação Aeronáutica MCA 53-1. 2000.

MINISTÉRIO DA AERONÁUTICA. Procedimentos de Telecomunicações - IMA 102-2. 2001. 
MINISTÉRIO DA AERONÁUTICA. Plano Nacional de Implantação dos Sistemas CNS/ATM - PCA 63-1. 2002.

MINISTÉRIO DA AERONÁUTICA. Programa de Transição do SISCEAB para os Sistemas CNS/ATM. Portaria. 2003. Leitura complementar: TORELLI, DANIEL; Transição para o CNS/ATM. Janeiro, 2005. 8p. Disponível em:<http://www.asasbrasil.com.br/artigos >. Último acesso: em 19 de fevereiro de 2007.

NETO, João Evangelista; Segurança em Redes de Telecomunicações Aeronáuticas e seu desempenho em canal VDL modo 2. 2005. 91p. Dissertação (Mestrado) - Instituto Tecnológico de Aeronáutica. São José dos Campos.

OLIVEIRA, Ítalo R.; et al. Uma Arquitetura Lógica para Auxílio à Tomada de decisão no Gerenciamento de tráfego Aéreo. IV Simpósio de Transporte Aéreo, São José dos Campos, Brasil, p187 a 205, 2005.

ONTIVEROS, J. Descubrir el control aéreo. Madri: Edita Centro de Documentación y Publicaciones de Aena, 2003.

PERRONS, R. K.; Make-Buy Decisions in the U. S. Aircraft industry. 1997. 143p. Dissertação (Master of Science) - Massachusetts Institute of Technology. 1997.

PERKINS, C. E.; JOHNSON, D. B. Mobility Support in IPv6. International Conference on Mobile Computing and Networking. Rye, New York, pag 27-37. 1996.

PRGP, "Movimento Operacional Acumulado na Rede Infraero". Material Institucional. INFRAERO, 2008. Leitura Complementar: Acessado em: 28 de junho 2008. Disponível em: $<\mathrm{ttp}: / /$ www.infraero.gov.br>.

ROLIM, Higino L. et al. O Controle do Espaço Aéreo. São José dos Campos: DECEA, 2006. Leitura Complementar: DECEA. Departamento de Controle do Espaço Aéreo: sítio na internet. Disponível em: <http://www.decea.gov.br>. Último acesso: em 01 de Fevereiro de 2007. 2005 .

ROSSI, Magali A. et al. Um Novo Conceito para Redes de Telecomunicações Aeronáuticas e a Aviação Civil Brasileira. IV Simpósio de Transporte Aéreo, São José dos Campos, Brasil, p307, 2005. 
ROSSI, Magali A.; ALMEIDA, Jorge Rady; MENEZES, Genivaldo J. Análise Espectral na Identificação de Comunicações que Utilizam o Canal VHF Aeronáutico. V Simpósio de Transporte Aéreo, Brasília, Brasil, p 165 - 172, 2006.

RTCA. ADS-B 1090 MHz MOPS. RTCA Special Committee 186, Working Group 3 Meeting 2. 2001. Leitura Complementar: FAA. ACB nº 420 - Welcome to ADS-B Home Page: sítio na internet. Disponível em: < http://adsb.tc.faa.gov>. Último acesso: em 20 de Fevereiro de 2007. 2006.

SGNORE, T. L.; GIRARD, Mary. The Aeronautical Telecomunications Network (ATN). Military Communications Conference. MILCOM 98. Proceedings., IEEE Volume 1, p40 - 44, vol 1, 1998.

SIQUEIRA, CRISTIANE DE A.; Navegação Aérea Segundo Conceito CNS/ATM: Custos e Benefícios. 2005. 145p. Dissertação (Mestrado) - Instituto Tecnológico de Aeronáutica. São José dos Campos.

SOUZA, Marilia Vidigal da Costa; Estudo da solução de segurança na ATN (Rede de Telecomunicações Aeronáuticas) e seu desempenho em canal via satélite. 2004. 85p. Dissertação (Mestrado) - Instituto Tecnológico de Aeronáutica. São José dos Campos.

SCHAWARZ, Ralph J., FRIEDLAND, Bernard. "Sistemas Lineares 1". Ao Livro Técnico, Rio de Janeiro, 1972.

TANENBAUM, A. S. Redes de Computadores. São Paulo: Editora Campus, 2003.

VISMARI, Lúcio Flávio; Vigilância Dependente Automática no Controle de Tráfego Aéreo: Avaliação de Risco Baseada em Modelagem em Redes de Petri Fluidas e Estocásticas. 2007. 272p. Dissertação (Mestrado) - Escola Politécnica da Universidade de São Paulo.

YAIZ, R.; OZTURK, O. Mobility in IPv6. University of Twente, Netherlands.2006. 


\section{Apêndice}

\section{A}

Apêndice A: Código MIPv6

Este Apêndice contém o algoritmo que possui as estruturas atendendo as necessidades para simulação de ambiente utilizando MIPv6. Através deste algoritmo será aferido o comportamento do protocolo.

Conteúdo disponível em CD. 